\title{
Covariance Matrices for Direct Dissolution of Vial Insert Samples in DWPF Mock-Up Facility
}

by

C. P Reeve

Westinghouse Savannah River Company

Savannah River Site

Aiken, South Carolina 29808

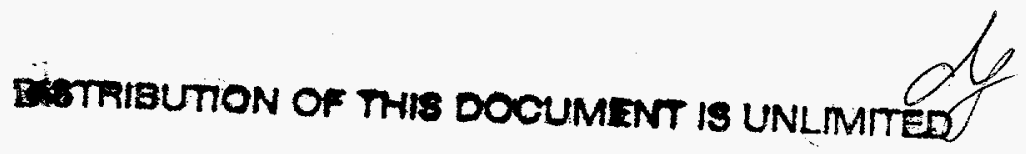

DOE Contract No. DE-AC09-96SR18500

This paper was prepared in connection with work done under the above contract number with the U.S.

Department of Energy. By acceptance of this paper, the publisher and/or recipient acknowledges the U. S. Government's right to retain a nonexclusive, royalty-free license in and to any copyright covering this paper, along with the right to reproduce and to authorize others to reproduce all or part of the copyrighted paper. 


\section{DISCLAIMER}

This report was prepared as an account of work sponsored by an agency of the United States Government. Neither the United States Government nor any agency thereof, nor any of their employees, makes any warranty, express or implied, or assumes any legal liability or responsibility for the accuracy, completeness, or usefulness of any information, apparatus, product, or process disclosed, or represents that its use would not infringe privately owned rights. Reference herein to any specific commercial product, process, or service by trade name, trademark, manufacturer, or otherwise does not necessarily constitute or imply its endorsement, recommendation, or favoring by the United States Government or any agency thereof. The views and opinions of authors expressed herein do not necessarily state or reflect those of the United States Government or any agency thereof.

This report has been reproduced directly from the best available copy.

Available to DOE and DOE contractors from the Office of Scientific and Technical Information, P. O. Box 62, Oak Ridge, TN 37831; prices available from (423) 576-8401.

Available to the public from the National Technical Information Service, U. S. Department of Commerce, 5285 Port Royal Road, Springfield, VA 22161. 


\section{DISCLAIMER}

Portions of this document may be illegible electronic image products. Images are produced from the best available original document. 
WSRC-TR-97-00286

RECORDS ADMINISTRATION

\section{Covariance Matrices for Direct Dissolution of Vial Insert Samples in DWPF Mock-up Facility (U)}

C.P. Reeve

September 9, 1997

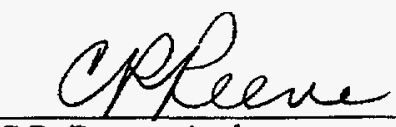

C.P. Reeve, Author

Thmos V Etwands

T.B. Edwards/Fecmicat Reyiewer

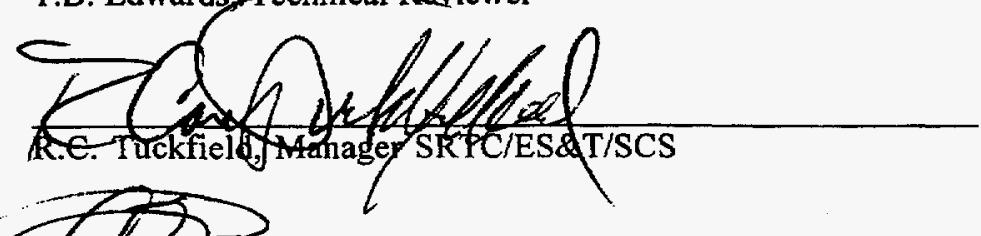

C.T. Randall, Authorized Derivative Classifier

$\frac{\mathrm{A} / \mathrm{s}}{\text { D.E. Snyder, BWPF TTR Originator }}$
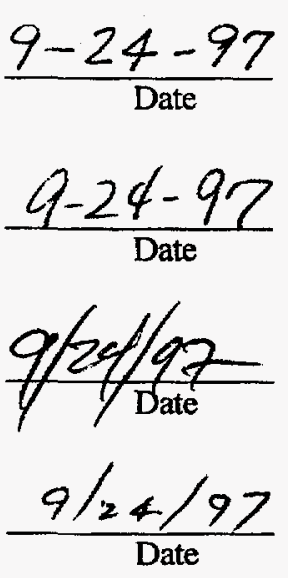

$\frac{9 / 25 / 97}{\text { Date }}$ 
<This page intentionally left blank> 


\section{Contents}

Abstract .....................................................................................................................................................1

1. Preliminaries. ..............................................................................................................................2

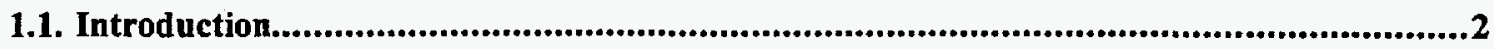

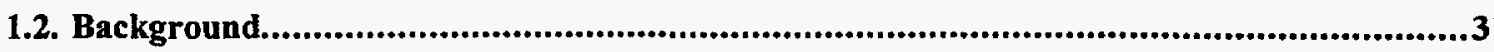

2. Design of the Experiment.................................................................................................................4

3. Analytical Methods..........................................................................................................................5

4. Statistical Models for the Data .................................................................................................5

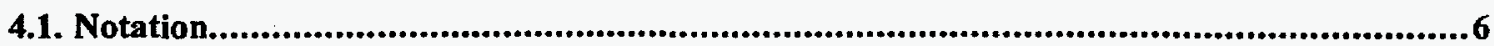

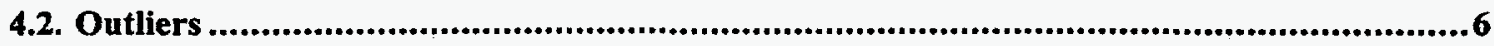

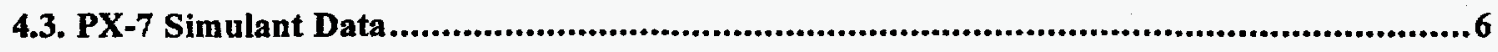

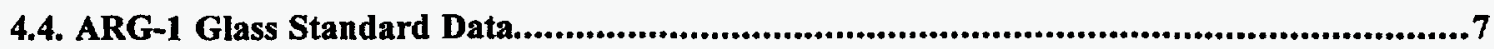

5. Estimating Components of the Total Covariance Matrices .................................................7

5.1. Computational Methods for Direct Dissolution (DD) Test Data.....................................7

5.2. Computational Methods for Prototypic (PRO) Test Data .............................................9

6. Estimating the Total Covariance Matrices............................................................................9

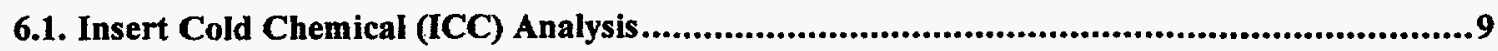

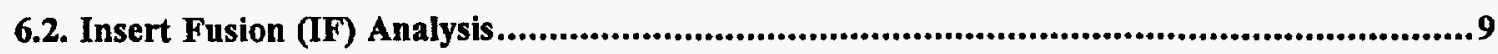

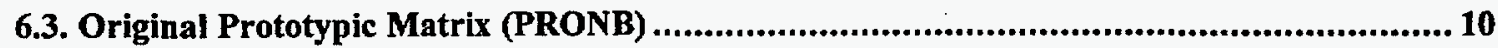

6.4. Prototypic Matrix by Fixed Sample Size Method (PROF4)................................................ 10

7. Comparison of Property Variabilities...................................................................................10

8. Quality Control Issues...........................................................................................................12

9. Summary and Recommendations ...........................................................................................13 
Westinghouse Savannah River Company

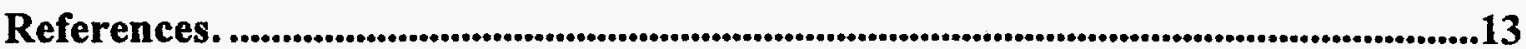

Appendix. Property Models........................................................................................14 


\section{List of Tables}

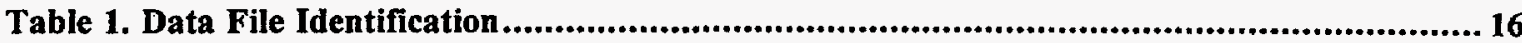

Table 2. Calcine Factor Total Coefficient of Variation vs. Block Size......................................... 16

Table 3. Mean Elemental Weight Percents for PX-7 in DD Test and

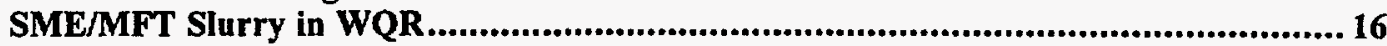

Table 4a. Mean Elemental Weight Percents for ARG-1 by Four Methods, and Corning Values

Table 4b. Total Coefficients of Variation (\%) for ARG-1 Data Analyzed by Four Methods, Assuming a Fixed Block Size of $2(v=5)$

Table 5a. Total Coefficients of Variation (\%) for Inserts and Peanut Vial Dip Samples, Assuming a Fixed Block Size of $2(v=5)$

Table 5b. Total Coefficients of Variation (\%) for Inserts and Peanut Vial Hydragard Samples, Assuming a Fixed Block Size of $4(v=5)$.

Table 5c. Total Coefficients of Variation (\%) for Inserts and Combined Peanut Vial Dip and Hydragard Samples, Assuming a Fixed Block Size of $6(v=5)$

Table 5d. Total Coefficients of Variation (\%) for Insert Data, Assuming a Fixed Block Size of $8(v=5)$.

Table 5e. Total Coefficients of Variation (\%) for Prototypic Data, Assuming

1) No Block Effects, and 2) Fixed Block Sizes of 4 20

Table 6a. Correlation Matrix for Prototypic Data, Ignoring Block Effects $(v=23)$

Table 6b. Correlation Matrix for Prototypic Data, Assuming a

Fixed Block Size of $4(v=5)$.

Table 7a. Correlation Matrix for Insert Cold Chemical Data (Unadjusted), Assuming a Fixed Block Size of $2(v=5)$

Table 7b. Correlation Matrix for Insert Cold Chemical Data (Unadjusted), Assuming a Fixed Block Size of $4(v=5)$

Table 7c. Correlation Matrix for Insert Cold Chemical Data (Unadjusted), Assuming a Fixed Block Size of $6(v=5)$

Table 7d. Correlation Matrix for Insert Cold Chemical Data (Unadjusted), Assuming a Fixed Block Size of $8(v=5)$

Table 8a. Correlation Matrix for Insert Fusion Data (Unadjusted), Assuming a Fixed Block Size of $2(v=5)$

Table 8b. Correlation Matrix for Insert Fusion Data (Unadjusted), Assuming

a Fixed Block Size of $4(v=5)$

Table 8c. Correlation Matrix for Insert Fusion Data (Unadjusted), Assuming a Fixed Block Size of $6(v=5)$. 
Table 8d. Correlation Matrix for Insert Fusion Data (Unadjusted), Assuming a Fixed Block Size of $8(v=5)$

Table 9. Insert Cold Chemical Data Randomized for Bootstrap Procedure

(Reps 9 Not Used)

Table 10. Insert Fusion Data Randomized for Bootstrap Procedure

(Reps 9, 10, 11 Not Used)

Table 11. Calcine Weight Percent Data Randomized for Bootstrap Procedure (Reps 9, 10, 11 Not Used) 26

Table 12. Property Coefficients, Gravimetric Factors, and Oxide Molecular Weights.

Table 13. Coefficients for Three Methods of Combining Direct Dissolution Data: Cold Chem only, Fusion only, and Average of Cold Chem and Fusion.

Table 14a. Half-Widths of $95 \%$ Confidence Intervals for Properties vs. Mean Composition, Number of Blocks, and Number of Samples per Block (ICC Data Only).

Table 14b. Half-Widths of $95 \%$ Confidence Intervals for Properties vs. Mean Composition, Number of Blocks, and Number of Samples per Block (IF Data Only)

Table 14c. Half-Widths of $95 \%$ Confidence Intervals for Properties vs. Mean Composition, Number of Blocks, and Number of Samples per Block (ICC+IF Data).

Table 15. Minimum Block/Sample Sizes in Direct Dissolution Method Required for Equivalent Variability to One Block of Four Samples by Prototypic Methods (Basis for Comparison: Half-Widths of $95 \%$ Confidence Intervals for Properties)

\section{List of Figures}

Figure 1. Insert Calcine Factors by Block, with Analysis of Variance and Test for Equality of Within-Block Variances.

Figure 2. Insert Cold Chemical Data (Unadjusted).

Figure 3. Insert Fusion Elemental Weight Percents. 


\title{
Covariance Matrices for Direct Dissolution of Vial Insert Samples in DWPF Mock-up Facility (U)
}

\author{
C.P. Reeve \\ Key Words: Coefficient of Variation, Cold Chemical, Covariance Matrix, Direct Dissolution, \\ DWPF Mock-up, Fusion, Prototypic, Slurry Mix Evaporator
}

\section{Abstract}

This report is prepared as part of Technical/QA Task Plan WSRC-RP-97-351, Rev. 0 which was issued in response to Technical Task Request HLW/DWPF/TTR-970132. The issue to be addressed is the evaluation of a new method for analyzing the feedstreams in the Slurry Mix Evaporator (SME) and Melter Feed Tank (MFT) at the Defense Waste Processing Facility (DWPF). The new method involves the direct dissolution (DD) of slurry samples which is intended to replace the more time-consuming current method (CM) of vitrification of slurry samples.

A comparison test between the new and current methods, known as DWPF Lab Insert Test, HLWMD-DWPF-005, was performed in the DWPF Analytical Cell Mock-up Facility using PX-7 simulant. This report is concerned with the evaluation of the precision (variability) of the new method in comparison with the current method. This includes determining the number of samples analyzed by the new method that will give equivalent precision to four samples analyzed by the current (vitrification) method. The basis of comparison will be the precision of four feedstream properties: liquidus, viscosity, durability, and homogeneity. A companion report, Harris(1997b), addresses the issue of bias of the new method with respect to the current method.

The DD sampling method differs from the CM in that samples are collected in $3 \mathrm{ml}$ inserts rather than $15 \mathrm{ml}$ peanut vials. The DD method involves two types of sample preparation: cold chemical and fusion. The cold chemical method allows the measurement of the weight percent of all 15 elements of interest: $\mathrm{Al}, \mathrm{B}, \mathrm{Ca}, \mathrm{Cr}, \mathrm{Cu}, \mathrm{Fe}, \mathrm{K}, \mathrm{Li}, \mathrm{Mg}, \mathrm{Mn}, \mathrm{Na}, \mathrm{Ni}, \mathrm{Si}, \mathrm{Ti}$, and $\mathrm{Zr}$. The fusion method allows the measurement of all but $\mathrm{Na}$ and $\mathrm{Zr}$. Covariance matrices will be developed for three cases: cold chemical analysis only, fusion analysis only (with the addition of $\mathrm{Na}$ and $\mathrm{Zr}$ results from cold chemical analysis), and the arithmetic average of the two analyses. For each case there will be a single total covariance matrix which represents the combined contribution of within-block and between-block variability.

A total of six blocks of data was called for by the statistical design. A total of eight blocks was analyzed in the DWPF lab, and six (nos. $1,2,4,5,7,8$ ) were transferred to SRTC for evaluation. Two blocks of data were not reported because of their failure to meet $\mathrm{QC}$ release criteria.

The DD test results indicate that the insert cold chemical dissolution and insert fusion dissolution methods are reasonably stable and have similar variability characteristics to the $\mathrm{CM}$ of microwave and fusion dissolutions of vitrified material. Based on the statistical analysis, there is no indication that the new method would be any less reliable than the current method. However, it must be emphasized that this test was conducted in a mock-up facility using a single feedstream composition. During implementation in a production environment, its performance should be closely monitored to ensure compatibility with these initial results.

There is no one sample size for which the DD method is equivalent to the CM for each of five important properties. A table is provided that compares, for each property, the variability of the DD method to that of the current method for a variety of block and sample sizes. The user may select the block/sample combination which is most appropriate for the task at hand. 


\section{Preliminaries.}

\subsection{Introduction}

This report is prepared as part of TechnicalQA Task Plan WSRC-RP-97-351, Rev. 0 which was issued in response to Technical Task Request HLW/DWPF/TTR-970132. The issue to be addressed is the evaluation of a new method for analyzing the feedstreams in the Slurry Mix Evaporator (SME) and Melter Feed Tank (MFT) at the Defense Waste Processing Facility (DWPF). The new method involves the direct dissolution (DD) of slurry samples which is intended to replace the more time-consuming current method (CM) of vitrification, grinding, and dissolution of slurry samples.

This report is concerned with the evaluation of the precision (variability) of the new method in comparison with the current method. The comparison includes determining the number of samples analyzed by the DD method that will give equivalent precision to four samples analyzed by the CM. The baseline for the comparison will be the variability of four feedstream properties (liquidus, viscosity, durability, and homogeneity) as computed using both the original covariance matrix from the prototypic (PRO) test and the covariance matrix computed by the new method from the same prototypic data. A companion report, Harris(1997b), will address the issue of bias of the DD method with respect to the CM.

The DD sampling method differs from the $\mathrm{CM}$ in that samples are collected in $3 \mathrm{ml}$ inserts rather than $15 \mathrm{ml}$ peanut vials. The DD method involves two types of sample preparation: cold chemical and fusion. (The fusion method is not actually direct dissolution since drying, calcining, and grinding are involved.) The cold chemical method allows the measurement of the weight percent of all 15 elements of interest: $\mathrm{Al}, \mathrm{B}, \mathrm{Ca}, \mathrm{Cr}, \mathrm{Cu}, \mathrm{Fe}, \mathrm{K}, \mathrm{Li}, \mathrm{Mg}, \mathrm{Mn}, \mathrm{Na}, \mathrm{Ni}, \mathrm{Si}$, $T i$, and $\mathrm{Zr}$. The fusion method allows the measurement of all but $\mathrm{Na}$ and $\mathrm{Zr}$. Covariance matrices will be developed for three cases: cold chemical analysis only, fusion analysis only (with the addition of $\mathrm{Na}$ and $\mathrm{Zr}$ results from cold chemical analysis), and the arithmetic average of the two analyses. For each case there will be a single covariance matrix computed for each of four sample sizes: $2,4,6$, and 8 . These should be sufficient to cover future situations in the production environment. If more than 8 samples are required, then multiple blocks of 8 or fewer samples each should be analyzed.

General statistical guidelines for this comparison test were given in Reeve (1996b). Specific guidelines in terms of number of blocks, number of vials per block for each sampling method and each sample preparation method, number and type of analyses of the ARG-1 glass standard per block, and instrument operating parameters (vial flow rate, valve circulation time, valve opening and closing rate, hold time, etc.) were given in Harris (1997a). The test was completed in accordance with the design, and a hardcopy of the data was transferred to the Statistical Consulting Section in Swain and Spencer (1997). A diskette containing the same data was also transferred. A total of six blocks of data was called for by the design. A total of eight blocks was analyzed, and six (nos. $1,2,4,5,7,8)$ were transferred. Two blocks were not reported because of failure to meet $Q C$ release criteria.

This test, known as DWPF Lab Insert Test, HLWMD-DWPF-005, was performed in the DWPF Analytical Cell Mock-up Facility using PX-7 simulant. It will be referred to as the DD Test. The facility and feedstream simulant were designed as a reasonable match to the actual conditions of operation. As will be discussed, the ICP instrument used to measure the elemental concentrations of the slurry and ARG-1 standard was different from the one used in the previous Waste Qualification Runs (WQR).

A detailed analysis of the covariance structure of the elemental measurements made under the CM, based on the WQR data, was reported in Reeve (1996a). That analysis incorporated a two matrix approach: a between-block matrix and a within-block matrix. That approach was made necessary due to the variations of feed material between blocks. In the DD test the material was nominally the same from block to block, which allowed for a more accurate estimation of variance through a 
single covariance matrix for each sample size. That method differs from those used in the PRO and WQR tests.

Statistical calculations were performed using version 3.2.1 of JMP software by SAS Institute of Cary, North Carolina.

\subsection{Background}

Covariance matrices for use in the Product Composition Control System (PCCS) were first computed during Prototypic tests (PRO) as reported in Reeve (1993). In that test, simulated feedstreams for several tanks were sampled by prototypic methods and analyzed by the ICP instrument. Later, during Waste Qualification Runs (WQR), actual nonradioactive feedstreams in the SME and MFT were sampled and analyzed. Covariance matrices were computed for these data as reported in Reeve (1996a). The subject of this report, the Direct Dissolution (DD) test, was conducted on simulated feedstream material in a mock-up facility at DWPF using prototypic sampling methods. The elemental analyses were again performed by an ICP instrument.

Several factors remained constant throughout the three tests. At least six blocks of measurements were made with at least four samples measured per block by at least two different dissolution methods each. The ICP was always recalibrated between blocks, and the effects of using different operators were assumed to be negligible based on earlier studies. The ARG-1 glass standard was prepared twice per block by each dissolution method used on the samples, and analyzed by the ICP.

Some factors varied from test to test. The compositions of the simulated feedstreams in the PRO and $\mathrm{DD}$ tests remained constant from block-to-block, whereas the WQR feedstream varied significantly. The PRO and WQR tests used a sequential ICP, whereas the DD test used a simultaneous ICP. Over the course of these tests, the statistical modeling of the data has evolved due to 1) the different sets of test conditions, and 2) knowledge gained from previous experience.

Stated generally, the main purpose of computing covariance matrices is to be able to predict the variability of the mean elemental composition of $N$ samples taken during production runs. The samples would be prepared and measured closely in time, presumably in the same block (same ICP calibration). The following paragraphs summarize the statistical thinking toward that end.

In the PRO test, the block-to-block effects appeared to be small, thus for each dissolution method a single covariance matrix was computed from the combined data under the assumption of independence ( 6 blocks $\times 4$ measurements per block $=24$ total measurements). These covariance matrices were incorporated into the PCCS. They predicted the covariances of a single set of new observations on all elements. When $n$ new samples were taken, the variances of the sample means were computed by dividing the covariance matrix entries by $n$. Confidence intervals were computed using the $t$ statistic with 23 degrees of freedom. If block-to-block effects do exist, then this procedure is non-conservative in two ways: 1) it reduces the total variance of the mean by a factor of $1 / \mathrm{n}$ when only the within-block component of variation should be so reduced, and 2) due to non-independence of the data, a smaller number of degrees of freedom is more appropriate.

In the WQR test, the block-to-block differences were great due to the variation in feedstream material, thus the samples provided information about the within-block variability only. At the time it was not known what factors might affect the between-block variability. Certainly ICP calibration was one source. Rather than assume that between-block variability was not significant, an attempt was made to estimate it from the ARG-1 standard which did not change from block-toblock. A conservative procedure was employed for estimating the between-run matrix, thus overestimating the predicted variability of new data. Two covariance matrices for each dissolution method were reported in Reeve (1996a). An additional feature of that report was a method for separating errors into absolute and relative components. This approach provided an extremely flexible, though admittedly cumbersome, method of dealing with almost any conceivable feedstream composition. The report was produced under the assumption that the two matrix method would be incorporated into PCCS, but that did not happen. The TTR for this work 
therefore called for comparison of the DD method with the results of the PRO method which is currently implemented in PCCS.

In the DD test, a third approach to computing covariance matrices was tried. Instead of allowing a flexible number of samples, $n$, in a future production run, the new approach would assume that $n$ would be fixed. Since the DD feedstream was nominally the same for all blocks, the block means (each based on $n$ measurements) could be computed and then the sample variance of those block means would estimate the variance in the mean of $n$ samples in the production run. Since $n$ was not known ahead of time, a matrix was computed for each of the cases $n=2,4,6$, and 8 . In the future, all four matrices are available (for each method), and the appropriate matrix can be used. Of the three methods discussed here, this one should give the most accurate estimate of variance. This can be illustrated as follows without great statistical rigor.

For a given dissolution method and a given element, the statistical model for a single measurement of elemental weight percent is

$$
x_{i j}=\mu+\beta_{i}+\varepsilon_{i j} \text { and } \operatorname{Var}\left(x_{i j}\right)=\sigma_{b}^{2}+\sigma_{w}^{2}
$$

where $i=1,2, \ldots, b$ indexes the block and $j=1,2, \ldots, m$ indexes the replicate measurements within a block. The model for the block mean (mean of $m$ measurements in block $i$ ) is

$$
\bar{x}_{i \bullet}=\mu+\beta_{i}+\vec{\varepsilon}_{i \bullet} \text { and } \quad \operatorname{Var}\left(\bar{x}_{i \oplus}\right)=\sigma_{b}^{2}+\frac{1}{m} \sigma_{w}^{2} .
$$

Let $n$ denote the number of measurements in a single new block of data under the same assumptions of variability, and let $\bar{X}$ denote the mean of those $n$ measurements. Then the expectations of the predicted variances of $\bar{X}$, and the true variance of $\bar{X}$, are as follows for the different methods.

\begin{tabular}{|c|c|c|c|c|}
\hline Method & $\begin{array}{c}\text { Expectation of } \\
\text { Predicted variance of } \bar{X}\end{array}$ & True variance of $\bar{X}$ & $\begin{array}{c}\text { Estimator } \\
\text { d.f. }\end{array}$ & Comment \\
\hline PRO & $\frac{\sigma_{b}^{2}+\sigma_{w}^{2}}{n}$ & $\sigma_{b}^{2}+\frac{1}{n} \sigma_{w}^{2}$ & $b m-1$ & $\begin{array}{c}\text { True variance } \\
\text { underestimated }\end{array}$ \\
\hline $\mathrm{WQR}$ & $\left(\sigma_{b}^{2}+\frac{1}{m} \sigma_{w}^{2}\right)+\frac{1}{n} \sigma_{w}^{2}$ & $\sigma_{b}^{2}+\frac{1}{n} \sigma_{w}^{2}$ & $b-1$ & $\begin{array}{c}\text { True variance } \\
\text { overestimated }\end{array}$ \\
\hline $\begin{array}{c}\mathrm{DD} \\
(m=n)\end{array}$ & $\sigma_{b}^{2}+\frac{1}{n} \sigma_{w}^{2}$ & $\sigma_{b}^{2}+\frac{1}{n} \sigma_{w}^{2}$ & $b-1$ & $\begin{array}{c}\text { Unbiased for } \\
\text { true variance }\end{array}$ \\
\hline
\end{tabular}

\section{Design of the Experiment}

The design in Harris (1997a) called for six blocks of samples and measurements with each block containing:

9 insert samples for DD cold chemical analysis,

9 insert samples for calcine weight percent and DD fusion analysis.,

4 peanut vial Hydragard samples for CM fusion and microwave analysis,

2 peanut vial dip samples for CM fusion and microwave analysis,

2 ARG- 1 samples analyzed by $C M$ fusion,

2 ARG-1 samples analyzed by CM microwave,

2 ARG-1 samples analyzed by DD cold chemical, and

2 ARG-1 samples analyzed by DD fusion. 
Samples were pulled and measurements made in accordance with the design. A few insert samples were spilled, but at least 8 were analyzed by each method per block.

Measurements on blanks were also made in each block, but those are not relevant to the computation of covariance matrices. They are discussed in Harris (1997b).

The six blocks are identified by their original block numbers: $1,2,4,5,7$, and 8 . Blocks 3 and 6 were not transmitted.

\section{Analytical Methods}

For the DD cold chemical preps, all 15 elements of interest $(A l, B, C a, C r, C u, F e, K, L i, M g$, $\mathrm{Mn}, \mathrm{Na}, \mathrm{Ni}, \mathrm{Si}, \mathrm{Ti}$, and $\mathrm{Zr}$ ) were analyzed. For the $\mathrm{DD}$ fusion preparations and the $\mathrm{CM}$ fusion preparations, all elements but $\mathrm{Na}$ and $\mathrm{Zr}$ were analyzed. For the $\mathrm{CM}$ microwave preps, all elements but $B$ were analyzed. (This applies to both the PX-7 simulant samples and the ARG-1 standard.)

The insert samples for DD fusion analysis were first calcined and the weight percent calcined solids measured. The calcined material was then prepared by the DD fusion method to yield elemental weight percents relative to a calcine basis.

The insert samples for DD cold chemical analysis were analyzed directly to yield elemental weight percents relative to a slurry basis.

The peanut vial samples were vitrified before the $\mathrm{CM}$ fusion and microwave analyses were performed, which yielded elemental weight percents relative to a vitrified basis.

The PRO and WQR data were analyzed by a sequential type ICP (inductively coupled plasma) instrument. The DD data were analyzed by a simultaneous type ICP, thus a difference in variability of performance would not be surprising. However, no definite conclusions about that can be drawn from this test.

\section{Statistical Models for the Data}

The data for this test are not listed in this report since they appear in the transmittal report by Swain and Spencer (1997). The file identification names, Excel file names, date and time of transmittal, and description of file contents in the transmittal report are shown in Table 1. Block 8 data were transmitted separately and was added to the appropriate files shown in the table.

[In the case of the WQR data reported by Reeve (1996a), the net error in an elemental analysis of feedstream material (in this case, simulant) was modeled as the sum of within-block and betweenblocks errors. Sampling errors and ICP measurement errors were modeled as the main sources of within-block error. ICP calibration error and sample preparation error were modeled as the main source of between block error. Changes in feedstream material between blocks are modeled as changes in mean value rather than random variation. The reader is referred to that paper for a more detailed discussion of these topics as well as the philosophy of modeling the measurement errors as a combination of relative and absolute errors.]

The statistical method employed in analyzing the DD test data does not require identifying sources of error as being within-block or between-block. It simply assumes that the error sources will affect future production data in the same way that they affected the $D D$ test data. All errors will be modeled as relative for simplicity. This should present no problem as long as the concentrations of the trace elements $(C r, C u, T i$, and $Z r)$ remain small.

The advantage of a relative error form for the covariance matrices is that they may be applied to a wide variety of feedstream composition vectors (assuming, of course, that other feedstream compositions exhibit similar relative error behavior). Once a given feedstream mean vector is 
estimated, the absolute errors in that particular composition are easily obtained from the relative covariance matrices.

The insert calcine factors are plotted by block in Figure 1. The accompanying analysis of variance shows that block-to-block effects are significant at the 0.05 level. The insert cold chemical (ICC) unadjusted values are plotted vs. block in Figure 2, and the insert fusion (IF) values are plotted vs. block in Figure 3.

\subsection{Notation}

In order to identify measured and derived quantities in the computations which follow, the following notation will be used. Note that, for uniformity, the number of elements analyzed $(N=15)$ is the same for all vectors and matrices, thus all vectors will be of length $N$ and all matrices will be $N \times N$ arrays. In cases where certain elements are not measured, slots in the vectors and matrices are filled with zeros, but never used.

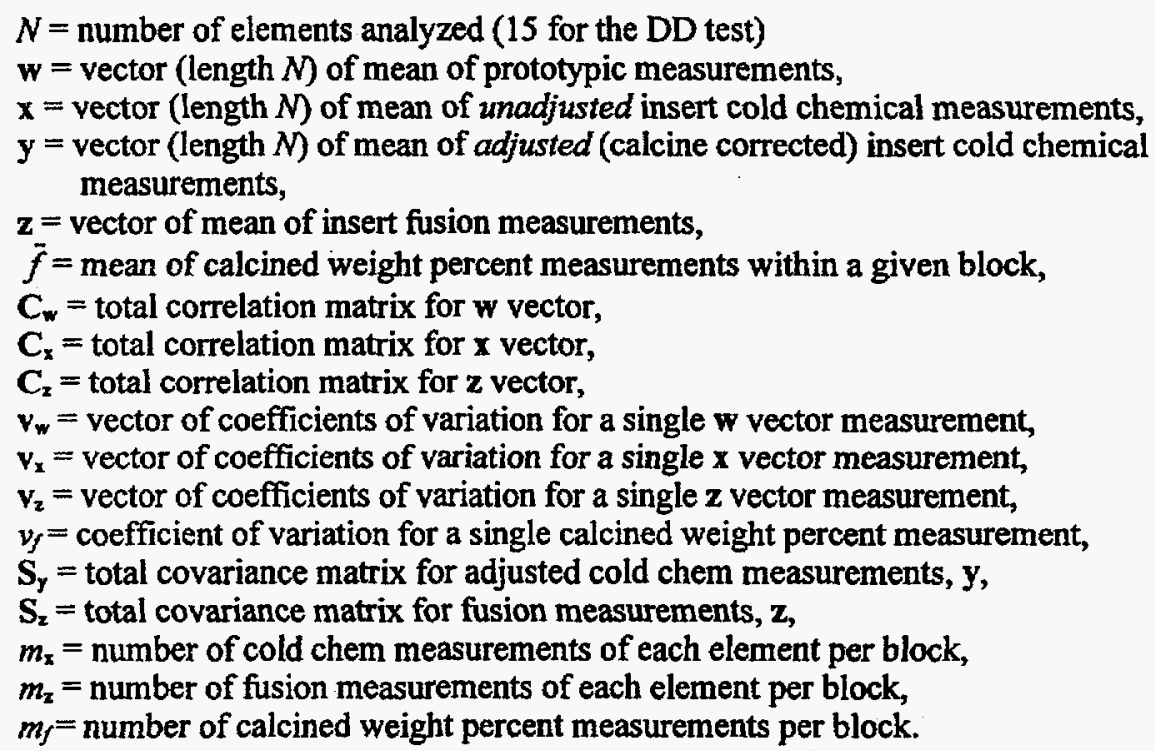

\subsection{Outliers}

The ICC and IF data were screened for outliers by examining the data in Figures 1, 2, and 3 and being conservative. Only two samples were excluded from the analyses:

1) block 2, pull 7 from the insert cold chemical analyses of PX-7, and

2) block 4 , pull 6 from the insert fusion analyses of PX-7.

The latter sample also resulted in one calcine value being excluded. These outlying values are indicated by square symbols in the appropriate figures.

\subsection{PX-7 Simulant Data}

The transmitted insert fusion analyses of the PX-7 simulant were on a calcine basis, whereas the corresponding transmitted insert cold chemical analyses were on a slurry basis. We will refer to the latter values as being unadjusted. Each block of unadjusted data was adjusted (converted to a calcine basis) by dividing the unadjusted values by the average calcine weight percent (expressed 
as a proportion) for the vials in that block. As a result, the adjusted data for each element contains errors from two independent sources.

The total covariance matrices for the NM will be estimated from the measurements on the PX-7 feedstream simulant. As requested in Technical/QA Task Plan WSRC-RP-97-351, separate covariance matrices will be computed for:

1) insert cold chemical data only,

2) insert fusion data only, and

3) the average of 1 ) and 2).

Since $\mathrm{Na}$ and $\mathrm{Zr}$ are not obtainable from the fusion data, values for these elements will be obtained solely from the cold chemical data. Each of the three combinations can be considered as a linear combination of the combined cold chemical and fusion data. The appropriate coefficients for the combination are shown in Table 13.

The mean elemental weight percents for the PX-7 simulant in the DD test, shown in Table 3, are not used in the computations of this report. They are examined in the companion report by Harris (1997b).

\subsection{ARG-1 Glass Standard Data}

The ARG-I glass standard was analyzed by four different methods in the DD test, but none of that data was used in computing covariance matrices. The elemental means from those methods are compared with the Corning means in Table 4a. The corresponding total coefficients of variation are shown in Table $4 \mathrm{~b}$. These represent the total percent relative error in the mean of 2 measurements within a block. On the whole, the four methods seem to give comparable results.

\section{Estimating Components of the Total Covariance Matrices}

A new, simpler, and more accurate method for computing covariance matrices was introduced in Section 1.2. This fixed sample size covariance matrix method was first implemented in the DD test. Since the sample size requirement for future production runs has not yet been established, fixed sample size covariance matrices were computed for sample sizes $2,4,6$, and 8 . The appropriate one can be chosen later.

In relative form, the covariance matrix actually takes the component form of a correlation matrix and a vector of coefficients of variation $(\mathrm{CV}=$ percent relative error $=100 \sigma / \mu$ where $\sigma$ is the standard deviation and $\mu$ is the mean). These are converted to a covariance matrix only after a vector of mean values is specified. In the conversion process, the CVs are divided by 100 to convert them to proportion relative errors. However, the elemental weight percents are not converted to proportions. In the case of cold chemical measurements, a third component is involved: the calcine factor which adjusted the data.

The various aspects of computing and using the covariance matrices for the difference methods and sample sizes are discussed in the following subsections.

\subsection{Computational Methods for Direct Dissolution (DD) Test Data}

The concept of a fixed sample size covariance matrix is built on the following principle: if you want to know the variance of the mean of $n$ future samples taken under a certain set of conditions, then do your initial test under the same set of conditions and with the same $n$ samples per block. Compute the mean within each block and then compute the sample variance of those block means. The resulting variance is then an unbiased estimator of the variance of the mean of the $n$ future samples. 
In the DD test, the number of blocks for each method was six. For the insert cold chemical (ICC) method there were 8-9 measured samples per block. For the insert fusion (IF) method there were 6-8 measured samples per block. For the ICC method the measurements were randomly sorted within each block, and the first 8 used to compute the sample size 8 covariance matrix. For the IF method the measurements were also randomly sorted within each block. In those blocks with less than 8 measurements, one or two measurements chosen at random were duplicated to yield exactly 8 measurements per block. The modified ICC and IF data sets are shown in Tables 9 and 10 respectively. The duplicated blocks in the latter table are indicated by $a$ " $R$ " appended to the pull number. The calcine weight percents were analyzed in the same way as the ICC data with 8 measurements per block. Those modified data are shown in Table 11 with the duplicated pulls indicated by " $\mathrm{R}$ ".

The total coefficients of variation for these $n=8$ cases are shown in Table $5 \mathrm{~d}$. The corresponding correlation matrices for the ICC and IF data are shown in Tables $7 \mathrm{~d}$ and $8 \mathrm{~d}$, respectively. The proper method for combining them to yield the absolute covariance matrices is discussed in section 6.

It may turn out that fewer than 8 samples will be required in production runs. (If more than 8 are required, it will be necessary to do multiple blocks of 8 or less in order to reduce the variation by a significant amount.) To allow for that situation, fixed sample size covariance matrices were also computed for sample sizes 2,4 , and 6 .

The fixed sample size 6 covariance matrix was computed as the average of four covariance matrices which were computed using the following measurements within each block: $\{1,2,3,4,5,6\}$, $\{3,4,5,6,7,8\},\{5,6,7,8,1,2\}$, and $\{7,8,1,2,3,4\}$. Note that each measurement was used three times and that each covariance matrix has the same expected value. Once the covariance matrix was computed, it was separated into coefficients of variation (Table 5c) and correlation matrices (Tables $7 \mathrm{c}$ and $8 \mathrm{c}$ ).

The fixed sample size 4 covariance matrix was computed as the average of four covariance matrices which were computed using the following measurements within each block: $\{1,2,3,4\},\{3,4,5,6\}$, $\{5,6,7,8\}$, and $\{7,8,1,2\}$. Note that each measurement was used twice and that each matrix has the same expected value. The covariance matrix was separated into coefficients of variation (Table $5 b$ ) and correlation matrices (Tables $7 b$ and $8 b$ ).

The fixed sample size 2 covariance matrix was computed as the average of four covariance matrices which were computed using the following measurements within each block: $\{1,2\},\{3,4\},,\{5,6\}$, and $\{7,8\}$. Note that each measurement was used once and that each matrix has the same expected value. The covariance matrix was separated into coefficients of variation (Table 5a) and correlation matrices (Tables $7 a$ and $8 a$ ).

The calcine factors shown in Table 2 were computed in a corresponding manner. The appropriate calcine CV was combined with each unadjusted ICC CV to determine the adjusted ICC CV as shown in Tables 5a-d.

The number of degrees of freedom for each covariance matrix computed in this manner is one less than the number of blocks, or 5 for the DD test.

In addition to direct dissolution of vial insert samples, the DD test included some analyses of peanut vial (PV) dip and Hydragard samples by microwave and fusion dissolutions of vitrified samples. Two vials of dip samples and four vials of Hydragard samples were drawn per block for each type of preparation, and they were measured in the same blocks as the insert samples. The CV's for the dip samples are shown in Table 5a, and the CV's for the Hydragard samples are shown in Table 5b. The CV's for the combined dip and Hydragard samples are shown in Table 5c. Comparisons of the peanut vial means with the insert means are discussed in Harris (1997b). 


\subsection{Computational Methods for Prototypic (PRO) Test Data}

The prototypic data consisted of 6 blocks of 4 measurements each for the same 15 elements as in the DD test. The original prototypic matrix was computed from the 24 measurements on each element under the assumption that block effects were not significant. As a result, the covariance matrix was based on 23 degrees of freedom. The corresponding coefficients of variation are shown in Table 5e and the correlation matrix in Table 6a.

Using the same data, the fixed sample size 4 covariance matrix was computed according to the methods described in the previous section. The coefficients of variation are also shown in Table $5 \mathrm{e}$ and the correlation matrix in Table $6 \mathrm{~b}$. The number of degrees of freedom is 5 . This matrix should provide the best basis for comparison of the DD test results to the PRO test results. The original prototypic matrix is less conservative in two respects: 1) block-to-block effects (whose variability cannot be reduced by multiple sampling) were ignored and 2) the number of degrees of freedom is considerably greater, resulting in a narrower $95 \%$ confidence interval as implemented in PCCS.

\section{Estimating the Total Covariance Matrices}

Formulas for computing (absolute) within-block covariance matrices for the elemental weight percents are discussed in the following subsections. The conversion from relative to absolute form requires a set of mean elemental weight percents. For the purpose of illustration, two such sets of data are used: 1) the mean elemental weight percents from the WQR tests, and 2) the mean elemental weight percents from RADOPS batches 22-30. (These are shown in the rightmost columns of Table 3.) The former feedstream included simulated PHA along with sludge and frit. The latter feedstream included only sludge and frit, thus virtually no potassium was present. The latter also included about one weight percent uranium which is omitted from all the property computations in this report. Eventually, variances, covariances, and correlations for uranium should be added to those of the other elements.

It should be remembered that, in this report, we are comparing the variances of the properties for the different means and methods, not the values of the properties themselves.

\subsection{Insert Cold Chemical (ICC) Analysis}

Let $\mathbf{C}_{\mathrm{x}}^{m}$ denote the fixed sample size $m$ correlation matrix for the mean unadjusted ICC data vector $\mathbf{x}, \mathbf{v}_{\mathbf{x}}$ denote the coefficient of variation vector for the unadjusted $\mathrm{ICC}$ data vector, $\bar{f}_{m}$ denote the corresponding mean calcine factor, and $v_{\bar{f}_{m}}$ denote the coefficient of variation of the mean calcine factor (based on sample size $m$ ). The mean adjusted ICC data vector $y$ then has the covariance matrix

$$
\mathrm{S}_{\mathrm{y}}=\left(\mathrm{yy}^{T}\right) \#\left(\mathbf{v}_{\mathrm{x}} \mathbf{v}_{\mathrm{x}}^{T}\right) \# \mathrm{C}_{\mathrm{x}}^{m}+v_{f_{\mathrm{m}}}^{2} \mathrm{yy}^{T}
$$

where "\#" indicates the multiplication of corresponding entries in the adjacent matrices (a\#b is also the diagonal vector of the matrix $\mathbf{a b}$ ). Alternatively, the individual components of the covariance matrix can be expressed as

$$
\left(\mathbf{S}_{\mathbf{y}}\right)_{i j}=(\mathbf{y})_{i}(\mathbf{y})_{j}\left(\mathbf{v}_{\mathbf{x}}\right)_{i}\left(\mathbf{v}_{\mathbf{x}}\right)_{j}\left(\mathbf{C}_{\mathbf{x}}^{m}\right)_{i j}+v_{f_{m}}^{2}(\mathbf{y})_{i}(\mathbf{y})_{j}
$$

\subsection{Insert Fusion (IF) Analysis}

Let $\mathrm{C}_{\mathbf{z}}^{m}$ denote the fixed sample size $\boldsymbol{m}$ correlation matrix for the mean IF data vector $\mathbf{z}$ and $\mathbf{v}_{\mathbf{z}}$ denote the coefficient of variation vector for $\mathbf{z}$. Then $\mathbf{z}$ has the covariance matrix 


$$
\mathrm{S}_{\mathrm{z}}=\left(\mathrm{zz}^{T}\right) \#\left(\mathrm{v}_{\mathrm{z}} \mathbf{v}_{\mathrm{z}}^{T}\right) \# \mathrm{C}_{\mathrm{z}}^{m}
$$

or, in terms of components,

$$
\left(\mathbf{S}_{\mathbf{z}}\right)_{i j}=(\mathbf{z})_{j}(\mathbf{z})_{j}\left(\mathbf{v}_{\mathbf{z}}\right)_{i}\left(\mathbf{v}_{\mathbf{z}}\right)_{j}\left(\mathbf{C}_{\mathbf{z}}^{m}\right)_{i j}
$$

\subsection{Original Prototypic Matrix (PRONB)}

Let the subscript $p$ denote quantities computed for the original covariance matrix for the prototypic data, and let the subscript $q$ denote quantities computed for the sample size 4 covariance matrix for the prototypic data.

Let $\mathbf{C}_{p}^{1}$ denote the fixed original correlation matrix for a single measurement vector of prototypic data, and let $w$ be the mean vector of four measurements. Let $v_{p}$ denote the corresponding coefficient of variation vector for a single measurement. Then, by this method, $w$ has the covariance matrix

$$
\mathrm{S}_{p}=\frac{1}{4}\left(\mathbf{w} \mathbf{w}^{T}\right) \#\left(\mathbf{v}_{p} \mathbf{v}_{p}^{T}\right) \# C_{p}^{1}
$$

or, in terms of components,

$$
\left(\mathbf{S}_{p}\right)_{i j}=\frac{1}{4}(\mathbf{w})_{i}(\mathbf{w})_{j}\left(\mathbf{v}_{p}\right)_{i}\left(\mathbf{v}_{p}\right)_{j}\left(\mathbf{C}_{p}^{\mathrm{l}}\right)_{i j}
$$

\subsection{Prototypic Matrix by Fixed Sample Size Method (PROF4)}

Let $\mathrm{C}_{q}^{4}$ denote the fixed sample size 4 correlation matrix for the mean of four measurements, $\mathbf{w}$, and $v_{q}$ denote the corresponding coefficient of variation vector for that mean. Then, by this method, w has the covariance matrix

$$
\mathbf{S}_{q}=\left(\mathbf{w} \mathbf{w}^{T}\right) \#\left(\mathbf{v}_{q} \mathbf{v}_{q}^{T}\right) \# \mathbf{C}_{q}^{4}
$$

or, in terms of components,

$$
\left(\mathbf{S}_{q}\right)_{i j}=(\mathbf{w})_{i}(\mathbf{w})_{j}\left(\mathbf{v}_{q}\right)_{i}\left(\mathbf{v}_{q}\right)_{j}\left(\mathbf{C}_{q}^{4}\right)_{i j}
$$

\section{Comparison of Property Variabilities}

From the formulas in the previous section we can compute the total covariance matrices for the PRO and DD methods, using different sample size scenarios for the latter. From these we can compute and compare the variabilities of the properties of interest. This comparison requires the use of a common mean elemental weight percent vector. We have chosen two: 1) the mean from the WQR test and 2) the mean of SME batches 22-30 from radioactive operations (RADOPS). Note that the mean composition of the PX-7 simulant is similar to that of the WQR mean, and could have been used as well. 
As directed by HLW/DWPF/TTR-970132, we are to compute sample sizes for the DD method which will yield equivalent variability to the $\mathrm{CM}$ which uses a covariance matrix from prototypic tests computed under the assumption of no block-to-block effects. Property variances computed by this method are denoted PRONB in Table 14a-c. As an additional comparison, the prototypic data were re-analyzed using the fuxed sample size 4 method. Property variances computed by that method are denoted PROF4 in the same tables.

Comparisons are to be made with respect to four properties that are of most importance in the Product Composition Control System (PCCS): liquidus temperature, viscosity, durability $\left(\Delta G_{p}\right)$, and homogeneity. Since there are upper and lower bounds on viscosity, we will take low viscosity and high viscosity as separate properties, giving a total of five. Each property constraint involves a linear combination of the mean oxide weight percents of the feedstream composition, a constant, and an inequality indicator $(<,>, \leq, \geq)$. The appropriate linear combinations for the five properties of interest are shown in Table 12 along with gravimetric factors and oxide molecular weights. See the Appendix section for more details on the property constraints.

As further directed by HLW/DWPF/TTR-970132, we are to consider the three different combinations of insert cold chemical and insert fusion methods which are defined by the coefficients in Table 13.

Let $\mathbf{c}$ be the vector of coefficients $c_{1}, c_{2}, \ldots, c_{n}$ for a given property (as in Table 12), $\theta$ be the vector of ratios of gravimetric factors to oxide molecular weights $\theta_{1}, \theta_{2}, \ldots, \theta_{n}$, and $\mathbf{w}, \mathbf{y}$, and $\mathbf{z}$ be the vectors of elemental weight percents as previously defined. For a given combination of methods in Table 13, let $\tau_{y}$ be the vector of insert cold chemical coefficients and $\tau_{z}$ be the vector of insert fusion coefficients.

From the combined DD data, the estimate of the property itself, except for the constant, is

$$
\left(\mathbf{c} \# \theta \# \tau_{\mathbf{y}}\right)^{T} \mathbf{y}+\left(\mathbf{c} \# \theta \# \tau_{\mathbf{z}}\right)^{T} \mathbf{z}=\sum_{i=1}^{n} c_{i} \theta_{i}\left[\left(\tau_{\mathbf{y}}\right)_{i} \mathbf{y}_{i}+\left(\tau_{\mathbf{z}}\right)_{i} \mathbf{z}_{i}\right]
$$

Numerical values of properties computed with the WQR mean composition inserted for $y$ and $z$ are given for the purpose of illustration in the Appendix.

The corresponding estimate of property variance is

$$
\begin{aligned}
& \left(c \# \theta \# \tau_{y}\right)^{T} S_{y}\left(c \# \theta \# \tau_{y}\right)+\left(c \# \theta \# \tau_{z}\right)^{T} S_{z}\left(c \# \theta \# \tau_{z}\right)= \\
& \sum_{i=1}^{n} \sum_{j=1}^{n} c_{i} \theta_{i}\left(\tau_{\mathbf{y}}\right)_{i}\left[(\mathbf{y})_{i}(\mathbf{y})_{j}\left(\mathbf{v}_{\mathbf{x}}\right)_{i}\left(\mathbf{v}_{\mathbf{x}}\right)_{j}\left(\mathbf{C}_{\mathbf{x}}^{m}\right)_{i j}+v_{f_{m}}^{2}(\mathbf{y})_{i}(\mathbf{y})_{j}\right] c_{j} \theta_{j}\left(\tau_{\mathbf{y}}\right)_{j} \\
& +\sum_{i=1}^{n} \sum_{j=1}^{n} c_{i} \theta_{i}\left(\tau_{\mathbf{z}}\right)_{i}\left[(\mathbf{z})_{j}(\mathbf{z})_{j}\left(\mathbf{v}_{\mathbf{z}}\right)_{i}\left(\mathbf{v}_{\mathbf{z}}\right)_{j}\left(\mathbf{C}_{\mathbf{z}}^{m}\right)_{i j}\right] c_{j} \theta_{j}\left(\tau_{\mathbf{z}}\right)_{j}
\end{aligned}
$$

where $S_{y}$ and $S_{\mathbf{z}}$ are as defined in $(1 a, b)$ and $(2 a, b)$, respectively.

For sample size determination, we are interested only in the property variances, thus we can use (4) with the "typical" vector of elemental means, w, substituted in place of both $y$ and $z$. This results in

$$
\begin{array}{r}
\sum_{i=1 j=1}^{n} \sum_{j=1}^{n} c_{i} \theta_{i}\left(\tau_{y}\right)_{i} w_{i}\left[\left(\mathbf{v}_{\mathbf{x}}\right)_{i}\left(\mathbf{v}_{\mathbf{x}}\right)_{j}\left(\mathbf{C}_{\mathbf{x}}^{m}\right)_{i j}+v_{f_{m}}^{2}\right] c_{j} \theta_{j}\left(\tau_{\mathbf{y}}\right)_{j} w_{j} \\
+\sum_{i=1}^{n} \sum_{j=1}^{n} c_{i} \theta_{i}\left(\tau_{\mathbf{z}}\right)_{i} w_{i}\left[\left(\mathbf{v}_{\mathbf{z}}\right)_{i}\left(\mathbf{v}_{\mathbf{z}}\right)_{j}\left(\mathbf{C}_{\mathrm{z}}^{m}\right)_{i j}\right] c_{j} \theta_{j}\left(\tau_{\mathrm{z}}\right)_{j} w_{j}
\end{array}
$$

as the general expression for a given property variance under the DD method. 
For the original prototypic matrix (PRONB), the variance equivalent to (7) is

$$
\sum_{i=1}^{n} \sum_{j=1}^{n} c_{i} \theta_{i} w_{i}\left[\frac{\left(\mathrm{v}_{p}\right)_{i}\left(\mathrm{v}_{p}\right)_{j}\left(\mathrm{C}_{p}^{\mathrm{l}}\right)_{i j}}{4}\right] c_{j} \theta_{j} w_{j}
$$

and for the fixed sample size 4 prototypic matrix (PROF4), the equivalent variance is

$$
\sum_{i=1}^{n} \sum_{j=1}^{n} c_{i} \theta_{i} w_{i}\left[\left(\mathbf{v}_{q}\right)_{i}\left(\mathbf{v}_{q}\right)_{j}\left(\mathbf{C}_{q}^{4}\right)_{i j}\right] c_{j} \theta_{j} w_{j} .
$$

For each of the five properties, and for selected sample sizes, the half-width of a $95 \%$ confidence interval was computed using values from Student's $t$ distribution and the square roots of (7), (8), and (9). The results appear in Tables 14a-c. The PRONB method had 23 degrees of freedom and a $t$ value of 2.069. All of the other methods had 5 degrees of freedom and a $t$ value of 2.571 . (These $t$ values give two-sided 95\% confidence intervals.) The methods denoted "ICC", "IF" and "ICC+IF" were computed by (7) using the respective weights in Table 13. The indicated sample size applies to each of $m_{\mathbf{x}}, m_{\mathbf{y}}$, and $m_{f}$ as defined earlier. Entries in Tables 14a-c corresponding to the direct dissolution methods were computed for 1,2 , and 3 blocks of $2,4,6$, and 8 measurements per block.

Table 15 summarizes the minimum block/sample combinations in Tables 14a-c which yield equivalent (or less) variability when compared to the indicated prototypic method with four samples per block. The largest sample size considered was 8 because that was (roughly) the sample size used in the DD test. At some point, increasing the sample size becomes ineffective as it reduces only the within-block component of variation. Increasing the number of blocks, $b$, is more effective as it reduces the entire covariance matrix by a factor of $1 / b$.

The fact that the PRONB intervals are significantly shorter than the PROF4 intervals is not surprising. Two factors contribute to this: 1) the PRONB data uses a smaller $t$ value, and 2) the PRONB method inappropriately reduces the between-block component of variability with increased sample size.

\section{Quality Control Issues}

Several laboratory quality control measures were recommended in section 4.3 of Reeve (1996a). The two most important were the variabilities of the sum of oxides and $\mathrm{Fe} / \mathrm{L} i$ ratio. Those will still be appropriate if the Direct Dissolution (DD) method is implemented.

An additional feature of the DD method is the computation of a calcine factor several times per block. The variability of this quantity would also be a useful quality control measure.

The variability data from the DD test showed a somewhat different correlation matrix structure and elemental CV (relative error) structure than that seen in previous tests. This was not too surprising given that different types of ICP instruments were used in the two tests. The DD test showed larger positive correlations than the PRO test. Although this could be attributable to ICP differences, no such conclusions can be drawn from this test.

It should be stressed that the covariance matrices computed from the DD test are valid only if the conditions and instrumentation in the actual production facility are reasonably similar to those in the mock-up facility. 


\section{Summary and Recommendations}

This paper has addressed variability issues in the DD test. A companion paper, Harris (1997b), addresses bias and other issues. The primary purpose of the variability study has been to determine the number of samples per block in the DD method that would give equivalent variability to four samples per block in the $\mathrm{CM}$ based on prototypic data. In some cases the DD method would require multiple blocks to sufficiently reduce the variability.

As seen in Tables 14a-c and 15, there is no one block/sample size combination for which the DD method is equivalent to the CM for all properties (this is true even though only sample sizes 2,4 , 6 , and 8 were examined). The knowledgeable user must determine which sample size jointly provides such equivalence.

The DD test results indicate that the insert cold chemical (ICC) dissolution and insert fusion (IF) dissolution methods are stable and have similar variability characteristics to the $\mathrm{CM}$ of microwave and fusion dissolutions of vitrified material. Based on statistical analysis, there is nothing to indicate that the new method would be any less reliable than the current method. However, it must be emphasized that this test was conducted in a mock-up facility using a single type of feedstream composition. When the new (DD) method is implemented in a production environment, its performance should be closely monitored to ensure compatibility with these initial results. I recommend that a statistician be involved in periodically reviewing the production data to verify that they are consistent with the results of the DD test.

\section{References.}

Brown, K.G. and Postles, R.L. (1996), "SME Acceptability Determination for DWPF Process Control (U)", WSRC-TR-95-0364, Rev. 3, February 21, 1996.

Edwards, T.B. (1997), "Statistical Review of Data from DWPF's Process Samples for Batches 19 Through 30 (U)", WSRC-RP-97-207, Rev. 0, March 18, 1997.

Harris, S.P. (1997a), "DWPF Sample Vial Insert Study: Mock-up Testing Study Design (U)", SRT-SCS-97004, Rev. 0, March 31, 1997.

Harris, S.P. (1997b), "DWPF Sample Vial Insert Study: Statistical Analysis of DWPF Mock-up Test Data (U)", WSRC-TR-97-00292, Rev. 0, September 18, 1997.

Reeve, C.P. (1993), "PCCS Covariance Matrices Based on DWPF Prototypic Tests (U)", SCSASG-93-0048, June 4, 1993.

Reeve, C. P. (1996a), "Computation of PCCS Covariance Matrices for the SME Based on Waste Qualification Runs (U)", WSRC-TR-96-0022, March 20, 1996.

Reeve, C. P. (1996b), "A Statistical Plan for Evaluating a New DWPF Laboratory Analytical Method (U)”, WSRC-TR-96-0098, April 16, 1996.

Swain, M.J. and Spencer, R.B. (1997), "Formal Transmittal of Test DWPF-0005 Data Blocks 1,2,4,5,7,8 (U), OPS-DTX-970023, August 14, 1997. 


\section{Appendix. Property Models}

In order to be acceptable for processing and waste compliance, a given feedstream must satisfy constraints on each of four properties: durability, liquidus, viscosity, and homogeneity. The durability and homogeneity constraints are on linear combinations of the elemental weight percents of the significant elements in the feedstream. The liquidus and viscosity constraints involve nonlinear combinations of the elemental weight percents. These are converted to linear forms by incorporating the bounds as shown below. The variance of a linear combination of elemental weight percents is straightforwardly computed from the covariance matrix (or matrices) of the elemental weight percents. Such computations are illustrated in section 7 of this report using the specific linear combinations shown below.

The property coefficients were obtained from Appendix C of Brown and Postles (1996). They are applied to the molar oxides (moles per 100 grams of glass), indicated by [ ], which are the elemental weight percents times the gravimetric factors (Table 12) divided by the oxide molecular weights (Table 12).

The durability constraint is

$$
\begin{aligned}
& 37.68\left[\mathrm{Al}_{2} \mathrm{O}_{3}\right]-10.43\left[\mathrm{~B}_{2} \mathrm{O}_{3}\right]-13.79[\mathrm{CaO}]+11.95\left[\mathrm{Cr}_{2} \mathrm{O}_{3}\right]-4.96[\mathrm{CuO}]+14.56\left[\mathrm{Fe}_{2} \mathrm{O}_{3}\right] \\
& -76.41\left[\mathrm{~K}_{2} \mathrm{O}\right]-24.04\left[\mathrm{Li}_{2} \mathrm{O}\right]-6.57[\mathrm{MgO}]-24.44[\mathrm{MnO}]-53.09\left[\mathrm{Na}_{2} \mathrm{O}\right]+0.37[\mathrm{NiO}] \\
& +4.05\left[\mathrm{SiO}_{2}\right]+16.27\left[\mathrm{TiO}_{2}\right]+17.49\left[\mathrm{ZrO}_{2}\right] \geq \beta
\end{aligned}
$$

where $\beta=-12.82,-12.72$, or -13.02 for $B, L i$, or $N a$ release, respectively. The variance of the left hand side (LHS) does not depend on the bound of the constraint. Using the WQR average elemental composition from Table 3 , this quantity evaluates to -9.360 , thus the constraint is satisfied for each type of release.

The liquidus constraint is

$$
\frac{134.00\left[\mathrm{Fe}_{2} \mathrm{O}_{3}\right]}{\left.155.60\left[\mathrm{SiO}_{2}\right]-35.98 .88 \mathrm{Al}_{2} \mathrm{O}_{3}\right]} \leq 0.0971
$$

which is equivalent to the linear constraint

$$
15.11\left[\mathrm{SiO}_{2}\right]-34.94\left[\mathrm{ALO}_{2}\right]-134.00\left[\mathrm{Fe}_{2} \mathrm{O}_{3}\right] \geq 0 \text {. }
$$

The variance of the LHS does depend on the bound of the original constraint. Using the WQR average elemental composition, the LHS evaluates to 2.270 , thus the constraint is satisfied.

The viscosity constraint is

$$
0.847 \leq \frac{\left[\mathrm{B}_{2} \mathrm{O}_{3}\right]+2\left(\left[\mathrm{Fe}_{2} \mathrm{O}_{3}\right]+\left[\mathrm{K}_{2} \mathrm{O}\right]+\left[\mathrm{Li}_{2} \mathrm{O}\right]+\left[\mathrm{Na}_{2} \mathrm{O}\right]-\left[\mathrm{AL}_{2} \mathrm{O}_{3}\right]\right)}{\left[\mathrm{SiO}_{2}\right]} \leq 1.268
$$

which is equivalent to the two linear constraints

$$
\begin{array}{r}
-2\left[\mathrm{AlO}_{3}\right]+\left[\mathrm{B}_{2} \mathrm{O}_{3}\right]+2\left[\mathrm{Fe}_{2} \mathrm{O}_{3}\right]+2\left[\mathrm{~K}_{2} \mathrm{O}\right]+2\left[\mathrm{Li}_{2} \mathrm{O}\right]+2\left[\mathrm{Na}_{2} \mathrm{O}\right]-0.847\left[\mathrm{SiO}_{2}\right] \geq 0 \\
2\left[\mathrm{Al}_{2} \mathrm{O}_{3}\right]-\left[\mathrm{B}_{2} \mathrm{O}_{3}\right]-2\left[\mathrm{Fe}_{2} \mathrm{O}_{3}\right]-2\left[\mathrm{~K}_{2} \mathrm{O}\right]-2\left[\mathrm{Li}_{2} \mathrm{O}\right]-2\left[\mathrm{Na}_{2} \mathrm{O}\right]+1.268\left[\mathrm{SiO}_{2}\right] \geq 0
\end{array}
$$

(top to bottom, the high viscosity and low viscosity constraints). As before, the variances of each LHS does depend on the bound of the original constraint. Using the WQR average elemental 
composition, the LHS evaluates to 0.070 and 0.285 , respectively, thus both constraints are satisfied.

The homogeneity constraint is most simply expressed in terms of oxide weight percents:

$$
1.6035\left(\mathrm{~B}_{2} \mathrm{O}_{3}+\mathrm{K}_{2} \mathrm{O}+\mathrm{Li}_{2} \mathrm{O}+\mathrm{Na}_{2} \mathrm{O}+\mathrm{SiO}_{2}\right)+5.6478\left(\mathrm{Al}_{2} \mathrm{O}_{3}+\mathrm{CaO}+\mathrm{Fe}_{2} \mathrm{O}_{3}\right) \geq 210.92 \text {. }
$$

In terms of molar oxides, the constraint is

$$
\begin{aligned}
& 575.8\left[\mathrm{Al}_{2} \mathrm{O}_{3}\right]+111.6\left[\mathrm{~B}_{2} \mathrm{O}_{3}\right]+316.7[\mathrm{CaO}]+901.9\left[\mathrm{Fe}_{2} \mathrm{O}_{3}\right] \\
& +151.1\left[\mathrm{~K}_{2} \mathrm{O}\right]+47.91\left[\mathrm{Li}_{2} \mathrm{O}\right]+99.38\left[\mathrm{Na}_{2} \mathrm{O}\right]+96.35\left[\mathrm{SiO}_{2}\right] \geq 210.92
\end{aligned}
$$

The variance of the LHS does not depend on the bound of the constraint. Using the WQR average elemental composition, the LHS evaluates to 208.972 , thus the constraint is not satisfied. 
Table 1. Data File Identification (Block 8 files have been incorporated into the appropriate files)

\begin{tabular}{|c|c|c|c|}
\hline File ID & Excel FileName & $\begin{array}{c}\text { Tinte } \\
\text { (Dale: } 8-12-97)\end{array}$ & Contents \\
\hline WW37 & INTFAREP.XLS & $2: 28 \mathrm{p}$ & ARG-1, Fusion, Peanut Vials \\
\hline WW38 & I34B18FB.XLS & $2: 27 p$ & Blanks, Fusion, Peanut Vials \\
\hline WW39 & INTMAREP.XLS & $2: 21 p$ & ARG-1, Microwave, Peanut Vials \\
\hline WW40 & INTMBREP.XLS & $2: 20 p$ & Blanks, Microwave, Peanut Vials \\
\hline WW41 & INT1REP.XLS & $1: 56 p$ & PX-7, Fusion, Inserts \\
\hline WW42 & INT2REP.XLS & $2: 16 p$ & PX-7, Cold Chem, Inserts \\
\hline WW43 & INT34REP.XLS & $2: 29 p$ & PX-7, Microwave \& Fusion, Peanut Vials \\
\hline WW44 & INT2AREP.XLS & $2: 17 p$ & ARG 1 , Cold Chem, Inserts \\
\hline WW45 & INT2BREP.XLS & $2: 18 p$ & Blanks, Cold Chem, Inserts \\
\hline WW46 & INT1AREP.XLS & $2: 14 p$ & ARG-1, Fusion, Zr Inserts \\
\hline WW47 & INT1BREP.XLS & $2: 13 p$ & Blanks, Fusion, Zr Inserts \\
\hline
\end{tabular}

Table 2. Calcine Factor Total Coefficient of Variation vs. Block Size

\begin{tabular}{|c|c|c|}
\hline $\begin{array}{c}\text { Block } \\
\text { Size }\end{array}$ & \multicolumn{2}{c|}{$\begin{array}{c}\text { Mlean ealcine } \\
\text { weight percent }\end{array}$} \\
\hline 2 & 36.394 & 2.345 \\
\hline 4 & 36.394 & 1.870 \\
\hline 6 & 36.394 & 1.724 \\
\hline 8 & 36.394 & 1.629 \\
\hline
\end{tabular}

Table 3. Mean Elemental Weight Percents for PX-7 in DD Test and SME/MFT Slurry in WQR

\begin{tabular}{|c|c|c|c|c|c|}
\hline Elt & $\begin{array}{l}\text { Insert cold chem, } \\
\text { unadjusted } \\
\text { (x) }\end{array}$ & $\begin{array}{l}\text { linsert cold chem, } \\
\text { calcine adjusted } \\
\text { (y) }\end{array}$ & $\begin{array}{l}\text { Iuscrt } \\
\text { fusion } \\
(z)\end{array}$ & $\begin{array}{c}\text { WQR } \\
\text { average } \\
\text { clemental }\end{array}$ & $\begin{array}{l}\text { RADOPS } \\
\text { averagc } \\
(22-30)\end{array}$ \\
\hline $\mathrm{Al}$ & 0.824 & 2.268 & 2.265 & 2.473 & 2.360 \\
\hline B & 0.895 & 2.461 & 2.486 & 2.140 & 2.718 \\
\hline $\mathrm{Ca}$ & 0.273 & 0.751 & 0.603 & 0.671 & 0.820 \\
\hline $\mathrm{Cr}$ & 0.013 & 0.036 & 0.085 & 0.091 & 0.759 \\
\hline $\mathrm{Cu}$ & 0.100 & 0.276 & 0.278 & 0.328 & 0.331 \\
\hline $\mathrm{Fe}$ & 2.714 & 7.471 & 7.666 & 7.367 & 8.467 \\
\hline $\mathrm{K}$ & 0.897 & 2.469 & 2.397 & 2.181 & 0.069 \\
\hline $\mathrm{Li}$ & 0.687 & 1.890 & 1.870 & 2.070 & 1.764 \\
\hline $\mathrm{Mg}$ & 0.288 & 0.792 & 0.822 & 0.888 & 1.279 \\
\hline $\mathrm{Mn}$ & 0.545 & 1.500 & 1.524 & 1.745 & 0.831 \\
\hline $\mathrm{Na}$ & 2.815 & 7.747 & - & 6.637 & 8.978 \\
\hline $\mathrm{Ni}$ & 0.294 & 0.809 & 0.829 & 0.628 & 0.107 \\
\hline $\mathrm{Si}$ & 7.391 & 20.341 & 22.424 & 23.624 & 24.169 \\
\hline$T i$ & 0.028 & 0.078 & 0.080 & 0.186 & 0.020 \\
\hline $\mathrm{Zr}$ & 0.291 & 0.801 & - & 0.805 & 0.016 \\
\hline
\end{tabular}


Table 4a. Mean Elemental Weight Percents for ARG-1 by Four Methods, and Corning Values

\begin{tabular}{|c|c|c|c|c|c|}
\hline \multicolumn{2}{c}{$\begin{array}{c}\text { Inscrt. } \\
\text { cold chem }\end{array}$} & \multicolumn{1}{c}{$\begin{array}{l}\text { Insert, } \\
\text { fusion }\end{array}$} & $\begin{array}{c}\text { Peanut vial, } \\
\text { fusion }\end{array}$ & $\begin{array}{c}\text { Peanut vial, } \\
\text { nicrowave }\end{array}$ & Corning \\
\hline $\mathrm{Al}$ & 2.401 & 2.461 & 2.453 & 2.444 & 2.503 \\
\hline $\mathrm{B}$ & 2.643 & 2.605 & 2.648 & - & 2.693 \\
\hline $\mathrm{Ca}$ & 1.062 & 0.958 & 0.965 & 1.067 & 1.027 \\
\hline $\mathrm{Cr}$ & 0.068 & 0.075 & 0.077 & 0.077 & 0.064 \\
\hline $\mathrm{Cu}$ & 0.005 & 0.007 & 0.007 & 0.010 & 0.003 \\
\hline $\mathrm{Fe}$ & 9.710 & 9.709 & 9.661 & 9.806 & 9.792 \\
\hline $\mathrm{K}$ & 2.335 & 2.217 & 2.271 & 2.353 & 2.250 \\
\hline $\mathrm{Li}$ & 1.486 & 1.433 & 1.453 & 1.496 & 1.491 \\
\hline $\mathrm{Mg}$ & 0.515 & 0.525 & 0.509 & 0.537 & 0.519 \\
\hline $\mathrm{Mn}$ & 1.451 & 1.425 & 1.427 & 1.460 & 1.460 \\
\hline $\mathrm{Na}$ & 8.483 & - & - & 8.519 & 8.531 \\
\hline $\mathrm{Ni}$ & 0.826 & 0.825 & 0.831 & 0.862 & 0.825 \\
\hline $\mathrm{Si}$ & 20.739 & 22.735 & 22.591 & 21.489 & 22.391 \\
\hline $\mathrm{Ti}$ & 0.700 & 0.688 & 0.688 & 0.706 & 0.689 \\
\hline $\mathrm{Zr}$ & 0.102 & - & - & 0.104 & 0.096 \\
\hline
\end{tabular}

Table 4b. Total Coefficients of Variation (\%) for ARG-1 Data Analyzed by Four Methods, Assuming a Fixed Block Size of $2(v=5)$

\begin{tabular}{|c|r|r|r|r|}
\hline \multicolumn{2}{|c}{$\begin{array}{c}\text { Instrt, } \\
\text { cold chen }\end{array}$} & \multicolumn{1}{c}{$\begin{array}{c}\text { Insert. } \\
\text { fusion }\end{array}$} & $\begin{array}{c}\text { Peanut vial, } \\
\text { fusion }\end{array}$ & $\begin{array}{c}\text { Peanut vial, } \\
\text { microwave }\end{array}$ \\
\hline $\mathrm{Al}$ & 2.89 & 2.72 & 2.19 & 1.58 \\
\hline $\mathrm{B}$ & 5.46 & 1.77 & 2.54 & - \\
\hline $\mathrm{Ca}$ & 8.41 & 2.99 & 8.06 & 3.41 \\
\hline $\mathrm{Cr}$ & 2.55 & 14.77 & 16.64 & 6.38 \\
\hline $\mathrm{Cu}$ & 12.17 & 55.99 & 29.97 & 23.91 \\
\hline $\mathrm{Fe}$ & 1.70 & 2.72 & 3.11 & 1.84 \\
\hline $\mathrm{K}$ & 1.31 & 2.65 & 3.70 & 3.24 \\
\hline $\mathrm{Li}$ & 2.56 & 1.78 & 2.87 & 1.57 \\
\hline $\mathrm{Mg}$ & 5.59 & 2.75 & 3.79 & 1.72 \\
\hline $\mathrm{Mn}$ & 1.79 & 2.08 & 3.24 & 2.06 \\
\hline $\mathrm{Na}$ & 1.92 & $\cdot$ & & 1.25 \\
\hline $\mathrm{Ni}$ & 1.53 & 2.78 & 4.59 & 1.64 \\
\hline $\mathrm{Si}$ & 0.97 & 2.46 & 2.29 & 2.30 \\
\hline $\mathrm{Ti}$ & 1.73 & 2.57 & 2.91 & 2.16 \\
\hline $\mathrm{Zr}$ & 2.21 & & & 2.81 \\
\hline
\end{tabular}


Table 5a. Total Coefficients of Variation (\%) for Inserts and Peanut Vial Dip Samples, Assuming a Fixed Block Size of $2(v=5)$

\begin{tabular}{|c|c|c|c|c|c|c|}
\hline Elt & $\begin{array}{l}\text { Insert } \\
\text { cold ehem, } \\
\text { unardi. }\end{array}$ & $\begin{array}{l}\text { Calcine } \\
\text { Factor }\end{array}$ & $\begin{array}{l}\text { Insert } \\
\text { cold chemt. } \\
\text { adjusted }\end{array}$ & $\begin{array}{l}\text { Insert } \\
\text { Fusion }\end{array}$ & $\begin{array}{l}\text { P'unt Vial } \\
\text { Dip, } \\
\text { Microwase }\end{array}$ & $\begin{array}{c}\text { P'nut Vial } \\
\text { Dip. } \\
\text { Fusion }\end{array}$ \\
\hline $\mathrm{Al}$ & 3.907 & 2.345 & 4.56 & 3.77 & 2.37 & 4.55 \\
\hline B & 7.562 & 2.345 & 7.92 & 3.21 & - & 1.26 \\
\hline $\mathrm{Ca}$ & 11.654 & 2.345 & 11.89 & 7.69 & 6.91 & 12.49 \\
\hline $\mathrm{Cr}$ & 15.416 & 2.345 & 15.59 & 29.51 & 8.32 & 20.05 \\
\hline $\mathrm{Cu}$ & 2.695 & 2.345 & 3.57 & 3.89 & 6.17 & 2.72 \\
\hline $\mathrm{Fe}$ & 2.979 & 2.345 & 3.79 & 4.73 & 2.59 & 2.94 \\
\hline $\mathrm{K}$ & 3.004 & 2.345 & 3.81 & 4.19 & 4.62 & 3.06 \\
\hline$\overline{L i}$ & 4.087 & 2.345 & 4.71 & 3.71 & 1.71 & 2.68 \\
\hline $\mathrm{Mg}$ & 4.618 & 2.345 & 5.18 & 3.64 & 0.72 & 2.35 \\
\hline $\mathrm{Mn}$ & 2.564 & 2.345 & 3.47 & 4.06 & 3.12 & 2.75 \\
\hline $\mathrm{Na}$ & 2.184 & 2.345 & 3.20 & 8 & 1.62 & - \\
\hline $\mathrm{Ni}$ & 3.379 & 2.345 & 4.11 & 4.04 & 3.22 & 3.66 \\
\hline $\mathrm{Si}$ & 4.379 & 2.345 & 4.97 & 3.98 & 1.90 & 2.01 \\
\hline $\mathrm{Ti}$ & 4.232 & 2.345 & 4.84 & 4.06 & 4.61 & 3.41 \\
\hline $\mathrm{Zr}$ & 2.964 & 2.345 & 3.78 & - & 2.47 & • \\
\hline
\end{tabular}

Table 5b. Total Coefficients of Variation (\%) for Inserts and Peanut Vial Hydragard Samples, Assuming a Fixed Block Size of $4(v=5)$

\begin{tabular}{|c|c|c|c|c|c|c|}
\hline Elt & $\begin{array}{l}\text { Insert } \\
\text { cold chen, } \\
\text { untadj. }\end{array}$ & $\begin{array}{l}\text { Calcine } \\
\text { Factor }\end{array}$ & $\begin{array}{l}\text { Insert } \\
\text { colll chem, } \\
\text { adjusted }\end{array}$ & $\begin{array}{l}\text { Insert } \\
\text { Fusion }\end{array}$ & $\begin{array}{l}\text { P`nut Vial } \\
\text { Hydragard, } \\
\text { Hicrowase }\end{array}$ & $\begin{array}{l}\text { P'nut Vial } \\
\text { Hydragard, } \\
\text { Fusion }\end{array}$ \\
\hline $\mathrm{Al}$ & 3.557 & 1.870 & 4.02 & 2.70 & 1.28 & 1.16 \\
\hline B & 7.294 & 1.870 & 7.53 & 2.32 & 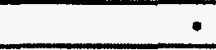 & 2.88 \\
\hline $\mathrm{Ca}$ & 11.378 & 1.870 & 11.53 & 7.06 & 5.73 & 7.64 \\
\hline $\mathrm{Cr}$ & 14.245 & 1.870 & 14.37 & 29.04 & 6.40 & 21.55 \\
\hline $\mathrm{Cu}$ & 2.088 & 1.870 & 2.80 & 2.72 & 1.26 & 2.25 \\
\hline $\mathrm{Fe}$ & 2.435 & 1.870 & 3.07 & 3.83 & 1.31 & 2.00 \\
\hline $\mathrm{K}$ & 2.428 & 1.870 & 3.06 & 3.02 & 2.58 & 4.47 \\
\hline $\mathrm{Li}$ & 3.534 & 1.870 & 4.00 & 3.05 & 1.67 & 2.51 \\
\hline $\mathrm{Mg}$ & 4.100 & 1.870 & 4.51 & 3.08 & 3.27 & 3.80 \\
\hline $\mathrm{Mn}$ & 2.007 & 1.870 & 2.74 & 2.83 & 1.51 & 1.77 \\
\hline $\mathrm{Na}$ & 1.461 & 1.870 & 2.37 & $\dot{-}$ & 1.31 & $\dot{-}$ \\
\hline $\mathrm{Ni}$ & 2.830 & 1.870 & 3.39 & 3.02 & 1.87 & 2.59 \\
\hline $\mathrm{Si}$ & 3.740 & 1.870 & 4.18 & 3.44 & 2.59 & 2.20 \\
\hline $\mathrm{Ti}$ & 3.763 & 1.870 & 4.20 & 2.94 & 2.78 & 3.91 \\
\hline $\mathrm{Zr}$ & 2.592 & 1.870 & 3.20 & 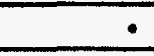 & 1.42 & $\dot{-}$ \\
\hline
\end{tabular}


Table 5c. Total Coefficients of Variation (\%) for Inserts and Combined Peanut Vial Dip and Hydragard Samples, Assuming a Fixed Block Size of $6(v=5)$

\begin{tabular}{|c|c|c|c|c|c|c|}
\hline Elt & $\begin{array}{l}\text { Insert } \\
\text { cold chem, } \\
\text { unadj. }\end{array}$ & $\begin{array}{l}\text { Calcine } \\
\text { factor }\end{array}$ & $\begin{array}{l}\text { lnsert } \\
\text { coll chem, } \\
\text { adjusted }\end{array}$ & $\begin{array}{l}\text { lusert, } \\
\text { fusion }\end{array}$ & $\begin{array}{l}\text { P'nut Vial } \\
\text { Dip \& H'grd, } \\
\text { microwave }\end{array}$ & $\begin{array}{l}\text { P'nut Vial } \\
\text { Dip \& Ir'grd, } \\
\text { fusion }\end{array}$ \\
\hline $\mathrm{Al}$ & 3.507 & 1.724 & 3.91 & 2.00 & 1.35 & 1.69 \\
\hline B & 7.158 & 1.724 & 7.36 & 2.10 & 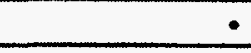 & 2.26 \\
\hline $\mathrm{Ca}$ & 11.300 & 1.724 & 11.43 & 6.72 & 6.09 & 8.23 \\
\hline $\mathrm{Cr}$ & 13.816 & 1.724 & 13.92 & 28.89 & 6.20 & 20.98 \\
\hline $\mathrm{Cu}$ & 2.008 & 1.724 & 2.65 & 1.96 & 1.61 & 2.32 \\
\hline $\mathrm{Fe}$ & 2.381 & 1.724 & 2.94 & 3.33 & 1.43 & 2.11 \\
\hline K & 2.412 & 1.724 & 2.96 & 2.22 & 3.14 & 3.77 \\
\hline $\mathrm{Li}$ & 3.226 & 1.724 & 3.66 & 2.96 & 1.35 & 2.06 \\
\hline $\mathrm{Mg}$ & 3.862 & 1.724 & 4.23 & 3.01 & 2.24 & 2.86 \\
\hline $\mathrm{Mn}$ & 1.981 & 1.724 & 2.63 & 2.04 & 1.80 & 1.90 \\
\hline $\mathrm{Na}$ & 1.213 & 1.724 & 2.11 & 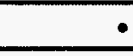 & 1.27 & - \\
\hline $\mathrm{Ni}$ & 2.766 & 1.724 & 3.26 & 2.40 & 2.17 & 2.86 \\
\hline $\mathrm{Si}$ & 3.444 & 1.724 & 3.85 & 3.38 & 2.17 & 1.50 \\
\hline $\mathrm{Ti}$ & 3.743 & 1.724 & 4.12 & 2.23 & 3.31 & 3.60 \\
\hline $\mathrm{Zr}$ & 2.565 & 1.724 & 3.09 & $\dot{-}$ & 1.34 & - \\
\hline
\end{tabular}

Table 5d. Total Coefficients of Variation (\%) for Insert Data, Assuming a Fixed Block Size of $8(v=5)$

\begin{tabular}{|c|c|c|c|c|}
\hline & $\begin{array}{c}\text { Insert } \\
\text { cold chem, } \\
\text { unali. }\end{array}$ & \multicolumn{1}{c|}{$\begin{array}{c}\text { Calcine } \\
\text { Factor }\end{array}$} & $\begin{array}{c}\text { Inscrt } \\
\text { cold chem, } \\
\text { adjusted }\end{array}$ & $\begin{array}{c}\text { Insert } \\
\text { Fusion }\end{array}$ \\
\hline $\mathrm{Al}$ & 3.453 & 1.629 & 3.82 & 1.65 \\
\hline $\mathrm{B}$ & 7.106 & 1.629 & 7.29 & 1.91 \\
\hline $\mathrm{Ca}$ & 11.255 & 1.629 & 11.37 & 6.59 \\
\hline $\mathrm{Cr}$ & 13.603 & 1.629 & 13.70 & 28.81 \\
\hline $\mathrm{Cu}$ & 1.904 & 1.629 & 2.51 & 1.56 \\
\hline $\mathrm{Fe}$ & 2.296 & 1.629 & 2.82 & 3.12 \\
\hline $\mathrm{K}$ & 2.328 & 1.629 & 2.84 & 1.83 \\
\hline $\mathrm{Li}$ & 3.101 & 1.629 & 3.50 & 2.86 \\
\hline $\mathrm{Mg}$ & 3.756 & 1.629 & 4.09 & 2.92 \\
\hline $\mathrm{Mn}$ & 1.896 & 1.629 & 2.50 & 1.61 \\
\hline $\mathrm{Na}$ & 1.030 & 1.629 & 1.93 & $\bullet$ \\
\hline $\mathrm{Ni}$ & 2.680 & 1.629 & 3.14 & 2.10 \\
\hline $\mathrm{Si}$ & 3.308 & 1.629 & 3.69 & 3.30 \\
\hline $\mathrm{Ti}$ & 3.677 & 1.629 & 4.02 & 1.88 \\
\hline $\mathrm{Zr}$ & 2.511 & 1.629 & 2.99 & \\
\hline
\end{tabular}


Table 5e. Total Coefficients of Variation (\%) for Prototypic Data, Assuming 1) No block effects, and 2) Fixed Block Sizes of 4

\begin{tabular}{|c|r|r|}
\hline Elt & $\begin{array}{c}\text { Prototypic data, } \\
\text { ignoring block } \\
\text { effects }(v=23)\end{array}$ & $\begin{array}{c}\text { Prototy pic data, } \\
\text { assuming block } \\
\text { size } 4(v=5)\end{array}$ \\
\hline $\mathrm{Al}$ & 5.12 & 2.89 \\
\hline $\mathrm{B}$ & 9.80 & 4.72 \\
\hline $\mathrm{Ca}$ & 5.89 & 3.69 \\
\hline $\mathrm{Cr}$ & 32.16 & 25.99 \\
\hline $\mathrm{Cu}$ & 5.78 & 3.75 \\
\hline $\mathrm{Fe}$ & 4.74 & 2.24 \\
\hline $\mathrm{K}$ & 6.25 & 5.34 \\
\hline $\mathrm{Li}$ & 4.10 & 2.12 \\
\hline $\mathrm{Mg}$ & 4.79 & 2.74 \\
\hline $\mathrm{Mn}$ & 5.21 & 3.10 \\
\hline $\mathrm{Na}$ & 4.45 & 3.03 \\
\hline $\mathrm{Ni}$ & 13.01 & 8.52 \\
\hline $\mathrm{Si}$ & 5.59 & 3.95 \\
\hline $\mathrm{Ti}$ & 4.41 & 1.93 \\
\hline $\mathrm{Zr}$ & 8.86 & 6.26 \\
\hline
\end{tabular}

Table 6a. Correlation Matrix for Prototypic Data, Ignoring Block Effects $(v=23)$

\begin{tabular}{|c|c|c|c|c|c|c|c|c|c|c|c|c|c|c|c|}
\hline Elt & Al & B & $\mathrm{Ca}$ & $\mathrm{Cr}$ & $\mathrm{Cu}$ & $\mathrm{Fe}$ & K & $\mathrm{Li}$ & $\mathrm{Mg}$ & $\mathrm{Mn}$ & $\mathrm{Na}$ & $\mathrm{Ni}$ & $\mathbf{S i}$ & $\mathrm{Ti}$ & $\mathrm{Zr}_{\mathbf{r}}$ \\
\hline$\overline{A l}$ & 1.000 & -.035 & .896 & -.140 & .678 & .916 & .763 & .715 & .834 & .907 & .917 & .270 & .555 & .843 & .289 \\
\hline B & 35 & 1.000 & -.026 & .155 & .194 & -.008 & .314 & .229 & .065 & .0 & .156 & -.225 & -.117 & .266 & -.148 \\
\hline $\mathrm{Ca}$ & 896 & -.026 & 1.000 & -.012 & .608 & .800 & .689 & .635 & .853 & .7 & .763 & .353 & .429 & .698 & .307 \\
\hline $\mathrm{Cr}$ & -.140 & -.155 & -.012 & 1.000 & -.229 & -.018 & -.245 & -.076 & .002 & -.2 & -.274 & .785 & -.156 & -.052 & .507 \\
\hline $\mathrm{Cu}$ & .678 & .194 & .608 & -.229 & 1.000 & .750 & .691 & .664 & .701 & .78 & .715 & .136 & .372 & .697 & .125 \\
\hline $\mathrm{Fe}$ & .916 & -.008 & .800 & -.018 & .750 & 1.000 & .709 & .732 & .828 & .9 & .879 & .414 & .402 & .906 & .305 \\
\hline $\mathbf{K}$ & .763 & .314 & .689 & -.245 & .691 & .709 & 1.000 & .636 & .663 & .7 & .829 & 0 & 3 & .753 & .032 \\
\hline $\mathbf{L i}$ & .715 & .229 & .635 & -.076 & .664 & .732 & .636 & 1.000 & .903 & .685 & .844 & .34 & .709 & .802 & .360 \\
\hline $\mathrm{Mg}$ & .834 & .065 & .853 & .002 & .701 & .828 & .663 & .903 & 1.000 & .758 & .847 & .442 & .634 & .775 & .360 \\
\hline $\mathrm{Mn}$ & .907 & .031 & .756 & -.254 & .787 & .964 & .732 & .685 & .758 & 1.000 & .889 & .201 & .383 & .881 & .167 \\
\hline $\mathrm{Na}$ & .917 & .156 & .763 & -.274 & .715 & .879 & .829 & .844 & .847 & .889 & 1.000 & .141 & .6 & .868 & .163 \\
\hline $\mathrm{Ni}$ & .270 & -.225 & .35 & .785 & .13 & .414 & .078 & .34 & .442 & .20 & .141 & 1.000 & .105 & .328 & .662 \\
\hline $\mathrm{Si}$ & .555 & -.117 & .429 & -.156 & .372 & .40 & .392 & .709 & .634 & .383 & .639 & .105 & 1.000 & .375 & .329 \\
\hline $\mathrm{Ti}$ & .843 & .266 & .698 & -.052 & .697 & .906 & .753 & .802 & .775 & .881 & .868 & .328 & .375 & 1.000 & .307 \\
\hline $\mathrm{Zr}$ & .289 & -.148 & .307 & .507 & .125 & .305 & .032 & .360 & .360 & .167 & .163 & .662 & .329 & .307 & 1.000 \\
\hline
\end{tabular}


Table 6b. Correlation Matrix for Prototypic Data, Assuming a Fixed Block Size of $4(v=5)$

\begin{tabular}{|c|c|c|c|c|c|c|c|c|c|c|c|c|c|c|c|}
\hline Elt & Al & B & $\mathrm{Ca}$ & $\mathrm{Cr}$ & $\mathrm{Cu}$ & $\mathrm{Fe}$ & $K$ & $\mathbf{L i}$ & $\mathrm{Mg}$ & $\mathrm{Mn}$ & $\mathrm{Na}$ & $\mathrm{Ni}$ & Si & $\mathrm{Ti}$ & $\mathrm{Zr}$ \\
\hline $\mathbf{A l}$ & 1.000 & .229 & .911 & -.570 & .870 & .938 & .877 & .659 & .907 & .884 & .925 & -.345 & .458 & .812 & -.439 \\
\hline $\mathbf{B}$ & .229 & 1.000 & 160 & .126 & .044 & -.052 & .124 & .746 & .472 & -.135 & 397 & -.086 & .709 & .268 & .042 \\
\hline $\mathrm{Ca}$ & .911 & .160 & 1.000 & -.307 & .858 & .834 & .745 & .571 & .937 & .724 & .704 & -.019 & .422 & .619 & -.058 \\
\hline $\mathrm{Cr}$ & -.570 & .126 & -.307 & 1.000 & -.608 & -.634 & -.451 & -.249 & -.301 & -.817 & -.663 & .920 & -.312 & -.317 & .885 \\
\hline $\mathrm{Cu}$ & .870 & .044 & .858 & -.608 & 1.000 & .770 & .818 & .647 & .834 & .792 & .770 & -.330 & .587 & .506 & -.316 \\
\hline $\mathrm{Fe}$ & .938 & -.052 & .834 & -.634 & .770 & 1.000 & .790 & .364 & .731 & .961 & .822 & -.377 & .157 & .783 & -.531 \\
\hline $\mathbf{K}$ & .877 & .124 & .745 & -.451 & .818 & .790 & 1.000 & .674 & .755 & .746 & .868 & -.216 & .373 & .863 & -.418 \\
\hline $\mathbf{L i}$ & .659 & .746 & $.57 !$ & -.249 & .647 & .364 & .674 & 1.000 & .809 & .329 & .768 & -.235 & .892 & .540 & -.174 \\
\hline $\mathrm{Mg}$ & .907 & .472 & .937 & -.301 & .834 & .731 & .755 & .809 & 1.000 & .630 & .805 & -.113 & .670 & .649 & -.100 \\
\hline $\mathrm{Mn}$ & .884 & -.135 & .724 & -.817 & .792 & .961 & .746 & .329 & .630 & 1.000 & .819 & -.582 & .198 & .676 & -.691 \\
\hline $\mathrm{Na}$ & .925 & .397 & .704 & -.663 & .770 & .822 & .868 & .768 & .805 & .819 & 1.000 & -.554 & .565 & .840 & -.643 \\
\hline $\mathrm{Ni}$ & -.345 & -.086 & -.019 & .920 & -.330 & -.377 & -.216 & -.235 & -.113 & -.582 & -.554 & 1.000 &,- 351 & -.184 & .909 \\
\hline $\mathrm{Si}$ & .458 & .709 & .422 & -.312 & .587 & .157 & .373 & .892 & .670 & .198 & .565 & -.351 & 1.000 & .148 & -.110 \\
\hline $\mathbf{T i}$ & .812 & .268 & .619 & -.317 & .506 & .783 & .863 & .540 & .649 & .676 & .840 & -.184 & .148 & 1.000 & -.468 \\
\hline $2 r$ & -.439 & .042 & -.058 & .885 & -.316 & -.531 & -.418 & -.174 & -.100 & -.691 & -.643 & .909 & -.110 & -.468 & 1.000 \\
\hline
\end{tabular}

Table 7a. Correlation Matrix for Insert Cold Chemical Data (Unadjusted), Assuming a Fixed Block Size of $2(v=5)$

\begin{tabular}{|c|c|c|c|c|c|c|c|c|c|c|c|c|c|c|c|}
\hline Elt & Al & B & $\mathrm{Ca}$ & $\mathrm{Cr}$ & $\mathrm{Cus}$ & $\mathrm{Fe}$ & $\mathbf{K}$ & $\mathrm{Li}$ & $\mathrm{Mg}$ & $\mathrm{Mn}$ & $\mathrm{Na}$ & $\mathrm{Ni}$ & Si & $\mathrm{Ti}$ & $\mathrm{Zr}$ \\
\hline Al & 1.000 & -.254 & .759 & .299 & .875 & .834 & .696 & .381 & .513 & .838 & .538 & .903 & .606 & .901 & .697 \\
\hline B & -.254 & 1.000 & .109 & .576 & -.176 & -.390 & -.553 & .637 & .310 & -.187 & .332 & -.304 & .379 & -.504 & .014 \\
\hline $\mathrm{Ca}$ & .759 & .109 & 1.000 & .323 & .458 & .373 & .139 & .356 & .310 & .371 & .188 & .508 & .495 & .456 & .271 \\
\hline $\mathrm{Cr}$ & .299 & .576 & .323 & 1.000 & .291 & .224 & -.093 & .842 & .843 & .346 & .558 & .156 & .783 & .111 & .621 \\
\hline $\mathrm{Cu}$ & .875 & -.176 & .458 & .291 & 1.000 & .875 & .823 & .408 & .503 & .971 & .746 & .914 & .595 & .871 & .842 \\
\hline $\mathrm{Fe}$ & .834 & -.390 & .373 & .224 & .875 & 1.000 & .843 & .276 & .469 & .926 & .590 & .900 & .481 & .904 & .813 \\
\hline $\mathbf{K}$ & .696 & -.553 & .139 & -.093 & .823 & .843 & 1.000 & .042 & .247 & .824 & .542 & .796 & .263 & .862 & .604 \\
\hline $\mathrm{Li}$ & .381 & .637 & .356 & .842 & .408 & .276 & .042 & 1.000 & .888 & .437 & .791 & .305 & .925 & .214 & .633 \\
\hline $\mathrm{Mg}$ & .513 & .310 & .310 & .843 & .503 & .469 & .247 & .888 & 1.000 & .563 & .745 & .397 & .918 & .418 & .770 \\
\hline $\mathrm{Mn}$ & .838 & -.187 & .371 & .346 & .971 & .926 & .824 & .437 & .563 & 1.000 & .772 & .914 & 601 & .867 & .910 \\
\hline $\mathrm{Na}$ & .538 & .332 & .188 & .558 & .746 & .590 & .542 & .791 & .745 & .772 & 1.000 & .629 & .787 & .525 & .797 \\
\hline Ni & .903 & -.304 & .508 & .156 & .914 & .900 & .796 & .305 & .397 & .914 & .629 & 1.000 & .481 & .926 & .743 \\
\hline $\mathbf{S i}$ & .606 & .379 & .495 & .783 & .595 & .481 & .263 & .925 & .918 & .601 & .787 & .481 & 1.000 & .475 & .738 \\
\hline $\mathrm{Ti}$ & .901 & -.504 & .456 & .111 & .871 & .904 & .862 & .214 & .418 & .867 & .525 & .926 & .475 & 1.000 & .704 \\
\hline $\mathrm{Zr}$ & .697 & .014 & .271 & .621 & .842 & .813 & .604 & .633 & .770 & .910 & .797 & .743 & .738 & .704 & 1.000 \\
\hline
\end{tabular}

Table 7b. Correlation Matrix for Insert Cold Chemical Data (Unadjusted), Assuming a Fixed Block Size of $4(v=5)$

\begin{tabular}{|c|c|c|c|c|c|c|c|c|c|c|c|c|c|c|c|}
\hline Elt & $\mathrm{Al}$ & B & $\mathrm{Ca}$ & $\mathrm{Cr}$ & $\mathrm{Cu}$ & $\mathrm{Fe}$ & $\mathbf{K}$ & $\mathrm{Li}$ & $\mathrm{Mg}$ & $\mathrm{Mn}$ & $\mathrm{Na}$ & $\mathrm{Ni}$ & $\mathrm{Si}$ & $\mathrm{Ti}$ & $Z_{r}$ \\
\hline Al & 1.000 & -.380 & .771 & .230 & 901 & .837 & .637 & .293 & .472 & .834 & 411 & .907 & .573 & .897 & .634 \\
\hline B & -.380 & 1.000 & .084 & .575 & -.407 & -.583 & -.843 & 621 & .256 & -.406 & 241 & -.494 & .314 & -.678 & -.098 \\
\hline $\mathrm{Ca}$ & .771 & .084 & 1.000 & .304 & .489 & .358 & .061 & .348 & .294 & .366 & 116 & .518 & .505 & .431 & 231 \\
\hline $\mathrm{Cr}$ & .230 & .575 & .304 & 1.000 & .226 & .162 & -.280 & .894 & .871 & .288 & .610 & .066 & .843 & .021 & .631 \\
\hline $\mathrm{Cu}$ & .901 & -.407 & .489 & .226 & 1.000 & 897 & .745 & 309 & .517 & 967 & SOG & .930 & .563 & .907 & 800 \\
\hline $\mathrm{Fe}$ & 837 & -.583 & .358 & .162 & .897 & 1.000 & .808 & .174 & .478 & 942 & 46 & 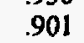 & .441 & .925 & .790 \\
\hline & .637 & -.843 & .061 & -.280 & .745 & .808 & 1.000 & -191 & .153 & & .2 & .74 & .16 & .883 & .460 \\
\hline $\mathbf{L i}$ & .293 & .621 & .348 & .894 & .309 & .174 & -191 & 1.000 & 883 & .343 & 80 & .174 & .912 & .076 & .615 \\
\hline M & .47 & .25 & .2 & 8 & .5 & .478 & .153 & .883 & 1.000 & .581 & .8 & 3 & 9 & .374 & .821 \\
\hline & & -.406 & .3 & .28 & 9 & .94 & .733 & .3 & .581 & 1.000 & & & & .89 & .891 \\
\hline $\mathrm{Na}$ & .411 & .241 & .116 & .610 & .60 & .466 & .282 & .80 & .812 & .655 & 1.000 & 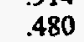 & .7 & .393 & .781 \\
\hline $\mathrm{Ni}$ & .907 & -.494 & .518 & .066 & .93 & .901 & .749 & .17 & .350 & .914 & 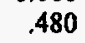 & 1.000 & .39 & .932 & .677 \\
\hline & .573 & .314 & .50 & .84 & .563 & .441 & .106 & .91 & .94 & .570 & .78 & .397 & 1.000 & .384 & .748 \\
\hline$T$ & .897 & -.678 & .431 & .021 & .907 & .925 & .883 & .076 & .374 & .890 & .393 & .932 & . 384 & 1.000 & .656 \\
\hline 2 & .634 & -.098 & .231 & .631 & .800 & .790 & .460 & .615 & .821 & .891 & .781 & .677 & .748 & .656 & 1.000 \\
\hline
\end{tabular}


Table 7c. Correlation Matrix for Insert Cold Chemical Data (Unadjusted), Assuming a Fixed Block Size of $6(v=5)$

\begin{tabular}{|c|c|c|c|c|c|c|c|c|c|c|c|c|c|c|c|}
\hline Elt & Al & B & $\mathrm{Ca}$ & $\mathrm{Cr}$ & $\mathrm{Cu}$ & $\mathrm{Fe}$ & $\mathrm{K}$ & $\mathrm{Li}$ & $\mathrm{Mg}$ & $\mathrm{Mn}$ & $\mathrm{Na}$ & $\mathrm{Ni}$ & $\mathrm{Si}$ & $\mathbf{T i}$ & $\mathrm{Z}_{\mathrm{I}}$ \\
\hline Al & 1.000 & -.414 & .777 & .218 & .920 & .856 & .634 & .269 & .453 & .835 & .409 & .911 & .583 & .895 & .630 \\
\hline B & .414 & 1.000 & .079 & .580 & -.479 &. .598 & -.884 & .616 & .222 & -.451 & .175 & .536 & .272 & -.711 & -.128 \\
\hline $\mathrm{Ca}$ & .777 & .079 & 1.000 & .295 & .520 & .372 & .063 & .362 & .286 & .377 & .119 & .534 & .532 & .430 & .236 \\
\hline $\mathrm{Cr}$ & .218 & .580 & .295 & 1.000 & 233 & .178 & -.286 & .945 & .900 & .297 & .690 & .051 & .883 & .000 & .650 \\
\hline $\mathrm{Cu}$ & .920 & -.479 & .520 & .233 & 1.000 & .961 & .754 & .265 & .507 & .975 & .599 & .950 & .563 & .936 & .804 \\
\hline $\mathrm{Fe}$ & .856 & -.598 & .372 & .178 & .961 & 1.000 & .824 & .174 & .491 & .972 & .553 & .921 & .490 & .952 & .813 \\
\hline K & .634 & -.884 & .063 & -.286 & .754 & .824 & 1.000 & -.263 & .116 & .733 & .262 & .757 & .076 & .890 & .455 \\
\hline $\mathbf{L i}$ & .269 & .616 & .362 & .945 & .265 & .174 & -.263 & 1.000 & .878 & .307 & .775 & .13 & .895 & .038 & .620 \\
\hline $\mathrm{Mg}$ & .453 & .222 & .286 & .900 & .507 & .491 & .116 & .878 & 1.000 & .566 & .818 & .324 & .950 & .352 & .833 \\
\hline $\mathrm{Mn}$ & .835 & -.451 & . 377 & .297 & .975 & .972 & .733 & .307 & .566 & 1.000 & .682 & .916 & .567 & 897 & .888 \\
\hline $\mathrm{Na}$ & .409 & .175 & .119 & .690 & .599 & .553 & .262 & .775 & .818 & .682 & 1.000 & .485 & .759 & .413 & .852 \\
\hline $\mathrm{Ni}$ & .911 & -.536 & .534 & .051 & .950 & .921 & .757 & .133 & .324 & .916 & .485 & 1.000 & .393 & .942 & .674 \\
\hline Si & .583 & .272 & .53 & .883 & .563 & .49 & .076 & .895 & .950 & $.5 t$ & .759 & .393 & 1.000 & .385 & .769 \\
\hline $\mathrm{Ti}$ & .895 & -.711 & .430 & .000 & .936 & .952 & .890 & .038 & .352 & .897 & .413 & .9 & .385 & 1.000 & .657 \\
\hline $\mathrm{Z}_{\mathbf{r}}$ & .630 & -.128 & .236 & .650 & .804 & .813 & .455 & .620 & .833 & .888 & .852 & .674 & .769 & .657 & 1.000 \\
\hline
\end{tabular}

Table 7d. Correlation Matrix for Insert Cold Chemical Data (Unadjusted), Assuming a Fixed Block Size of $8(v=5)$

\begin{tabular}{|c|c|c|c|c|c|c|c|c|c|c|c|c|c|c|c|}
\hline Elt & $\mathrm{Al}$ & B & $\mathrm{Ca}$ & $\mathrm{Cr}$ & $\mathrm{Cu}$ & $\mathrm{Fe}$ & $\mathbf{K}$ & $\mathrm{Li}$ & $\mathbf{M g}$ & Mn & $\mathrm{Na}$ & $\mathrm{Ni}$ & $\mathrm{Si}$ & $\mathrm{Ti}$ & $\mathrm{Zr}$ \\
\hline Al & 1.000 & -.438 & .780 & .205 & .933 & .862 & .623 & .248 & .443 & .836 & .390 & .913 & .580 & .894 & .619 \\
\hline$\pi$ & 438 & .000 & .075 & .580 & -.538 & .636 & -.943 & .61 & .208 & -.500 & .140 & -.576 & 2 & -.743 & -150 \\
\hline $\mathrm{Ca}$ & .780 & .075 & 1.000 & .291 & .535 & .374 & .051 & .364 & .283 & .380 & .106 & .539 & .541 & .427 & .231 \\
\hline $\mathrm{Cr}$ & .205 & .580 & .291 & 1.000 & .223 & .170 & -.321 & .966 & .910 & .289 & .762 & .032 & .903 & -.018 & .655 \\
\hline $\mathrm{Cu}$ & .933 & -.538 & .535 & .223 & 1.000 & .981 & .739 & .232 & .509 & .976 & .557 & .959 & .5 & .952 & .798 \\
\hline $\mathrm{Fe}$ & .862 & -.636 & .374 & .170 & .98 & 1.000 & .820 & .153 & .495 & .982 & .5 & .926 & .4 & .962 & .813 \\
\hline $\mathrm{K}$ & .623 & .943 & .051 & -.321 & .739 & .820 & 1.000 & -.328 & .090 & .714 & .174 & .749 & .036 & .896 & .427 \\
\hline $\mathbf{L i}$ & .248 & .615 & .364 & .966 & .232 & .153 & -.328 & 1.000 & .876 & .278 & .792 & .097 & .889 & .005 & .618 \\
\hline $\mathrm{Mg}$ & .443 & .208 & .283 & .910 & .509 & .495 & .090 & .876 & 1.000 & .568 & .872 & .310 & .957 & .341 & .845 \\
\hline $\mathrm{Mn}$ & .836 & -.500 & .3 & .289 & .976 & .98 & .714 & .278 & .568 & 1.000 & .668 & .9 & .5 & .905 & .885 \\
\hline $\mathrm{Na}$ & .390 & .140 & .10 & .762 & .557 & .558 & .174 & .792 & .872 & .668 & 1.000 & .454 & .771 & .397 & .905 \\
\hline $\mathrm{Ni}$ & .913 & -.576 & .539 & .032 & .959 & .926 & .749 & .097 & .310 & .917 & .454 & 1.000 & .375 & .946 & .661 \\
\hline Si & .580 & .254 & .541 & .903 & .555 & .492 & .036 & .889 & .957 & .560 & .771 & .375 & 1.000 & .369 & .776 \\
\hline $\mathbf{T i}$ & .894 & -.743 & .427 & -.018 & .952 & .962 & .896 & .005 & .341 & .905 & .397 & .946 & .369 & 1.000 & .649 \\
\hline $\mathrm{Zr}$ & .619 & -150 & .231 & .655 & .798 & .813 & .427 & .618 & .845 & .885 & .905 & .661 & .776 & .649 & 1.000 \\
\hline
\end{tabular}

Table 8a. Correlation Matrix for Insert Fusion Data, Assuming a Fixed Block Size of $2(v=5)$

\begin{tabular}{|c|c|c|c|c|c|c|c|c|c|c|c|c|c|c|c|}
\hline Elt & $\mathrm{Al}$ & B & $\mathrm{Ca}$ & $\mathrm{Cr}$ & $\mathrm{Cu}$ & $\mathrm{Fe}$ & $\mathbf{K}$ & $\mathrm{Li}$ & $\mathrm{Mg}$ & $\mathrm{Mn}$ & $\mathrm{Na}$ & $\mathrm{Ni}$ & Si & $\mathrm{Ti}$ & $\mathrm{Zr}$ \\
\hline Al & 1.000 & .547 & .546 & .358 & .983 & .919 & .755 & .438 & .466 & .935 & .000 & .945 & .429 & .894 & .000 \\
\hline B & .547 & 1.000 & .004 & -.008 & .547 & .346 & .452 & .776 & .762 & .478 & .000 & .355 & .768 & .717 & .000 \\
\hline $\mathrm{Ca}$ & .546 & .004 & 1.000 & .591 & .530 & .673 & .437 & .109 & .225 & .460 & .000 & .54 & .057 & .381 & .000 \\
\hline $\mathrm{Cr}$ & .358 & -.008 & .591 & 1.000 & .334 & .630 & -.069 & .426 & .399 & 158 & .000 & .242 & .399 & .232 & .000 \\
\hline $\mathrm{Cu}$ & .983 & .547 & .530 & .334 & 1.000 & .924 & .820 & .402 & .414 & .961 & .000 & .943 & .379 & .887 & .000 \\
\hline $\mathbf{F e}$ & .919 & 346 & .673 & .630 & .924 & 1.000 & .662 & .392 & .391 & .8 & .000 & .886 & .361 & .767 & .000 \\
\hline $\mathbf{K}$ & .755 & .452 & .437 & -.069 & .820 & .662 & 1.000 & .029 & .043 & .878 & .000 & .78 & -.02 & .730 & .000 \\
\hline $\mathbf{L i}$ & .438 & .776 & .109 & .426 & .402 & .392 & .029 & 1.000 & .959 & .271 & .000 & .232 & .986 & .465 & .000 \\
\hline Mg & .466 & .762 & .225 & .399 & .414 & .391 & .043 & .959 & 1.000 & .287 & .000 & .278 & .970 & .489 & .000 \\
\hline $\mathrm{Mn}$ & .935 & .478 & .460 & .158 & .961 & .861 & .878 & .271 & .287 & 1.000 & .000 & .970 & .249 & .811 & .000 \\
\hline $\mathrm{Na}$ & .000 & .000 & .000 & .000 & .000 & .0 & .000 & .000 & .000 & .000 & .000 & .000 & .000 & .000 & .000 \\
\hline $\mathrm{Ni}$ & .945 & .355 & .544 & .242 & .943 & .886 & .783 & .232 & .278 & .970 & .000 & 1.000 & .226 & .785 & .000 \\
\hline $\mathrm{Si}$ & .429 & .768 & .057 & .399 & .379 & .361 & -.021 & .986 & .970 & .249 & .000 & .226 & 1.000 & .470 & .000 \\
\hline $\mathrm{T} \mathbf{i}$ & .894 & .717 & .381 & .232 & .887 & .767 & .730 & .465 & .489 & .8 & .0 & .785 & .470 & 1.000 & .000 \\
\hline $\mathrm{Z}_{r}$ & .000 & .000 & .000 & .000 & .000 & .000 & .000 & .000 & .000 & .000 & .000 & .000 & .000 & .000 & .000 \\
\hline
\end{tabular}


Table 8b. Correlation Matrix for Insert Fusion Data, Assuming a Fixed Block Size of $4(v=5)$

\begin{tabular}{|c|c|c|c|c|c|c|c|c|c|c|c|c|c|c|c|}
\hline Elt & AI & B & $\mathrm{Ca}$ & $\mathrm{Cr}$ & $\mathrm{Cu}$ & $\mathrm{Fe}$ & $\mathbf{K}$ & Li & $\mathrm{Mg}$ & Mn & $\mathbf{N a}$ & $\mathbf{N i}$ & Si & $\mathrm{Ti}$ & $\mathrm{Zr}$ \\
\hline Al & 1.000 & .394 & .521 & .482 & .988 & .902 & .590 & .396 & .419 & .905 & .000 & .911 & .377 & .827 & .000 \\
\hline B & .394 & 1.000 & -.174 & -.004 & .325 & .104 & .103 & .689 & .704 & .180 & .000 & .107 & .715 & .697 & .000 \\
\hline $\mathrm{Ca}$ & .521 & -.174 & 1.000 & .628 & .535 & .699 & .431 & .027 & .148 & .452 & .000 & .524 & -.035 & .303 & .000 \\
\hline $\mathrm{Cr}$ & .482 & -.004 & .628 & 1.000 & .462 & .752 & -.107 & .524 & .471 & .202 & .000 & .297 & .463 & .307 & .000 \\
\hline $\mathrm{Cu}$ & .988 & .325 & .535 & .462 & 1.000 & .910 & .665 & .299 & .310 & .928 & .000 & .921 & .273 & .807 & .000 \\
\hline $\mathrm{Fe}$ & .902 & .104 & .699 & .752 & .910 & 1.000 & .477 & .333 & .320 & .793 & .000 & .833 & .283 & .647 & .000 \\
\hline $\mathbf{K}$ & .590 & .103 & .431 & -.107 & .665 & .477 & 1.000 & -.358 & -.301 & .776 & .000 & .668 & -.384 & .534 & .000 \\
\hline $\mathbf{L i}$ & .396 & .689 & .027 & .524 & .299 & .333 & -.358 & 1.000 & .957 & .064 & .000 & .107 & .989 & .428 & .000 \\
\hline $\mathrm{Mg}$ & .419 & .704 & .148 & .471 & .310 & .320 & -.301 & .957 & 1.000 & .096 & .000 & .159 & .966 & .467 & .000 \\
\hline $\mathrm{Mn}$ & .905 & .180 & .452 & .202 & .928 & .793 & .776 & .064 & .096 & 1.000 & .000 & .976 & .049 & .661 & .000 \\
\hline $\mathrm{Na}$ & .000 & .000 & .000 & .000 & .000 & .000 & .000 & .000 & .000 & .000 & .000 & .000 & .000 & .000 & .000 \\
\hline $\mathrm{Ni}$ & .911 & .107 & .524 & .297 & .921 & .833 & .668 & .107 & .159 & .976 & .000 & 1.000 & .096 & .631 & .000 \\
\hline $\mathbf{S i}$ & .377 & .715 & -.035 & .463 & .273 & .283 & -.384 & .989 & .966 & .049 & .000 & .096 & 1.000 & .441 & .000 \\
\hline $\mathrm{Ti}$ & .827 & .697 & .303 & .307 & .807 & .647 & .534 & .428 & .467 & .661 & .000 & .631 & .441 & 1.000 & .000 \\
\hline $\mathrm{Z}_{\mathbf{r}}$ & .000 & .000 & .000 & .000 & .000 & .000 & .000 & .000 & .000 & .000 & .000 & .000 & .000 & .000 & .000 \\
\hline
\end{tabular}

Table 8c. Correlation Matrix for Insert Fusion Data, Assuming a Fixed Block Size of $6(v=5)$

\begin{tabular}{|c|c|c|c|c|c|c|c|c|c|c|c|c|c|c|c|}
\hline Elt & $\mathrm{Al}$ & B & $\mathrm{Ca}$ & $\mathrm{Cr}$ & $\mathrm{Cu}$ & $\mathrm{Fe}$ & $\mathrm{K}$ & $\mathrm{Li}$ & $\mathrm{Mg}$ & $\mathrm{Mn}$ & $\mathrm{Na}$ & $\mathrm{Ni}$ & $\mathrm{Si}$ & $\mathrm{Ti}$ & $\mathrm{Zr}$ \\
\hline $\mathrm{Al}$ & 1.000 & .235 & 558 & .635 & .982 & .896 & .258 & 494 & 527 & .831 & .000 & .863 & .473 & .726 & .000 \\
\hline B & .235 & 1.000 & -263 & -018 & 139 & -.074 & -.201 & .697 & .733 & -.089 & & -.124 & & & \\
\hline $\mathrm{Ca}$ & .558 & -.263 & 1.000 & .643 & .599. & .739 & .464 & .016 & .128 & .499 & .000 & .547 & -.04 & .272 & .000 \\
\hline $\mathrm{Cr}$ & .635 & -.018 & 643 & 1.000 & 632 & .853 & -.158 & .530 & . 471 & .266 & .000 & .360 & .463 & .388 & .000 \\
\hline $\mathrm{Cu}$ & .982 & .139 & .599 & .632 & 1.000 & .921 & 377 & .383 & .403 & .872 & .000 & .878 & .350 & .678 & .000 \\
\hline $\mathrm{Fe}$ & .896 & -.074 & .739 & .853 & .921 & 1.000 & & & .35 & & & & & & \\
\hline $\mathrm{K}$ & .258 & -.201 & .464 & -.158 & .377 & .235 & 1.000 & -.556 & -.455 & .58 & .00 & .448 & -.576 & .199 & .000 \\
\hline $\mathbf{L i}$ & .494 & .697 & .016 & .530 & .38 & .367 & -.556 & 1.000 & .963 & .04 & .0 & .113 & .95 & .559 & .000 \\
\hline $\mathrm{Mg}$ & .527 & 733 & .128 & .47 & .40 & .357 &. .455 & .96 & 1.000 & .10 & .0 & 11 & & .624 & .000 \\
\hline $\mathrm{Mn}$ & .831 & .089 & .499 & .26 & .872 & .726 & 58 & .04 & .102 & 1.00 & 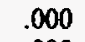 & .97 & .02 & .4 & \\
\hline $\mathrm{Ja}$ & .000 & .000 & .000 & .00 & .000 & .000 & .000 & .000 & .000 & .00 & .0 & .00 & .00 & .00 & \\
\hline $\mathrm{Ni}$ & .863 & -.124 & .547 & .36 & .878 & .775 & 448 & .11 & .18 & .975 & .000 & 1.000 & .101 & & \\
\hline si & .473 & .738 & -.047 & 46 & .350 & .310 & -.576 & .992 & .970 & .027 & .000 & .101 & 1.000 & .578 & 000 \\
\hline & 726 & .723 & .272 & .388 & 678 & 510 & 199 & .559 & .624 & .415 & .00 & 40 & .578 & 1.000 & 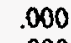 \\
\hline $\mathrm{Zt}$ & .000 & .000 & .000 & 000 & .000 & .000 & .000 & .000 & .000 & 000 & .00 & .000 & .000 & 000 & 00 \\
\hline
\end{tabular}

Table 8d. Correlation Matrix for Insert Fusion Data, Assuming a Fixed Block Size of $8(v=5)$

\begin{tabular}{|c|c|c|c|c|c|c|c|c|c|c|c|c|c|c|c|}
\hline Elt & Al & B & $\mathrm{Ca}$ & $\mathrm{Cr}$ & $\mathrm{Cu}$ & $\mathrm{Fe}$ & $\mathbf{K}$ & $\mathbf{L i}$ & $\mathrm{Mg}$ & $\mathrm{Mn}$ & $\mathrm{Na}$ & $\mathrm{Ni}$ & $\mathrm{Si}$ & $\mathrm{Ti}$ & $\mathbf{Z I}$ \\
\hline Al & 1.000 & .088 & .594 & .764 & .982 & .908 & -.068 & .536 & .574 & .758 & .000 & .823 & .513 & .623 & .000 \\
\hline B & .088 & 1.000 & -.332 & -.021 & -.071 & -.208 & -.519 & .680 & .732 & -.393 & .000 & -.319 & .739 & .733 & .000 \\
\hline$\overline{\mathrm{Ca}}$ & .594 & -.332 & 1.000 & .651 & .672 & .758 & .500 & -.001 & .110 & .554 & .000 & .563 & -.066 & .250 & .000 \\
\hline $\mathrm{Cr}$ & .764 & -.021 & .651 & 1.000 & .791 & .907 & -.196 & .550 & .484 & .328 & .000 & .404 & .474 & .456 & .000 \\
\hline $\mathrm{Cu}$ & .982 & -.071 & .672 & .791 & 1.000 & .956 & .060 & .399 & .427 & .802 & .000 & .850 & .365 & .540 & .000 \\
\hline $\mathrm{Fe}$ & .908 & -.208 & .758 & .907 & .956 & 1.000 & .056 & .362 & .350 & .692 & .000 & .741 & .300 & .414 & .000 \\
\hline $\mathrm{K}$ & -.068 & -.519 & .500 & .196 & .060 & .056 & 1.000 & -.798 & -.655 & .369 & .000 & .266 & -.799 & -.129 & .000 \\
\hline $\mathrm{Li}$ & .536 & .680 & -.001 & .550 & .399 & .362 & -.798 & 1.000 & .964 & -.048 & .000 & .078 & .994 & 610 & .000 \\
\hline $\mathrm{Mg}$ & .574 & .732 & .110 & .484 & .427 & .350 & -.655 & .964 & 1.000 & .037 & .000 & .158 & .970 & .694 & .000 \\
\hline $\mathrm{Mn}$ & .758 & -.393 & .554 & .328 & .802 & .692 & .369 & -.048 & .037 & 1.000 & .000 & 992 & -.056 & .148 & .000 \\
\hline $\mathrm{Na}$ & .000 & .000 & .000 & .000 & .000 & .000 & .000 & .000 & .000 & .000 & .000 & .000 & .000 & .000 & .000 \\
\hline $\mathbf{N i}$ & .823 & -.319 & .563 & .404 & .850 & .741 & .266 & .078 & .158 & .992 & .000 & 1.000 & .068 & .211 & .000 \\
\hline $\mathrm{Si}$ & .513 & .739 & -.066 & .474 & .365 & .300 & -.799 & .994 & 970 & .056 & .000 & .068 & 1.000 & .638 & .000 \\
\hline $\mathrm{Ti}$ & .623 & .733 & .250 & .456 & .540 & .414 & -.129 & .610 & .694 & .148 & .000 & 211 & .638 & 1.000 & .000 \\
\hline $\mathrm{Zr}$ & .000 & .000 & .000 & .000 & .000 & .000 & .000 & .000 & .000 & .000 & .000 & .000 & .000 & .000 & .000 \\
\hline
\end{tabular}


Table 9. Insert Cold Chemical Data Randomized for Bootstrap Procedure (Reps 9 Not Used)

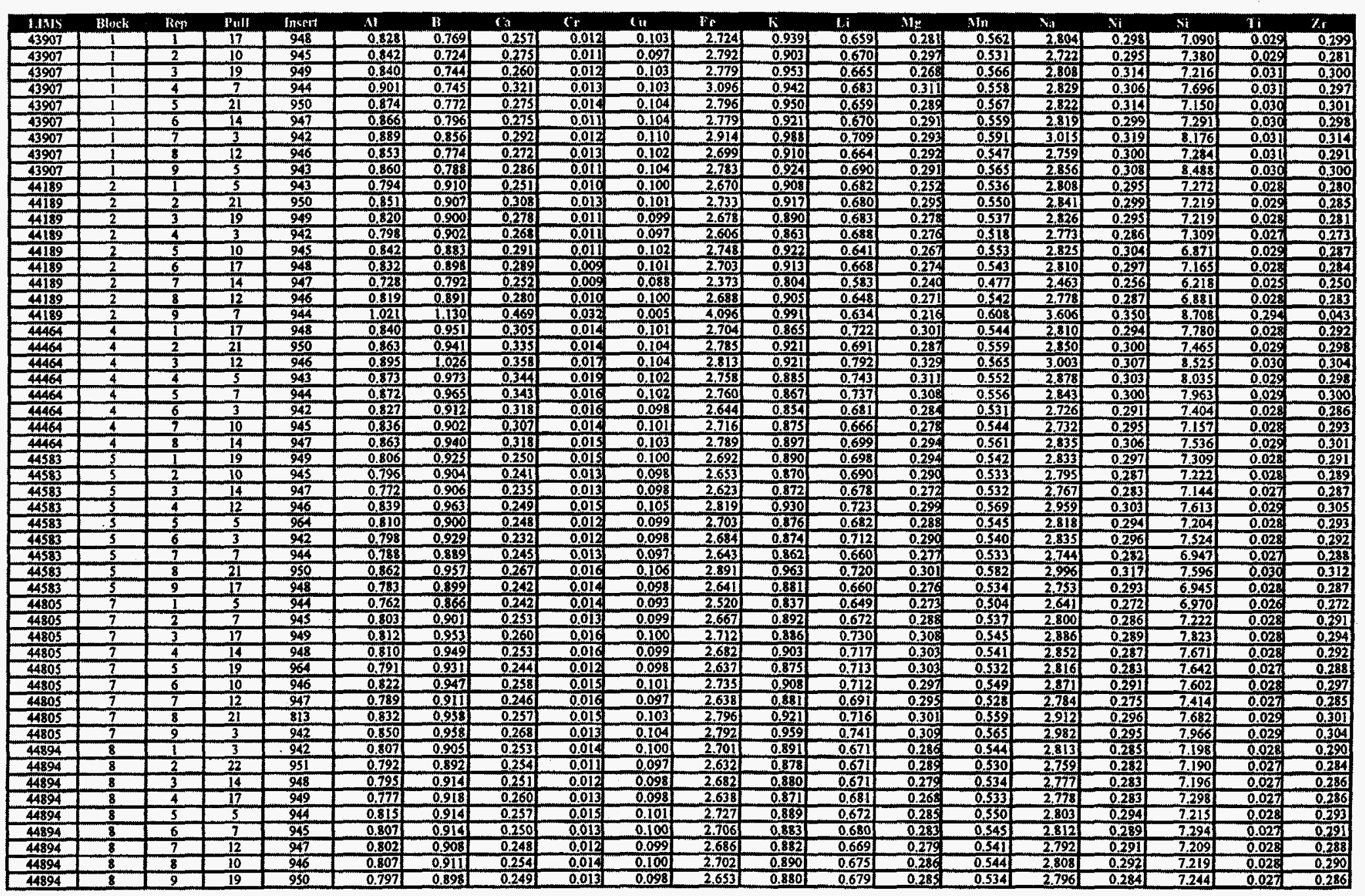


Table 10. Insert Fusion Data Randomized for Bootstrap Procedure (Reps 9, 10, 11 Not Used)

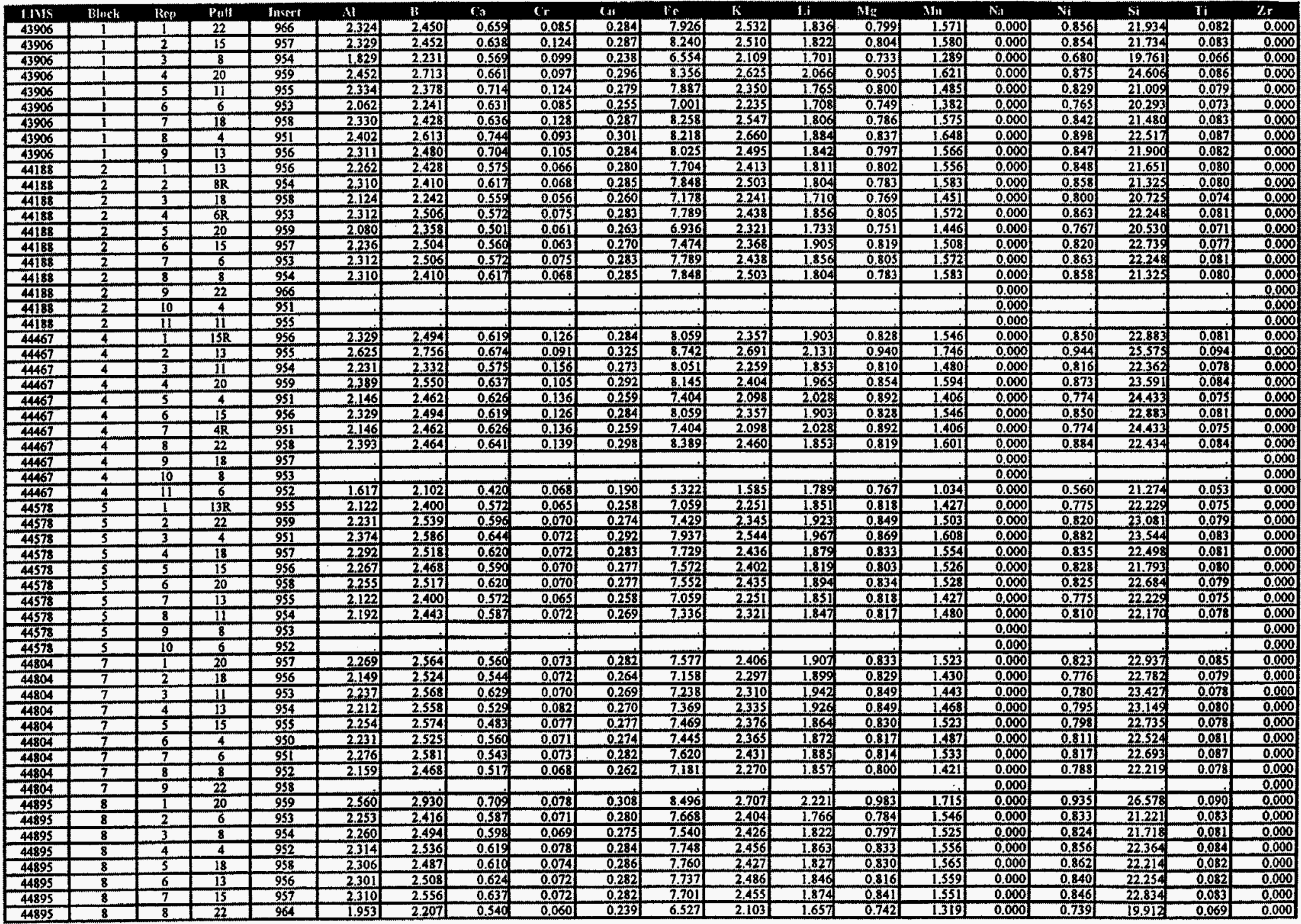


Table 11. Calcine Weight Percent Data Randomized for Bootstrap Procedure (Reps 9, 10, 11 Not Used)

\begin{tabular}{|c|c|c|c|c|c|}
\hline LINIS & 13hikk & $\mathrm{Re} n$ & P'ull| & Insert & 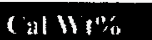 \\
\hline 43906 & 1 & 1 & 22 & 966 & 35.09 \\
\hline 43906 & 1 & 2 & 15 & 957 & 34.96 \\
\hline 43906 & 1 & 3 & 8 & 954 & 36.43 \\
\hline 43906 & 1 & 4 & 20 & 959 & 35.06 \\
\hline 43906 & 1 & 5 & 11 & 955 & 35.48 \\
\hline 43906 & 1 & 6 & 6 & 953 & 35.76 \\
\hline 43906 & 1 & 7 & 18 & 958 & 36.28 \\
\hline 43906 & 1 & 8 & 4 & 951 & 34.74 \\
\hline 43906 & 1 & 9 & 13 & 956 & 35.08 \\
\hline 44188 & 2 & 1 & 13 & 956 & 36.64 \\
\hline 44188 & 2 & 2 & $8 R$ & 954 & 36.79 \\
\hline 44188 & 2 & 3 & 18 & 958 & 34.94 \\
\hline 44188 & 2 & 4 & $6 \mathrm{R}$ & 953 & 38.55 \\
\hline 44188 & 2 & 5 & 20 & 959 & 34.95 \\
\hline 44188 & 2 & 6 & 15 & 957 & 37.91 \\
\hline 44188 & 2 & 7 & 6 & 953 & 38.55 \\
\hline 44188 & 2 & 8 & 8 & 954 & 36.79 \\
\hline 44188 & 2 & 9 & 22 & 966 & 36.11 \\
\hline 44188 & 2 & 10 & 4 & 951 & 39.90 \\
\hline 44188 & 2 & 11 & 11 & 955 & . \\
\hline 44467 & 4 & 1 & $15 R$ & 956 & 36.19 \\
\hline 44467 & 4 & 2 & 13 & 955 & 35.98 \\
\hline 44467 & 4 & 3 & 11 & 954 & 37.28 \\
\hline 44467 & 4 & 4 & 20 & 959 & 35.97 \\
\hline 44467 & 4 & 5 & 4 & 951 & 37.92 \\
\hline 44467 & 4 & 6 & 15 & 956 & 36.19 \\
\hline 44467 & 4 & 7 & $4 R$ & 951 & 37.92 \\
\hline 44467 & 4 & 8 & 22 & 958 & 35.07 \\
\hline 44467 & 4 & 9 & 18 & 957 & 35.87 \\
\hline 44467 & 4 & 10 & 8 & 953 & 37.75 \\
\hline 44467 & 4 & 11 & 6 & 952 & 40.73 \\
\hline 44578 & 5 & 1 & 13R & 955 & 38.63 \\
\hline 44578 & 5 & 2 & 22 & 959 & 36.80 \\
\hline 44578 & 5 & 3 & 4 & 951 & 39.07 \\
\hline 44578 & 5 & 4 & 18 & 957 & 35.67 \\
\hline 44578 & 5 & 5 & 15 & 956 & 36.12 \\
\hline 44578 & 5 & 6 & 20 & 958 & 36.43 \\
\hline 44578 & 5 & 7 & 13 & 955 & 38.63 \\
\hline 44578 & 5 & 8 & 11 & 954 & 37.64 \\
\hline 44578 & 5 & 9 & 8 & 953 & 35.68 \\
\hline 44578 & 5 & 10 & 6 & 952 & 35.13 \\
\hline 44804 & 7 & 1 & 20 & 957 & 35.87 \\
\hline 44804 & 7 & 2 & 18 & 956 & 37.42 \\
\hline 44804 & 7 & 3 & 11 & 953 & 36.91 \\
\hline 44804 & 7 & 4 & 13 & 954 & 36.93 \\
\hline 44804 & 7 & 5 & 15 & 955 & 35.93 \\
\hline 44804 & 7 & 6 & 4 & 950 & 36.23 \\
\hline 44804 & 7 & 7 & 6 & 951 & 35.90 \\
\hline 44804 & 7 & 8 & 8 & 952 & 36.40 \\
\hline 44804 & 7 & 9 & 22 & 958 & 36.20 \\
\hline 44895 & 8 & 1 & 20 & 959 & 36.51 \\
\hline 44895 & 8 & 2 & 6 & 953 & 35.26 \\
\hline 44895 & 8 & 3 & 8 & 954 & 35.90 \\
\hline 44895 & 8 & 4 & 4 & 952 & 35.64 \\
\hline 44895 & 8 & 5 & 18 & 958 & 35.63 \\
\hline 44895 & 8 & 6 & 13 & 956 & 35.91 \\
\hline 44895 & 8 & 7 & 15 & 957 & 35.75 \\
\hline 44895 & 8 & 8 & 22 & 964 & 37.07 \\
\hline
\end{tabular}


Table 12. Property Coefficients, Gravimetric Factors, and Oxide Molecular Weights

\begin{tabular}{|c|c|c|c|c|c|c|c|}
\hline Elt & $\begin{array}{l}\text { Dura- } \\
\text { bility } \\
\text { Cocff }\end{array}$ & $\begin{array}{l}\text { Liquidus } \\
\text { Temp. } \\
\text { Coeff }\end{array}$ & $\begin{array}{l}\text { High } \\
\text { Visc. } \\
\text { Coeff }\end{array}$ & $\begin{array}{l}\text { Low } \\
\text { Visc. } \\
\text { Coeff }\end{array}$ & $\begin{array}{l}\text { Homa- } \\
\text { geneity } \\
\text { Cocrf }\end{array}$ & $\begin{array}{l}\text { Gravi- } \\
\text { mettic } \\
\text { Factor }\end{array}$ & $\begin{array}{l}\text { Oxide } \\
\text { Molec. } \\
\text { Height }\end{array}$ \\
\hline $\mathrm{Al}$ & 37.68 & -34.94 & -2.000 & 2.000 & 575.80 & 1.890 & 101.961 \\
\hline B & -10.43 & 0.00 & 1.000 & -1.000 & 111.60 & 3.220 & 69.620 \\
\hline $\mathrm{Ca}$ & -13.79 & 0.00 & $\overline{0.000}$ & 0.000 & 316.70 & 1.399 & 56.079 \\
\hline $\mathrm{Cr}$ & 11.95 & 0.00 & 0.000 & 0.000 & 0.00 & 1.462 & 151.990 \\
\hline $\mathrm{Cu}$ & -4.96 & 0.00 & 0.000 & 0.000 & 0.00 & 1.252 & 79.539 \\
\hline $\mathrm{Fe}$ & 14.56 & -134.00 & 2.000 & -2.000 & 901.90 & 1.430 & 159.692 \\
\hline $\mathrm{K}$ & -76.41 & 0.00 & 2.000 & -2.000 & 151.10 & 1.205 & 94.203 \\
\hline $\mathrm{Li}$ & -24.04 & 0.00 & 2.000 & -2.000 & 47.910 & 2.153 & 29.877 \\
\hline $\mathrm{Mg}$ & -6.57 & 0.00 & 0.000 & 0.000 & 0.00 & 1.658 & 40.311 \\
\hline $\mathrm{Mn}$ & -24.44 & 0.00 & 0.000 & 0.000 & 0.00 & 1.291 & 70.937 \\
\hline $\mathrm{Na}$ & -53.09 & 0.00 & 2.000 & -2.000 & 99.38 & 1.348 & 61.979 \\
\hline $\mathrm{Ni}$ & 0.37 & 0.00 & 0.000 & 0.000 & 0.00 & 1.273 & 74.709 \\
\hline $\mathrm{Si}$ & 4.05 & 15.11 & -0.847 & 1.268 & 96.35 & 2.139 & 60.085 \\
\hline $\mathrm{Ti}$ & 16.27 & 0.00 & 0.000 & 0.000 & 0.00 & 1.668 & 79.899 \\
\hline $\mathrm{Zr}$ & 17.49 & 0.00 & 0.000 & 0.000 & 0.00 & 1.351 & 123.219 \\
\hline
\end{tabular}

Table 13. Coefficients for Three Methods of Combining Direct Dissolution Data: Cold Chem only, Fusion only, and Average of Cold Chem and Fusion

\begin{tabular}{|c|c|c|c|c|c|c|}
\hline & \multicolumn{2}{|c|}{ Cold Chem Only } & \multicolumn{2}{|c|}{ Fusion Only } & \multicolumn{2}{|c|}{ Average of $C C \&$ Fusion } \\
\hline 6 & 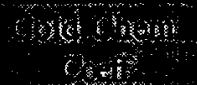 & 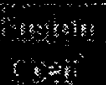 & 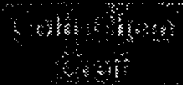 & Moms & a) & Mons \\
\hline $\mathrm{Al}$ & 1 & 0 & 0 & 1 & $1 / 2$ & $1 / 2$ \\
\hline B & 1 & 0 & 0 & 1 & $1 / 2$ & $1 / 2$ \\
\hline $\mathrm{Ca}$ & 1 & 0 & 0 & 1 & $1 / 2$ & $1 / 2$ \\
\hline $\mathrm{Cr}$ & 1 & 0 & 0 & 1 & $1 / 2$ & $1 / 2$ \\
\hline $\mathrm{Cu}$ & 1 & 0 & 0 & 1 & $1 / 2$ & $1 / 2$ \\
\hline $\mathrm{Fe}$ & 1 & 0 & 0 & 1 & $1 / 2$ & $1 / 2$ \\
\hline $\mathrm{K}$ & 1 & $\overline{0}$ & 0 & 1 & $1 / 2$ & $1 / 2$ \\
\hline $\mathrm{Li}$ & 1 & 0 & 0 & 1 & $1 / 2$ & $1 / 2$ \\
\hline $\mathrm{Mg}$ & 1 & 0 & 0 & 1 & $1 / 2$ & $1 / 2$ \\
\hline $\mathrm{Mn}$ & 1 & 0 & 0 & 1 & $1 / 2$ & $1 / 2$ \\
\hline $\mathrm{Na}^{\frac{3}{3}}$ & 1 & 0 & 1 & 0 & 1 & 0 \\
\hline $\mathrm{Ni}$ & 1 & 0 & 0 & 1 & $1 / 2$ & $1 / 2$ \\
\hline $\mathrm{Si}$ & 1 & 0 & 0 & 1 & $1 / 2$ & $1 / 2$ \\
\hline $\mathrm{Ti}$ & 1 & 0 & 0 & 1 & $1 / 2$ & $1 / 2$ \\
\hline $\mathrm{Zr}^{\mathrm{I}}$ & 1 & 0 & 1 & 0 & 1 & $\overline{0}$ \\
\hline
\end{tabular}

Elements not measured by the fusion method 
Table 14a. Half-Widths of $95 \%$ Confidence Intervals for Properties vs. Mean Composition, Number of Blocks, and Number of Samples per Block

\section{(ICC Data Only)}

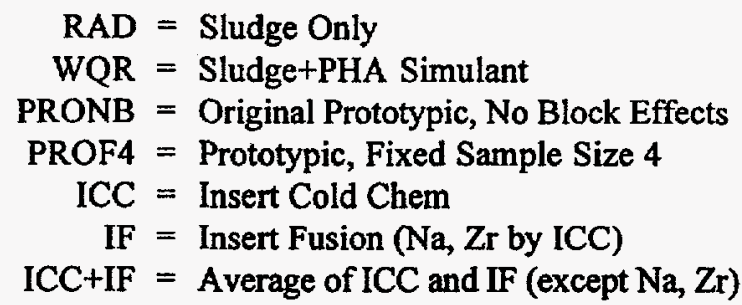

\begin{tabular}{|c|c|c|c|c|c|c|c|c|}
\hline $\begin{array}{l}\text { Mean } \\
\text { Comp. }\end{array}$ & $\begin{array}{l}\text { Method/ } \\
\text { Covar. } \\
\text { Matrix }\end{array}$ & $\begin{array}{c}\text { No. } \\
\text { Blocks }\end{array}$ & $\begin{array}{c}\text { No. } \\
\text { Samples }\end{array}$ & $\Delta G_{n}$ & $\begin{array}{l}\text { Liquidus } \\
\text { Temp. }\end{array}$ & $\begin{array}{l}\text { High } \\
\text { Viscos- } \\
\text { ity }\end{array}$ & $\begin{array}{l}\text { Low } \\
\text { Viscos- } \\
\text { ity }\end{array}$ & $\begin{array}{c}\text { Homoge- } \\
\text { neity }\end{array}$ \\
\hline RAD & PROF4 & 1 & 4 & 0.760 & .1 .358 & $\mathbf{0 . 0 4 9 2}$ & 0.0798 & 14.42 \\
\hline $\mathbf{R A D}$ & PRONB & 1 & 4 & 0.475 & 0.725 & 0.0383 & 0.0540 & 9.40 \\
\hline $\mathrm{RAD}$ & ICC & 1 & 2 & 0.898 & 1.269 & 0.0473 & 0.0812 & 22.30 \\
\hline RAD & $\mathrm{ICC}$ & 1 & 4 & 0.727 & 1.113 & 0.0446 & 0.0738 & 18.23 \\
\hline RAD & ICC & 1 & 6 & 0.664 & 0.997 & 0.0438 & 0.0706 & 17.13 \\
\hline $\mathrm{RAD}$ & ICC & 1 & 8 & 0.628 & 0.958 & 0.0433 & 0.0691 & 16.36 \\
\hline $\mathrm{RAD}$ & ICC & 2 & 2 & 0.635 & 0.897 & 0.0335 & 0.0574 & 15.77 \\
\hline $\mathrm{RAD}$ & ICC & 2 & 4 & 0.514 & 0.787 & 0.0316 & 0.0522 & 12.89 \\
\hline RAD & ICC & 2 & 6 & 0.469 & 0.705 & 0.0309 & 0.0499 & 12.11 \\
\hline $\mathrm{RAD}$ & ICC & 2 & 8 & 0.444 & 0.677 & 0.0306 & 0.0489 & 11.57 \\
\hline $\mathrm{RAD}$ & ICC & 3 & 2 & 0.518 & 0.732 & 0.0273 & 0.0469 & 12.88 \\
\hline $\mathrm{RAD}$ & ICC & 3 & 4 & 0.420 & 0.642 & 0.0258 & 0.0426 & 10.52 \\
\hline $\mathrm{RAD}$ & ICC & 3 & 6 & 0.383 & 0.576 & 0.0253 & 0.0408 & 9.89 \\
\hline $\mathrm{RAD}$ & ICC & 3 & 8 & 0.363 & 0.553 & 0.0250 & 0.0399 & 9.45 \\
\hline WQR & PROF4 & 1 & 4 & 0.820 & 1.306 & 0.0486 & 0.0789 & 13.82 \\
\hline WQR & PRONB & 1 & 4 & 0.488 & 0.691 & 0.0364 & 0.0520 & 8.94 \\
\hline WQR & ICC & 1 & 2 & 0.819 & 1.233 & 0.0436 & 0.0789 & 21.06 \\
\hline WQR & ICC & 1 & 4 & 0.634 & 1.080 & 0.0408 & 0.0712 & 17.24 \\
\hline WQR & $\mathrm{ICC}$ & 1 & 6 & 0.572 & 0.968 & 0.0399 & 0.0678 & 16.20 \\
\hline WQR & ICC & 1 & 8 & 0.533 & 0.930 & 0.0394 & 0.0662 & 15.48 \\
\hline WQR & ICC & 2 & 2 & 0.579 & 0.872 & 0.0308 & 0.0558 & 14.89 \\
\hline WQR & ICC & 2 & 4 & 0.448 & 0.764 & 0.0289 & 0.0503 & 12.19 \\
\hline WQR & ICC & 2 & 6 & 0.405 & 0.685 & 0.0282 & 0.0479 & 11.45 \\
\hline WQR & ICC & 2 & 8 & 0.377 & 0.657 & 0.0279 & 0.0468 & 10.95 \\
\hline WQR & ICC & 3 & 2 & 0.473 & 0.712 & 0.0252 & 0.0455 & 12.16 \\
\hline WQR & ICC & 3 & 4 & 0.366 & 0.624 & 0.0236 & 0.0411 & 9.95 \\
\hline WQR & ICC & 3 & 6 & 0.330 & 0.559 & 0.0231 & 0.0391 & 9.35 \\
\hline WQR & ICC & 3 & 8 & 0.308 & 0.537 & 0.0228 & 0.0382 & 8.94 \\
\hline
\end{tabular}


Table 14b. Half-Widths of $95 \%$ Confidence Intervals for Properties vs. Mean Composition, Number of Blocks, and Number of Samples per Block (IF Data Only)

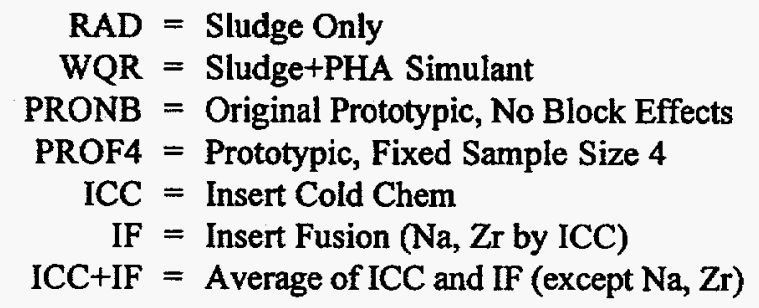

\begin{tabular}{|c|c|c|c|c|c|c|c|c|}
\hline $\begin{array}{l}\text { Mean } \\
\text { Comp. }\end{array}$ & $\begin{array}{l}\text { Method/ } \\
\text { Covar. } \\
\text { Matrix }\end{array}$ & $\begin{array}{l}\text { No. } \\
\text { Blockis }\end{array}$ & $\begin{array}{c}\text { No. } \\
\text { Samples }\end{array}$ & $\Delta \mathrm{G}_{\mathrm{n}}$ & $\begin{array}{c}\text { Liquidus } \\
\text { Temp. }\end{array}$ & $\begin{array}{c}\text { High } \\
\text { Viscos- } \\
\text { ity }\end{array}$ & $\begin{array}{c}\text { Low } \\
\text { Viscos- } \\
\text { ity }\end{array}$ & $\begin{array}{l}\text { Homoge- } \\
\text { neity }\end{array}$ \\
\hline RAD & PROF4 & 1 & 4 & 0.760 & 1.358 & 0.0492 & 0.0798 & 14.42 \\
\hline RAD & PRONB & 1 & 4 & 0.475 & 0.725 & 0.0383 & 0.0540 & 9.40 \\
\hline $\mathrm{RAD}$ & IF & 1 & 2 & 0.889 & 1.517 & 0.0557 & 0.0929 & 21.65 \\
\hline RAD & IF & 1 & 4 & 0.667 & 1.336 & 0.0477 & 0.0805 & 17.14 \\
\hline RAD & IF & 1 & 6 & 0.595 & 1.214 & 0.0456 & 0.0780 & 15.76 \\
\hline $\mathrm{RAD}$ & IF & 1 & 8 & 0.548 & 1.170 & 0.0441 & 0.0759 & 14.86 \\
\hline $\mathrm{RAD}$ & IF & 2 & 2 & 0.628 & 1.073 & 0.0394 & 0.0657 & 15.31 \\
\hline RAD & IF & 2 & 4 & 0.472 & 0.945 & 0.0337 & 0.0569 & 12.12 \\
\hline RAD & IF & 2 & 6 & 0.421 & 0.858 & 0.0322 & 0.0551 & 11.15 \\
\hline RAD & IF & 2 & 8 & 0.387 & 0.828 & 0.0312 & 0.0536 & 10.51 \\
\hline RAD & IF & 3 & 2 & 0.513 & 0.876 & 0.0321 & 0.0536 & 12.50 \\
\hline $\mathrm{RAD}$ & IF & 3 & 4 & 0.385 & 0.772 & 0.0275 & 0.0465 & 9.90 \\
\hline $\mathrm{RAD}$ & IF & 3 & 6 & 0.344 & 0.701 & 0.0263 & 0.0450 & 9.10 \\
\hline $\mathrm{RAD}$ & IF & 3 & 8 & 0.316 & 0.676 & 0.0255 & 0.0438 & 8.58 \\
\hline WQR & PROF4 & 1 & 4 & 0.820 & 1.306 & 0.0486 & 0.0789 & 13.82 \\
\hline WQR & PRONB & 1 & 4 & 0.488 & 0.691 & 0.0364 & 0.0520 & 8.94 \\
\hline WQR & IF & 1 & 2 & 0.670 & 1.418 & 0.0487 & 0.0857 & 20.54 \\
\hline WQR & IF & 1 & 4 & 0.498 & 1.254 & 0.0432 & 0.0758 & 16.19 \\
\hline WQR & IF & 1 & 6 & 0.445 & 1.148 & 0.0415 & 0.0738 & 14.86 \\
\hline WQR & IF & 1 & 8 & 0.408 & 1.110 & 0.0405 & 0.0721 & 13.99 \\
\hline WQR & IF & 2 & 2 & 0.474 & 1.003 & 0.0344 & 0.0606 & 14.52 \\
\hline WQR & IF & 2 & 4 & 0.352 & 0.886 & 0.0306 & 0.0536 & 11.45 \\
\hline WQR & IF & 2 & 6 & 0.315 & 0.812 & 0.0294 & 0.0522 & 10.51 \\
\hline WQR & IF & 2 & 8 & 0.289 & 0.785 & 0.0287 & 0.0510 & 9.89 \\
\hline WQR & IF & 3 & 2 & 0.387 & 0.819 & 0.0281 & 0.0495 & 11.86 \\
\hline WQR & IF & 3 & 4 & 0.288 & 0.724 & 0.0249 & 0.0438 & 9.35 \\
\hline WQR & IF & 3 & 6 & 0.257 & 0.663 & 0.0240 & 0.0426 & 8.58 \\
\hline WQR & IF & 3 & 8 & 0.236 & 0.641 & 0.0234 & 0.0416 & 8.08 \\
\hline
\end{tabular}


Table 14c. Half-Widths of $95 \%$ Confidence Intervals for Properties vs. Mean Composition, Number of Blocks, and Number of Samples per Block (ICC+IF Data)

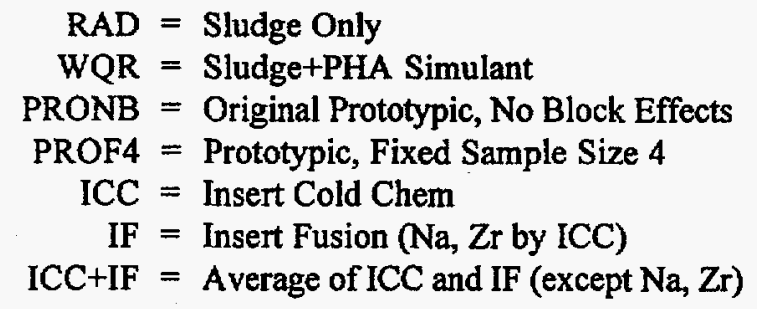

\begin{tabular}{|c|c|c|c|c|c|c|c|c|}
\hline $\begin{array}{l}\text { Mean } \\
\text { Comp. }\end{array}$ & $\begin{array}{l}\text { Method } \\
\text { Covar. } \\
\text { Matrix }\end{array}$ & $\begin{array}{l}\text { No. } \\
\text { Blockis }\end{array}$ & $\begin{array}{c}\text { No. } \\
\text { Samples }\end{array}$ & $\Delta G_{p}$ & $\begin{array}{l}\text { Liquidus } \\
\text { Temp. }\end{array}$ & $\begin{array}{c}\text { High } \\
\text { Viscos- } \\
\text { ity }\end{array}$ & $\begin{array}{l}\text { Low } \\
\text { Viscos- } \\
\text { ity }\end{array}$ & $\begin{array}{c}\text { Homoge- } \\
\text { neity }\end{array}$ \\
\hline $\mathbf{R A D}$ & PROF4 & 1 & 4 & 0.760 & 1.358 & 0.0492 & 0.0798 & 14.42 \\
\hline RAD & PRONB & 1 & 4 & 0.475 & 0.725 & 0.0383 & 0.0540 & 9.40 \\
\hline $\mathrm{RAD}$ & $\mathrm{ICC}+\mathrm{IF}$ & 1 & 2 & 0.854 & 0.989 & 0.0359 & 0.0561 & 16.04 \\
\hline RAD & $\mathrm{ICC}+\mathrm{IF}$ & 1 & 4 & 0.652 & 0.870 & 0.0317 & 0.0506 & 12.87 \\
\hline $\mathrm{RAD}$ & $\mathrm{ICC}+\mathrm{IF}$ & 1 & 6 & 0.581 & 0.786 & 0.0308 & 0.0493 & 11.95 \\
\hline $\mathrm{RAD}$ & $\mathrm{ICC}+\mathrm{IF}$ & 1 & 8 & 0.537 & 0.756 & 0.0301 & 0.0484 & 11.34 \\
\hline $\mathrm{RAD}$ & $\mathrm{ICC}+\mathrm{IF}$ & 2 & 2 & 0.604 & 0.699 & 0.0254 & 0.0397 & 11.34 \\
\hline $\mathrm{RAD}$ & $\mathrm{ICC}+\mathrm{IF}$ & 2 & 4 & 0.461 & 0.615 & 0.0224 & 0.0358 & 9.10 \\
\hline $\mathrm{RAD}$ & $\mathrm{ICC}+\mathrm{IF}$ & 2 & 6 & 0.411 & 0.555 & 0.0218 & 0.0349 & 8.45 \\
\hline $\mathrm{RAD}$ & $\mathrm{ICC}+\mathrm{IF}$ & 2 & 8 & 0.380 & 0.535 & 0.0213 & 0.0342 & 8.02 \\
\hline $\mathrm{RAD}$ & ICC+IF & 3 & 2 & 0.493 & 0.571 & 0.0207 & 0.0324 & 9.26 \\
\hline $\mathrm{RAD}$ & ICC+IF & 3 & 4 & 0.376 & 0.502 & 0.0183 & 0.0292 & 7.43 \\
\hline RAD & $\mathrm{ICC}+\mathrm{IF}$ & 3 & 6 & 0.335 & 0.454 & 0.0178 & 0.0285 & 6.90 \\
\hline $\mathrm{RAD}$ & ICC+IF & 3 & 8 & 0.310 & 0.437 & 0.0174 & 0.0279 & 6.55 \\
\hline WQR & PROF4 & 1 & 4 & 0.820 & 1.306 & 0.0486 & 0.0789 & 13.82 \\
\hline WQR & PRONB & 1 & 4 & 0.488 & 0.691 & 0.0364 & 0.0520 & 8.94 \\
\hline WQR & ICC+IF & 1 & 2 & 0.717 & 0.940 & 0.0317 & 0.0537 & 15.08 \\
\hline WQR & $\mathrm{ICC}+\mathrm{IF}$ & 1 & 4 & 0.538 & 0.827 & 0.0287 & 0.0488 & 12.09 \\
\hline WQR & $\mathrm{ICC}+\mathrm{IF}$ & 1 & 6 & 0.480 & 0.751 & 0.0280 & 0.0475 & 11.22 \\
\hline WQR & ICC + IF & 1 & 8 & 0.441 & 0.724 & 0.0275 & 0.0466 & 10.64 \\
\hline WQR & $\mathrm{ICC}+\mathrm{IF}$ & 2 & 2 & 0.507 & 0.664 & 0.0224 & 0.0380 & 10.66 \\
\hline WQR & $\mathrm{ICC}+\mathrm{IF}$ & 2 & 4 & 0.381 & 0.585 & 0.0203 & 0.0345 & 8.55 \\
\hline WQR & $\mathrm{ICC}+\mathrm{IF}$ & 2 & 6 & 0.339 & 0.531 & 0.0198 & 0.0336 & 7.94 \\
\hline WQR & $\mathrm{ICC}+\mathrm{IF}$ & 2 & 8 & 0.312 & 0.512 & 0.0194 & 0.0330 & 7.53 \\
\hline WQR & ICC+IF & 3 & 2 & 0.414 & 0.543 & 0.0183 & 0.0310 & 8.71 \\
\hline WQR & $\mathrm{ICC}+\mathrm{IF}$ & 3 & 4 & 0.311 & 0.478 & 0.0166 & 0.0282 & 6.98 \\
\hline WQR & $\mathrm{ICC}+\mathrm{IF}$ & 3 & 6 & 0.277 & 0.434 & 0.0162 & 0.0274 & 6.48 \\
\hline WQR & $\mathrm{ICC}+\mathrm{IF}$ & 3 & 8 & 0.255 & 0.418 & 0.0159 & 0.0269 & 6.14 \\
\hline
\end{tabular}


Table 15. Minimum Block/Sample Sizes in Direct Dissolution Method Required for Equivalent Variability to One Block of Four Samples by Prototypic Methods. (Basis for Comparison: Half-Widths of 95\% Confidence Intervals for Properties)

\begin{tabular}{|c|c|c|c|c|c|c|c|}
\hline Baseline & Method & $\begin{array}{c}\text { Mean } \\
\text { Composition }\end{array}$ & $\Delta \mathbf{G}_{\mathrm{n}}$ & Liquidus & $\begin{array}{c}\text { Highl } \\
\text { Viscosity }\end{array}$ & $\begin{array}{l}\text { Low } \\
\text { Viscosity }\end{array}$ & $\begin{array}{l}\text { Homo- } \\
\text { geneity }\end{array}$ \\
\hline \multirow{5}{*}{$\begin{array}{c}\text { PROF4 } \\
\text { (Fixed 4) }\end{array}$} & \multirow[b]{2}{*}{ ICC } & RAD & $1 / 4$ & $1 / 2$ & $1 / 2$ & $1 / 4$ & $2 / 4$ \\
\hline & & WQR & $1 / 2$ & $1 / 2$ & $1 / 2$ & $1 / 2$ & $2 / 4$ \\
\hline & \multirow[b]{2}{*}{ IF } & RAD & $1 / 4$ & $1 / 4$ & $1 / 4$ & $1 / 6$ & $2 / 4$ \\
\hline & & WQR & $1 / 2$ & $1 / 4$ & $1 / 4$ & $1 / 4$ & $2 / 4$ \\
\hline & & S & $x^{2}$ & & & 14 & 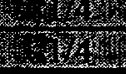 \\
\hline \multirow{5}{*}{$\begin{array}{l}\text { PRONB } \\
\text { (Original) }\end{array}$} & \multirow[b]{2}{*}{ ICC } & RAD & $2 / 6$ & $2 / 6$ & $2 / 2$ & $2 / 4$ & $3 / 8$ \\
\hline & & WQR & $2 / 4$ & $2 / 6$ & $2 / 2$ & $2 / 4$ & $3 / 8$ \\
\hline & \multirow[b]{2}{*}{ IF } & RAD & $2 / 4$ & $3 / 6$ & $2 / 4$ & $2 / 8$ & $3 / 6$ \\
\hline & & WQR & $1 / 6$ & $3 / 6$ & $2 / 2$ & $2 / 8$ & $3 / 8$ \\
\hline & & Rinor & & 2e. & (1) & (1) & 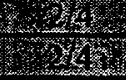 \\
\hline
\end{tabular}


Figure 1. Insert Calcine Factors by Block, with Anaysis of Variance and Test for Equality of Within-Block Variances

Cal_wtP By block

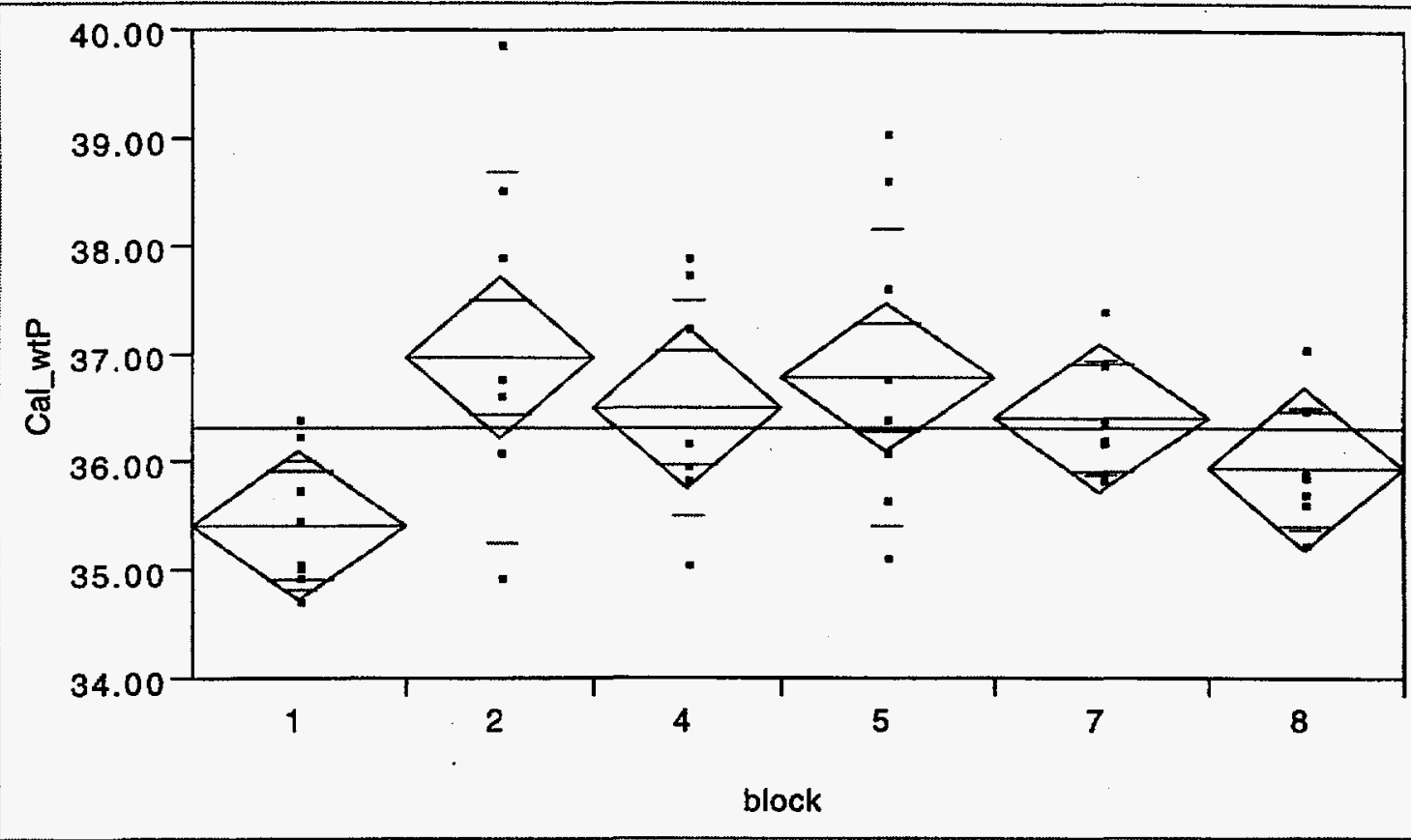

\begin{tabular}{lrrrr}
\multicolumn{7}{c}{ Oneway Anova } \\
Analysis of Variance \\
Source & DF Sum of Squares & Mean. Square & F Ratio \\
Model & 5 & 13.961258 & 2.79225 & 2.4618 \\
Error & 45 & 51.040240 & 1.13423 & Prob $>$ F \\
C Total & 50 & 65.001498 & 1.30003 & 0.0470
\end{tabular}

Tests that the Variances are Equal

$\begin{array}{lrrrr}\text { Level } & \text { Count } & \text { Std Dev } & \text { MeanAbsDif to Mean } & \text { MeanAbsDif to Median } \\ 1 & 9 & 0.602691 & 0.494568 & 0.457778 \\ 2 & 8 & 1.733987 & 1.359687 & 1.313750 \\ 4 & 8 & 1.019551 & 0.859688 & 0.781250 \\ 5 & 9 & 1.375082 & 1.100741 & 1.094444 \\ 7 & 9 & 0.547504 & 0.443704 & 0.421111 \\ 8 & 8 & 0.571475 & 0.415625 & 0.388750\end{array}$

$\begin{array}{lrrrr}\text { Test } & \text { F Ratio } & \text { DF Num } & \text { DF Den } & \text { Prob }>\text { F } \\ \text { O'Brien[.5] } & 3.2771 & 5 & 45 & 0.0131 \\ \text { Brown-Forsythe } & 2.6600 & 5 & 45 & 0.0344 \\ \text { Levene } & 4.1400 & 5 & 45 & 0.0035 \\ \text { Bartlett } & 3.4537 & 5 & \bullet & 0.0040\end{array}$

Welch Anova testing Means Equal, allowing Std's Not Equal
F Ratio
DF Num
DF Den
Prob>F
3.5791
$\begin{array}{lll}5 & 20.374 & 0.0175\end{array}$ 
Figure 2(AI-Ca). Insert Cold Chemical Data (Unadjusted)

(Squares indicate outliers or unused data)

Al By Block

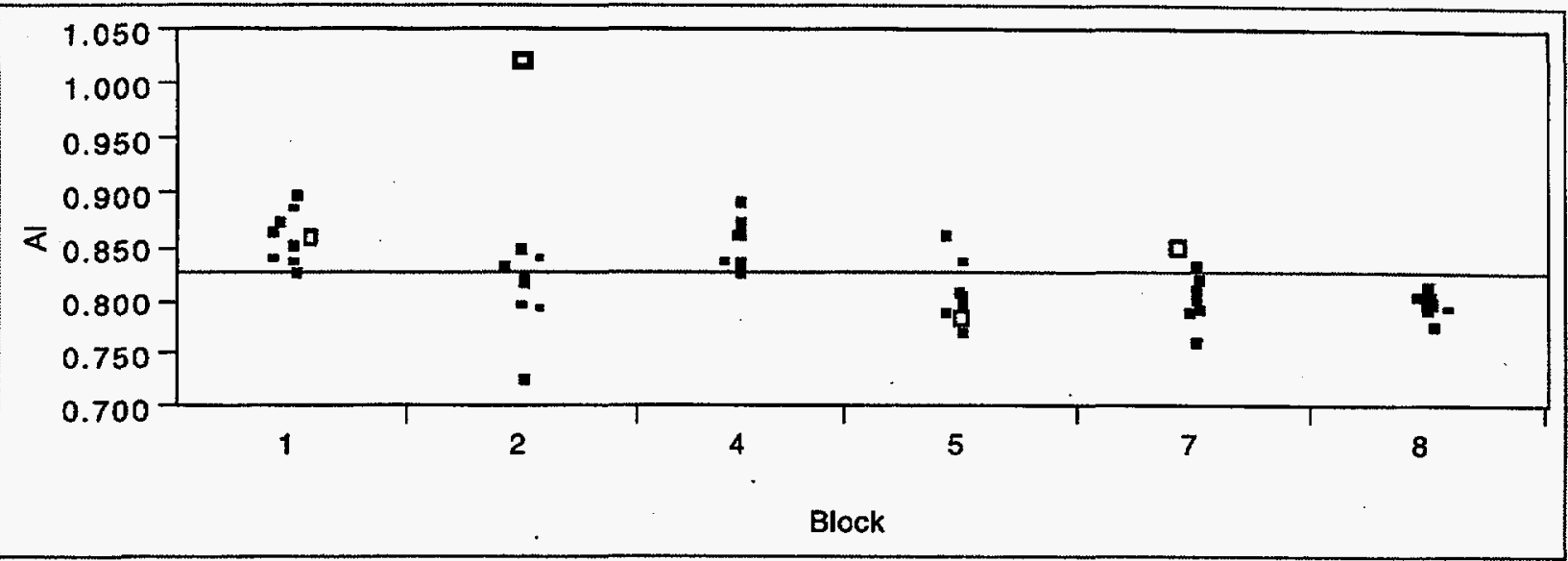

\section{B By Block}

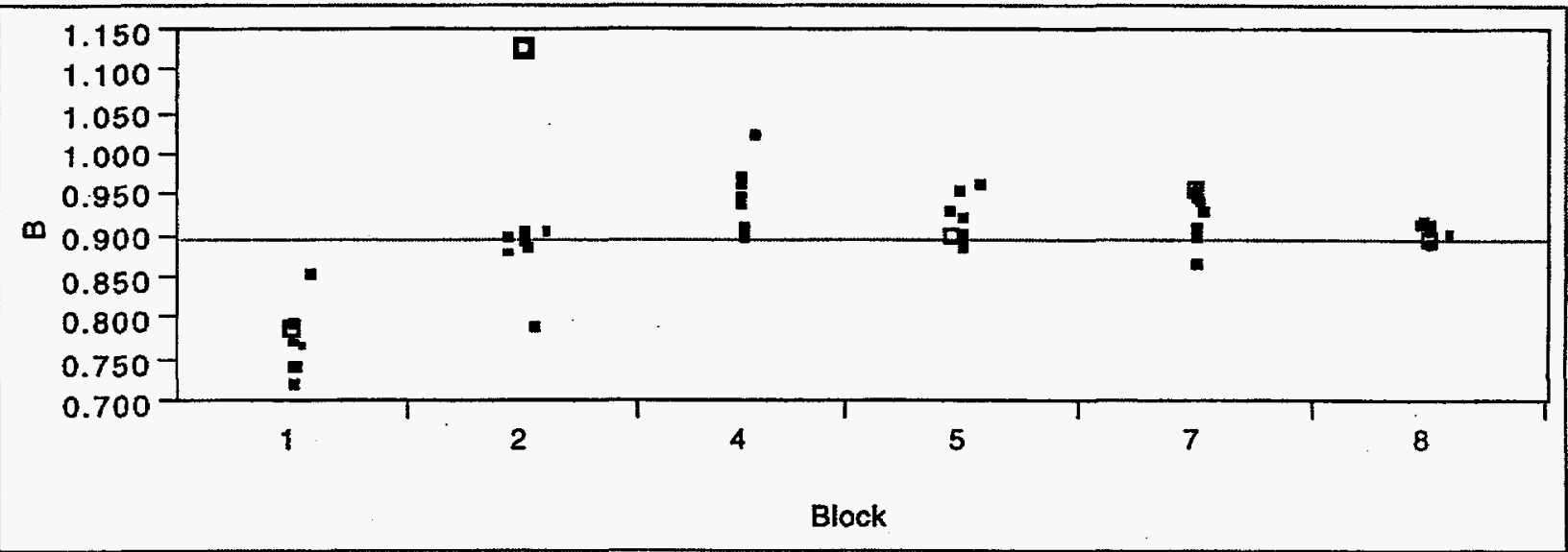

Ca By Block

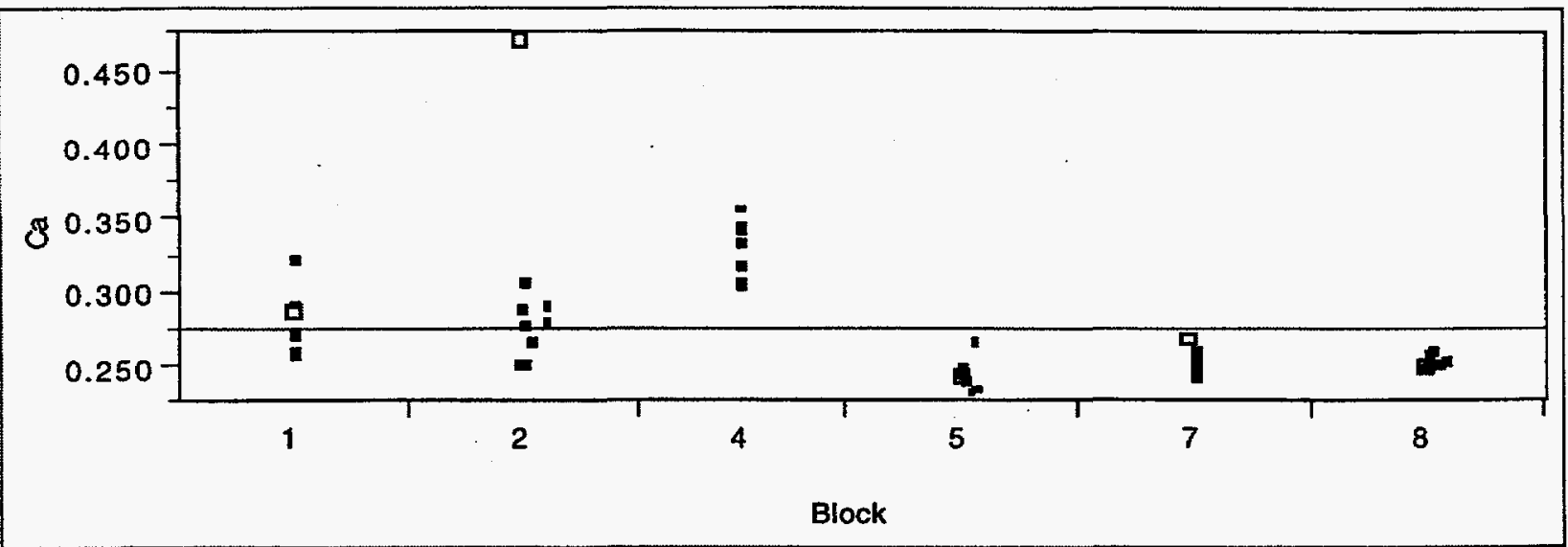


Figure 2(Cr-Fe). Insert Cold Chemical Data (Unadjusted)

(Squares indicate outliers or unused data)

\section{Cr By Block}

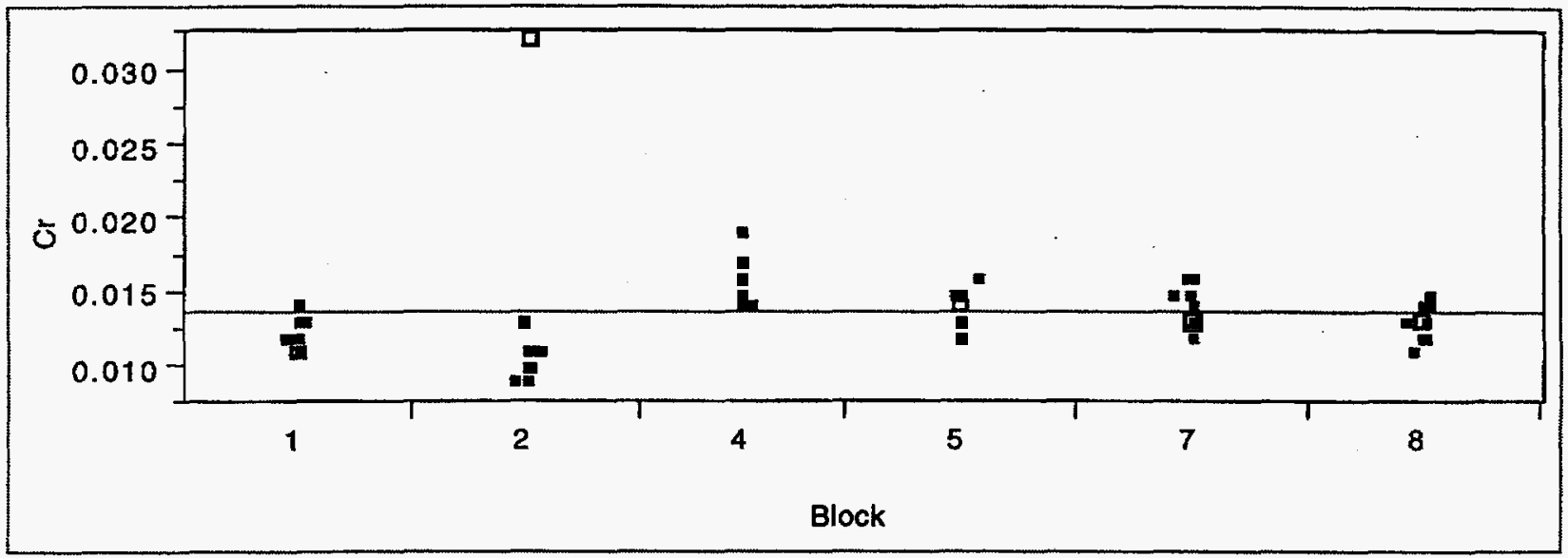

\section{Cu By Block}

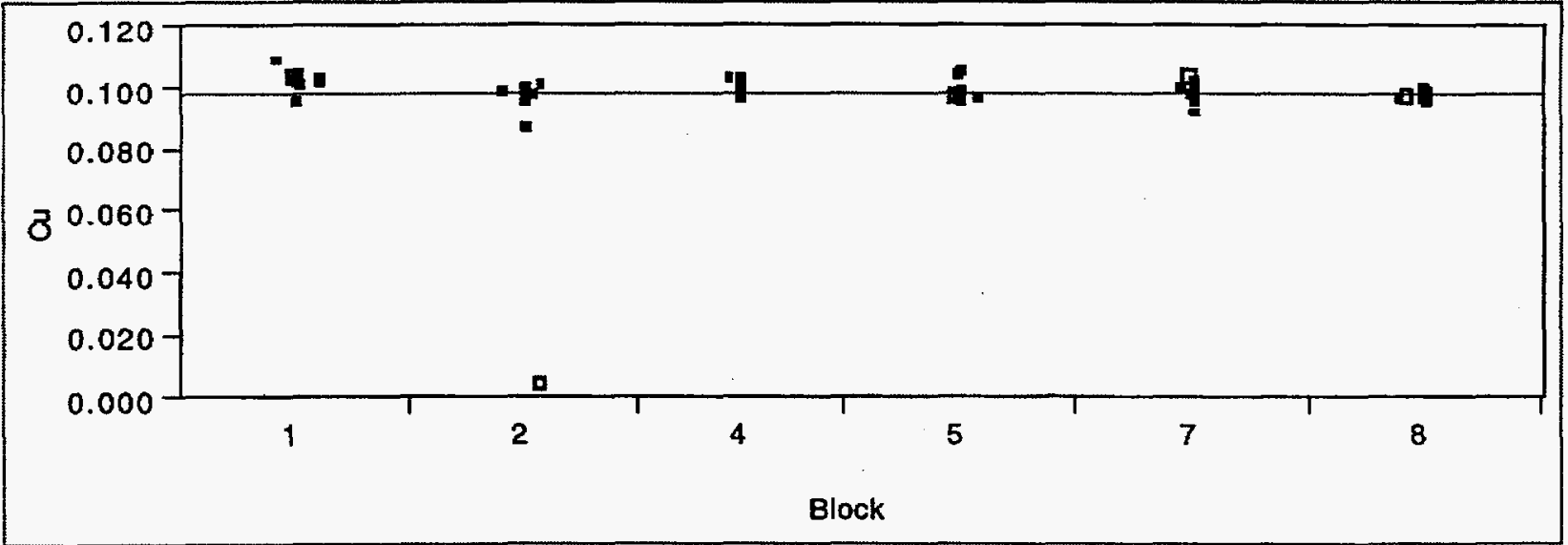

Fe By Block

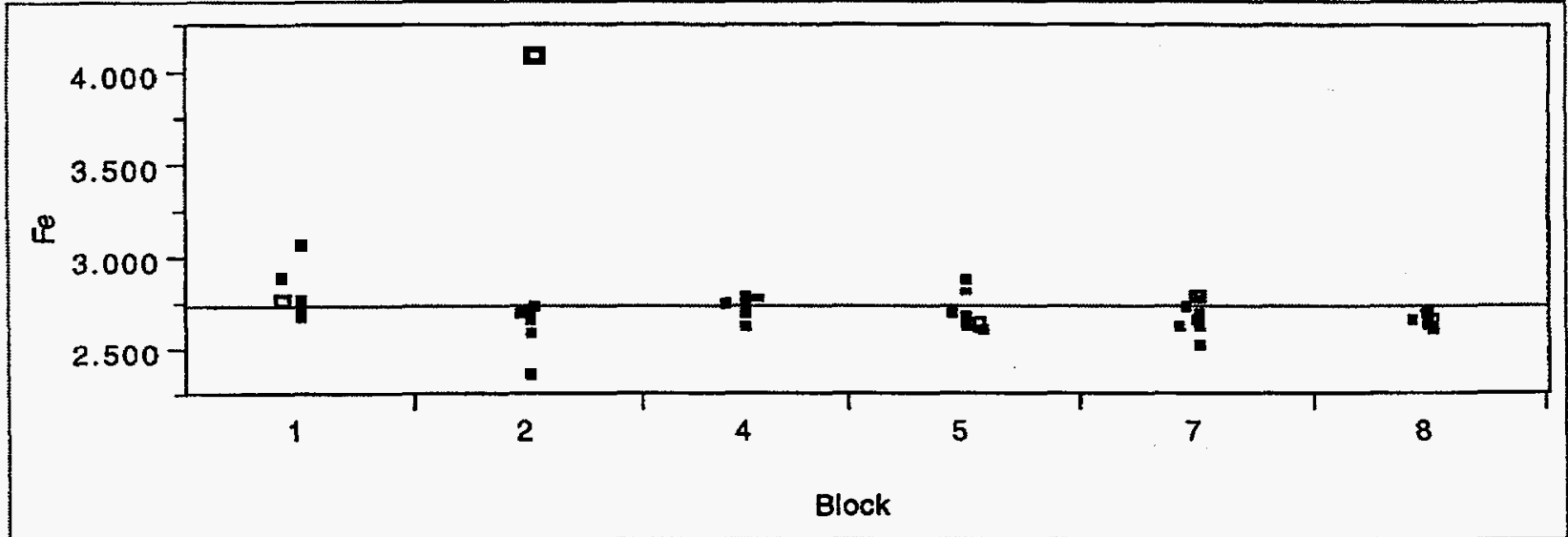


Figure 2(K-Mg). Insert Cold Chemical Data (Unadjusted)

(Squares indicate outliers or unused data)

K By Block

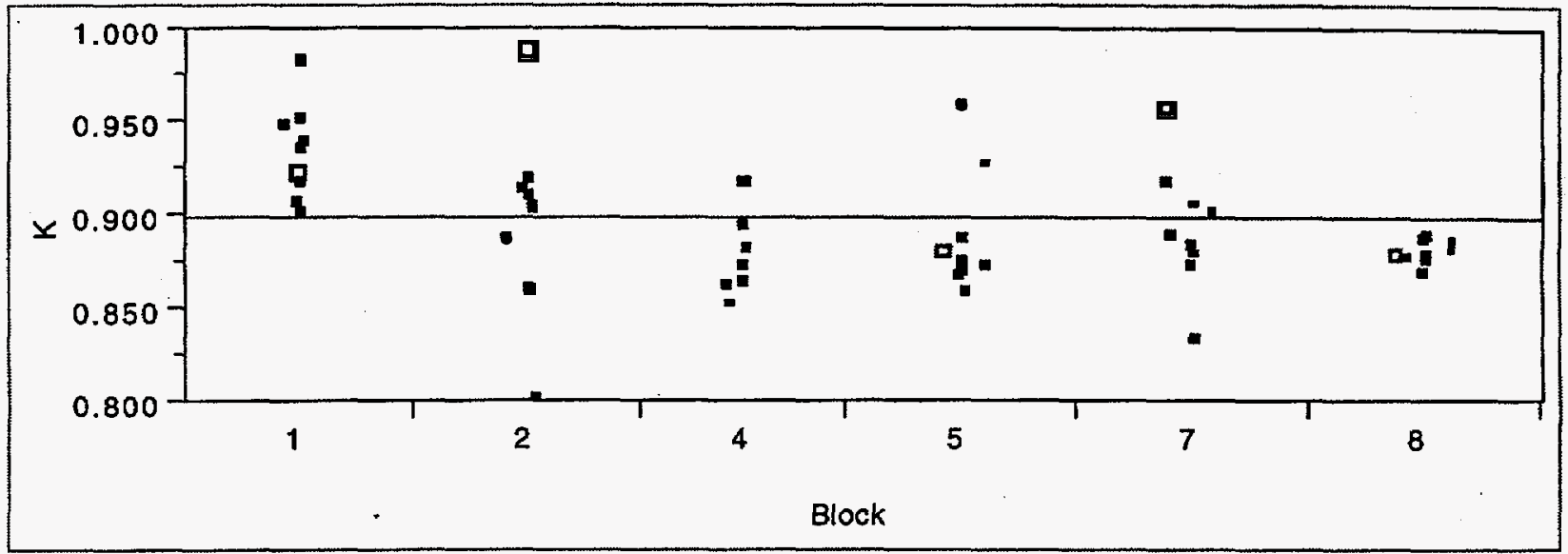

Li By Block

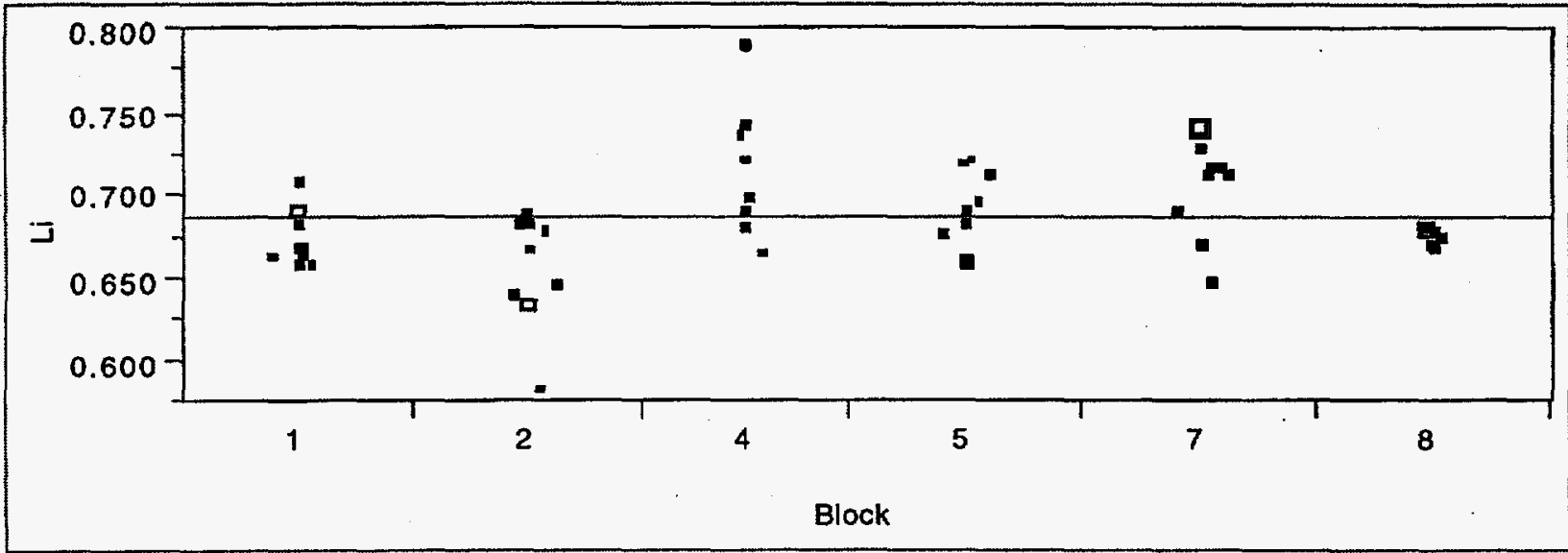

Mg By Block

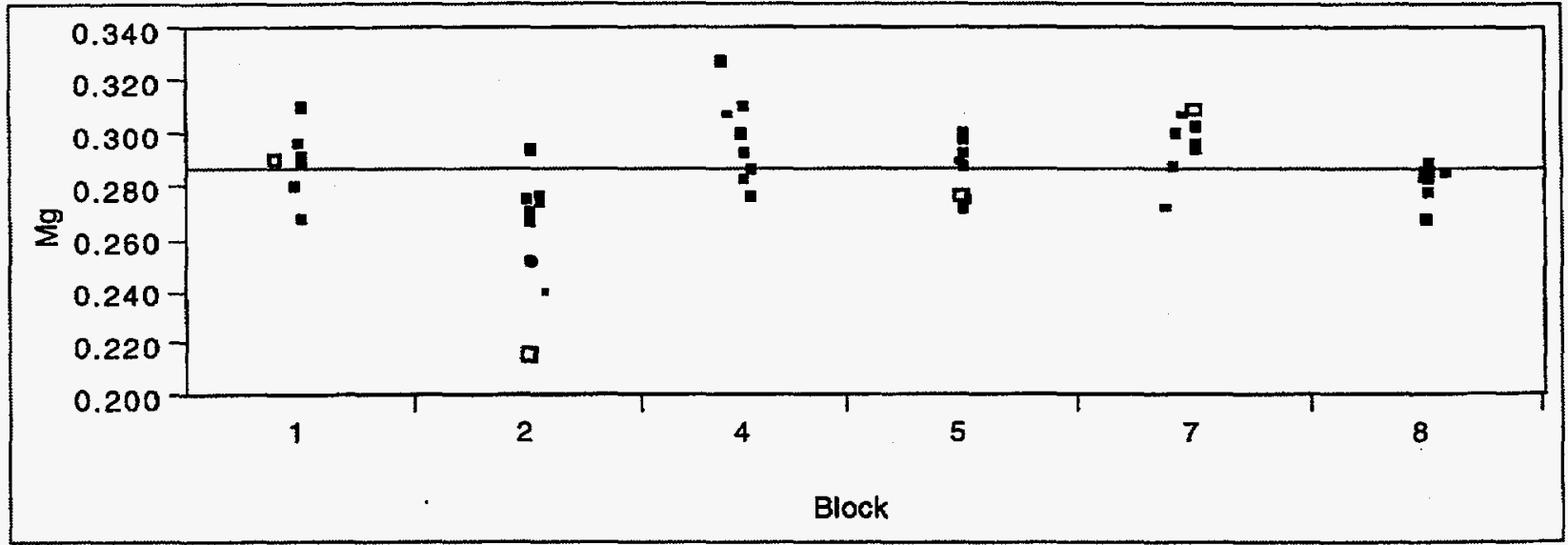


Figure 2(Mn-Ni). Insert Cold Chemical Data (Unadjusted)

(Squares indicate outliers or unused data)

Mn By Block

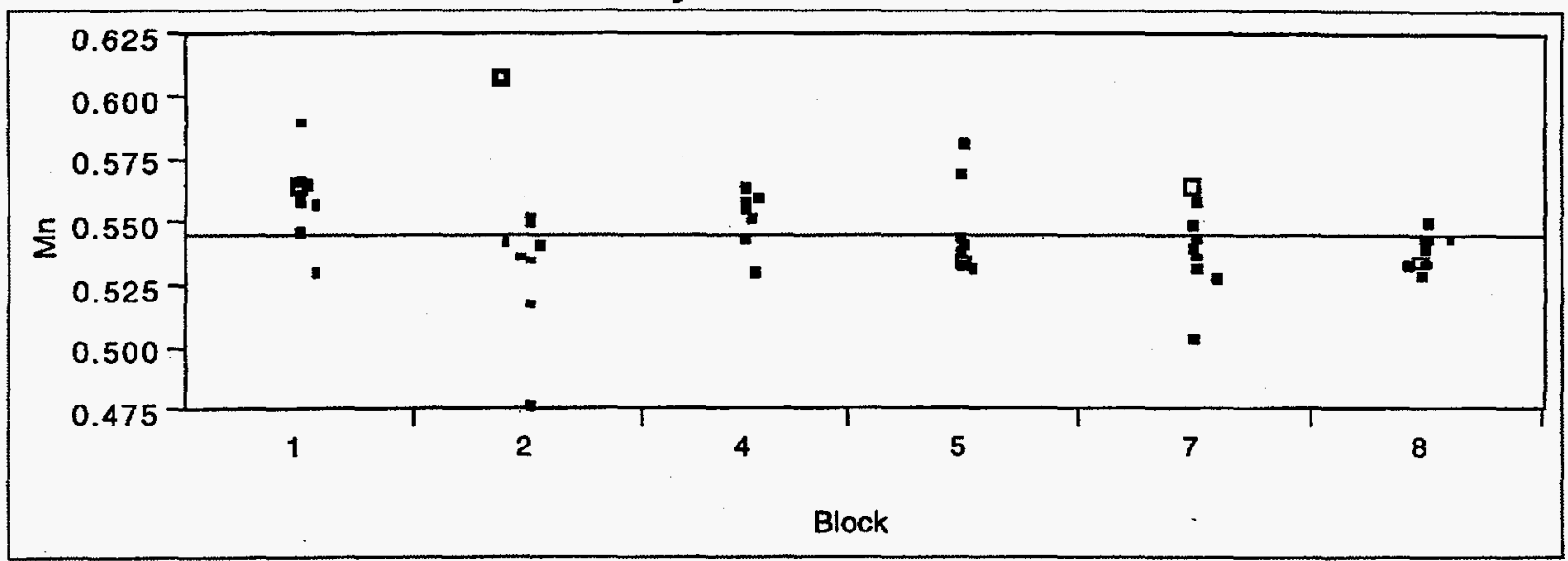

Na By Block

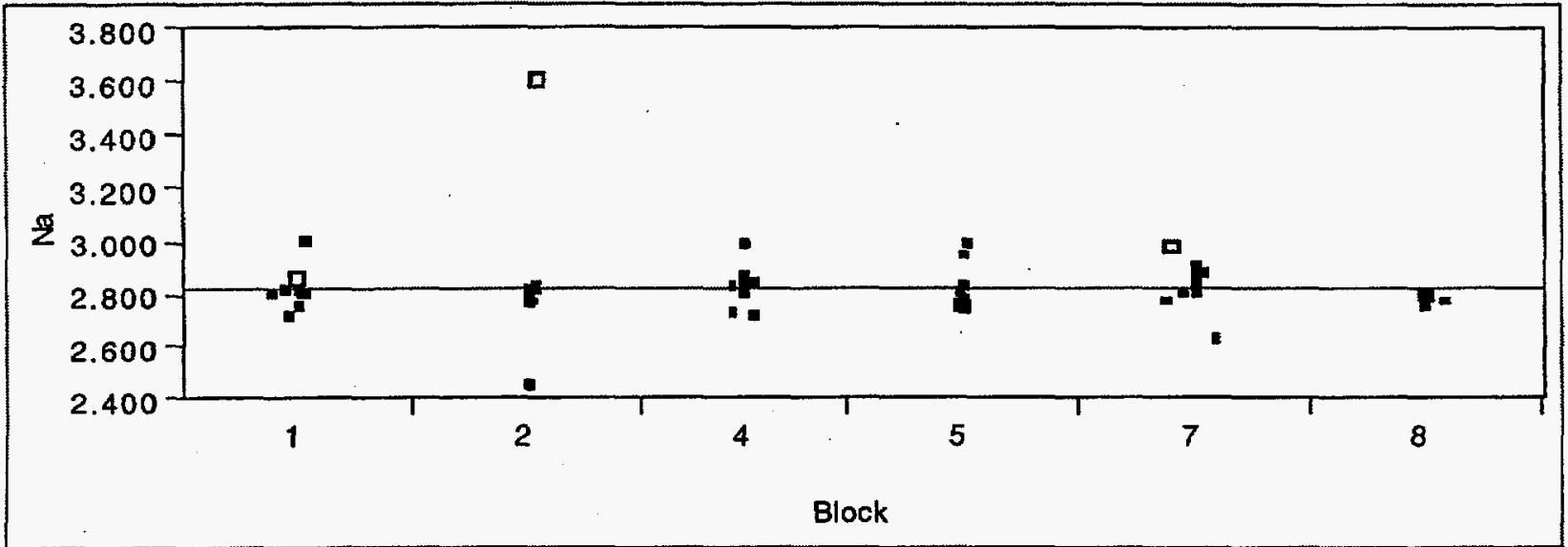

Ni By Block

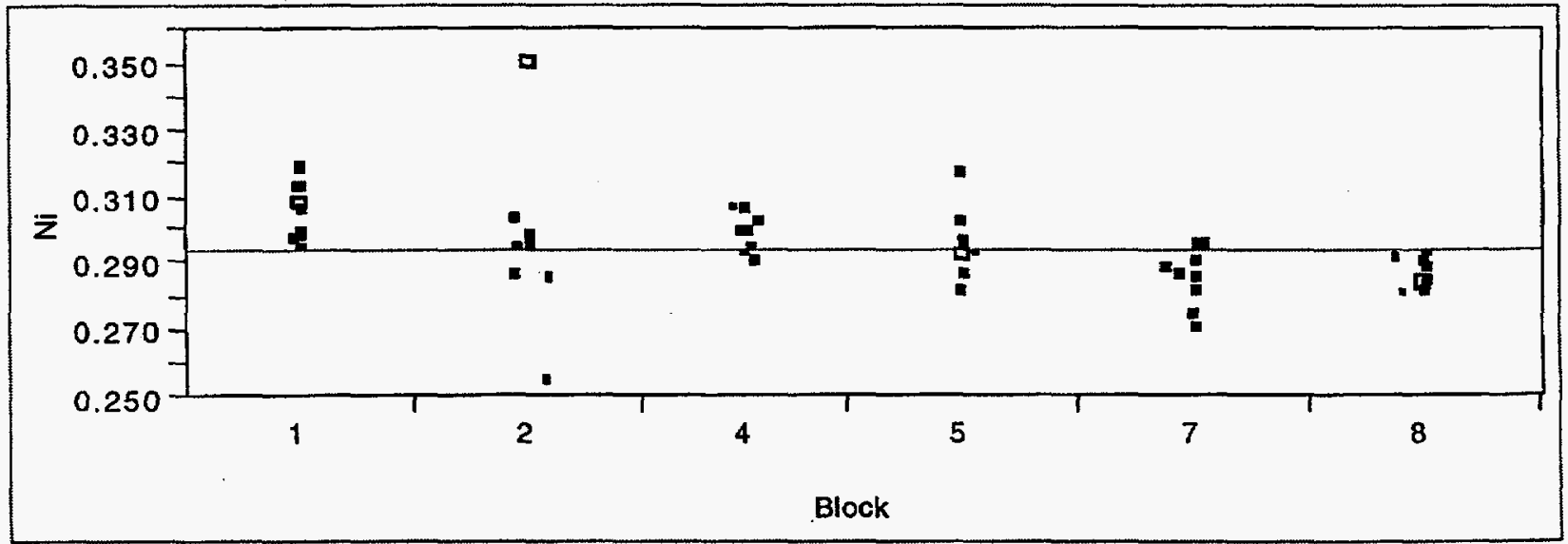


Figure 2(Si-Zr). Insert Cold Chemical Data (Unadjusted)

(Squares indicate outliers or unused data)

\section{Si By Block}

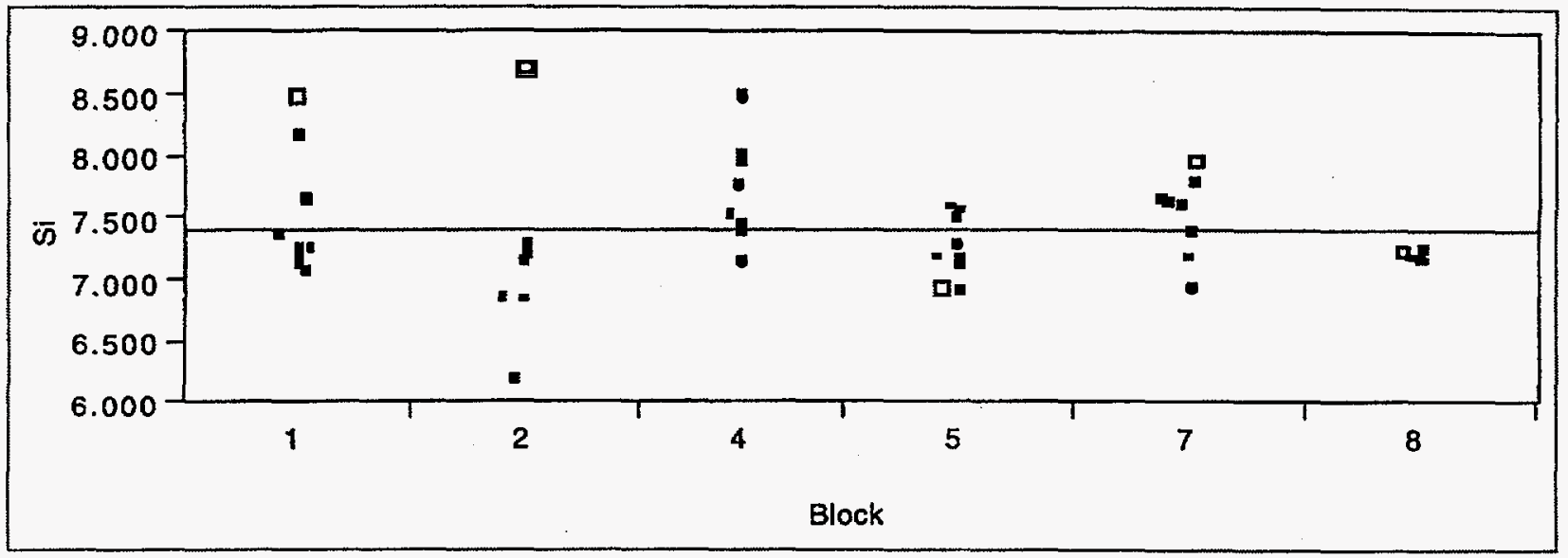

\section{Ti By Block}

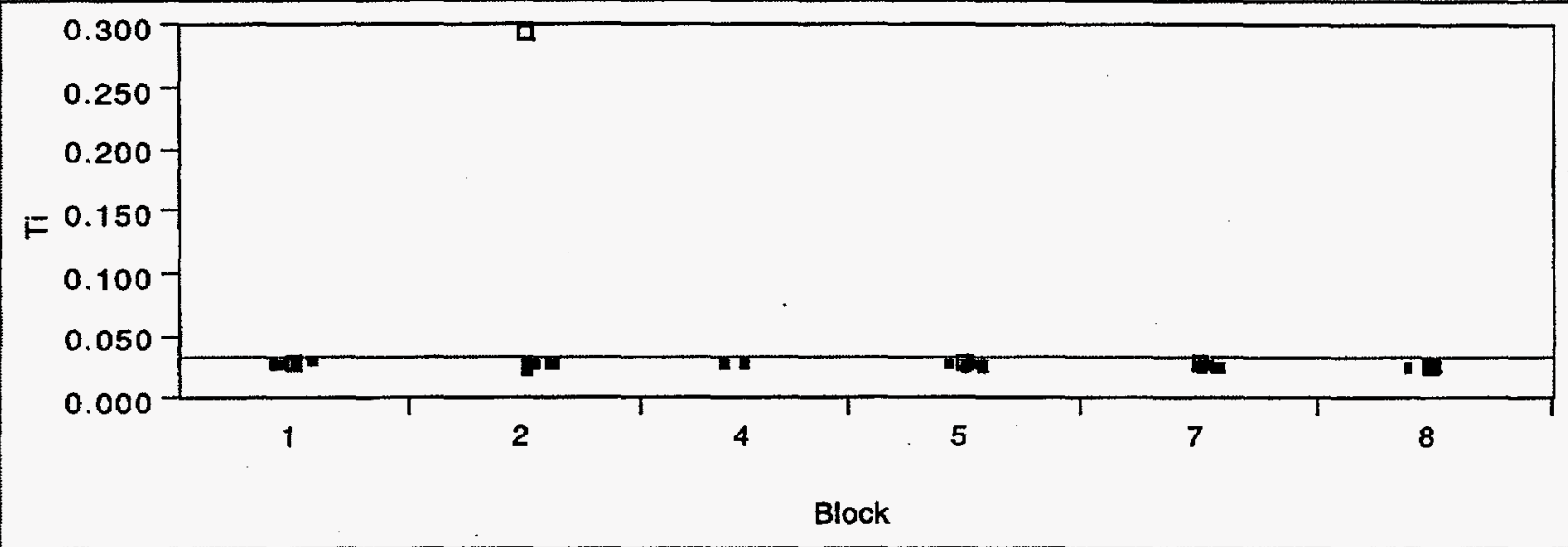

\section{Zr By Block}

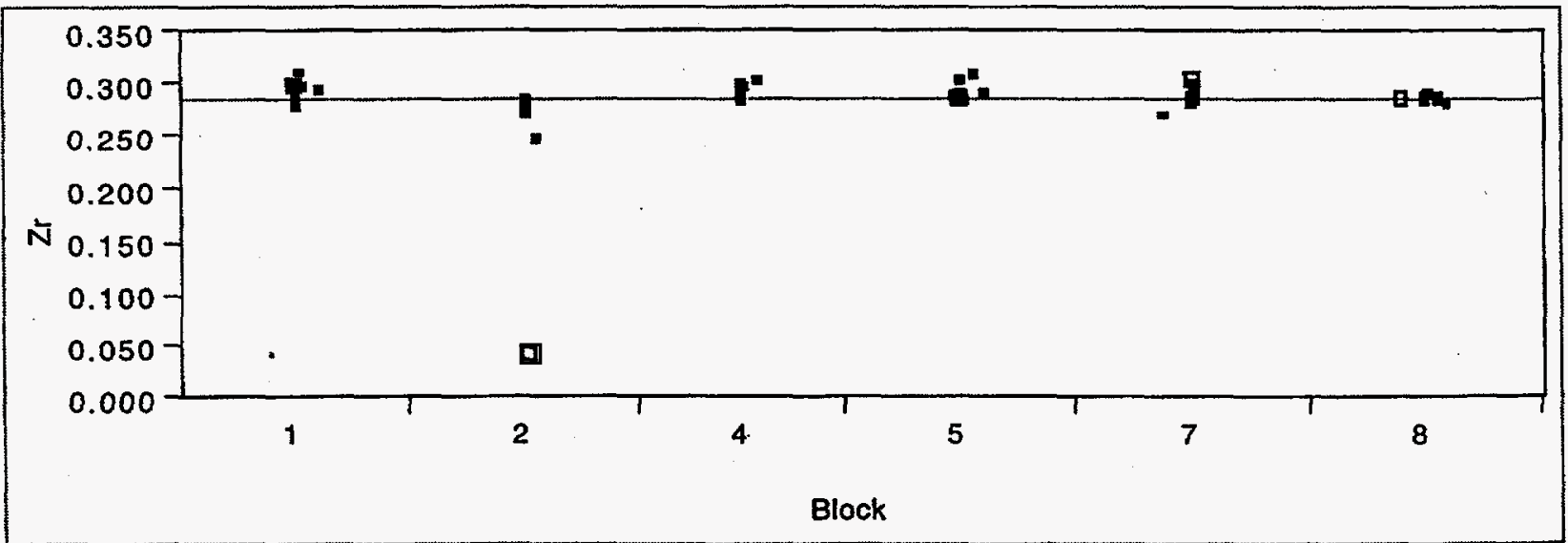


Figure 3(Al-Ca). Insert Fusion Elemental Weight Percents

(Squares indicate outliers or anused data)

Al By Block

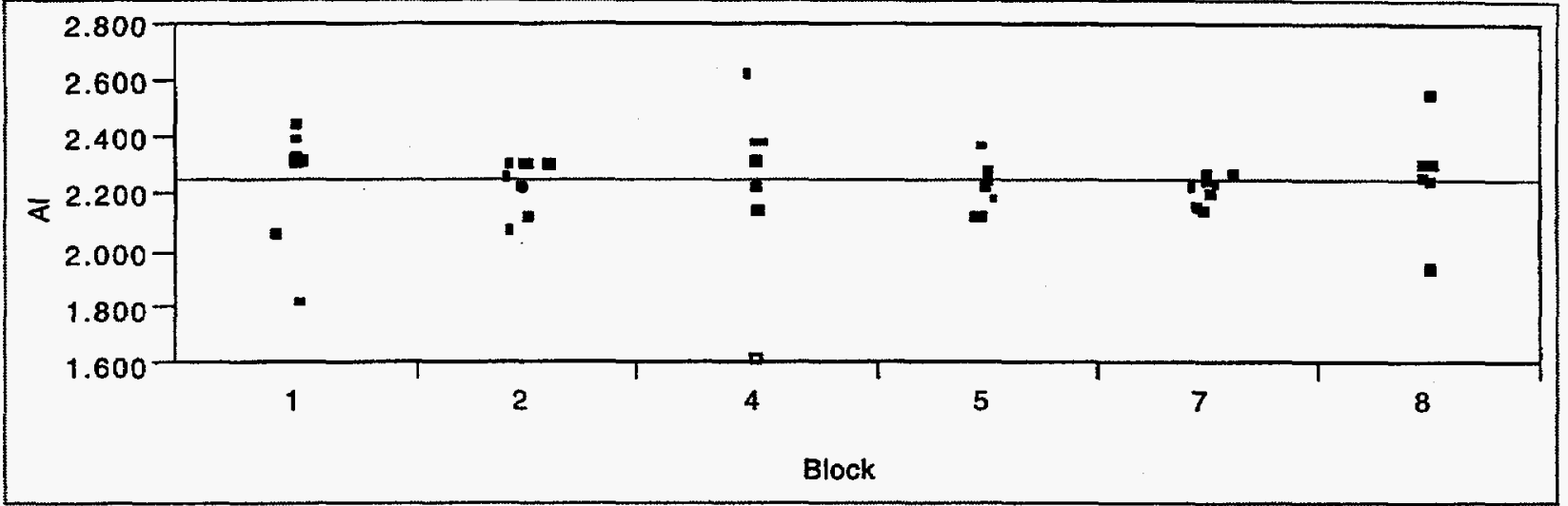

B By Block

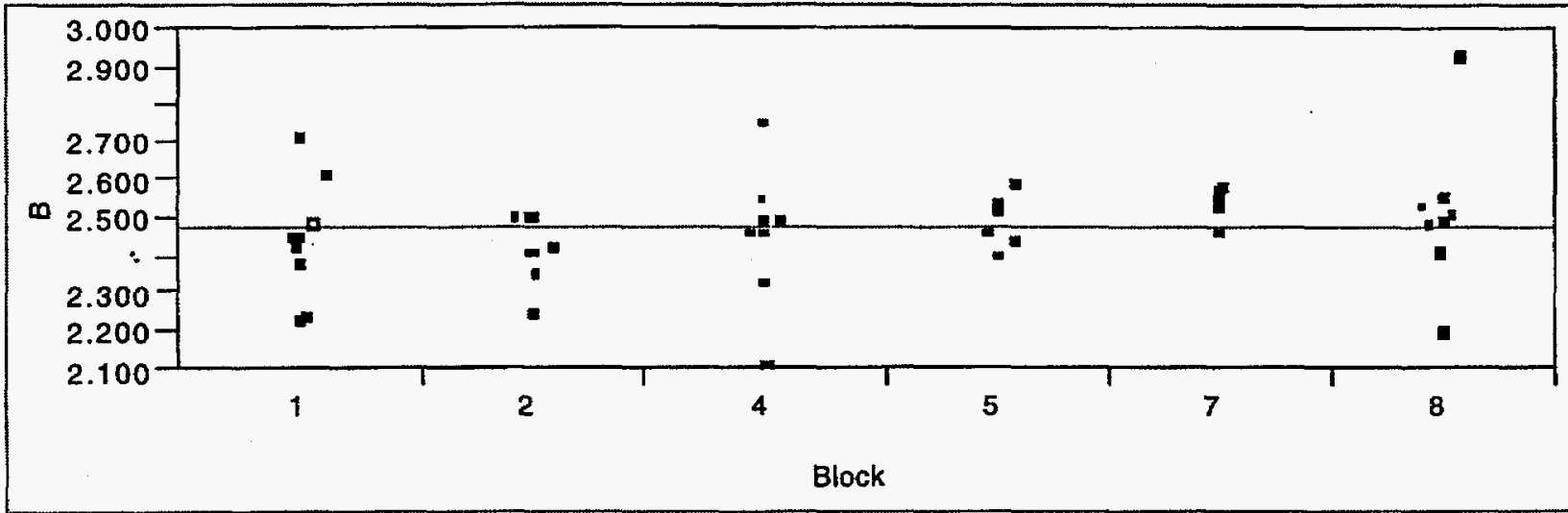

\section{Ca By Block}

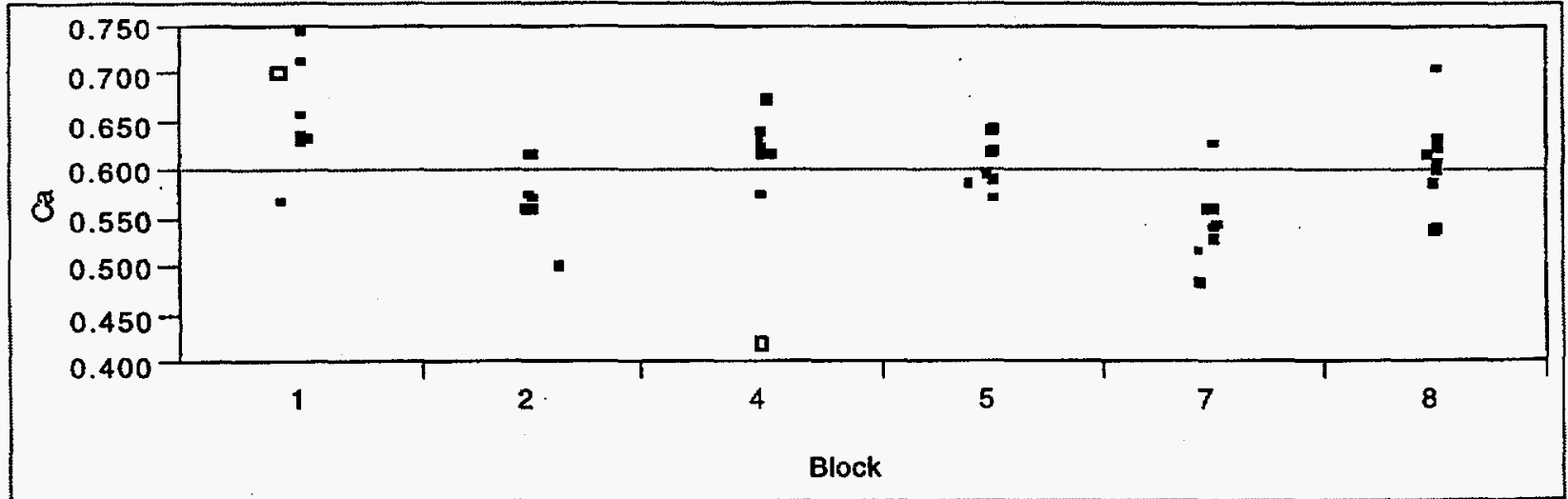


Figure 3(Cr-Fe). Insert Fusion Elemental Weight Percents

(Squares indicate outliers or unused data)

Cr By Block

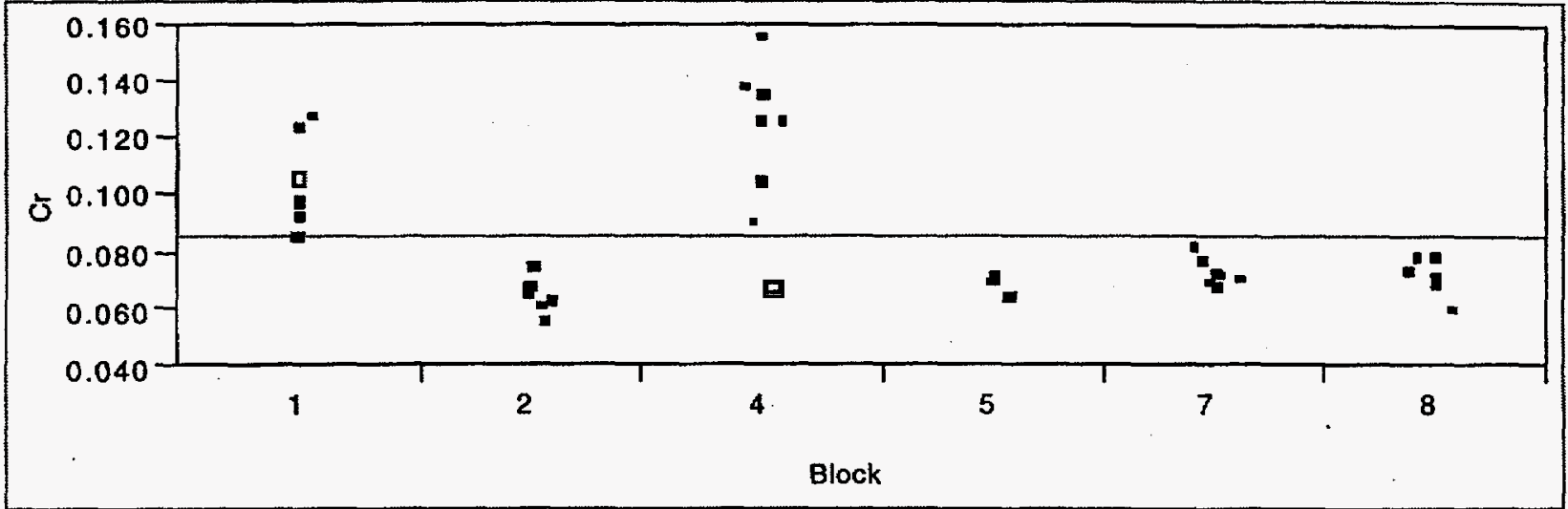

Cu By Block

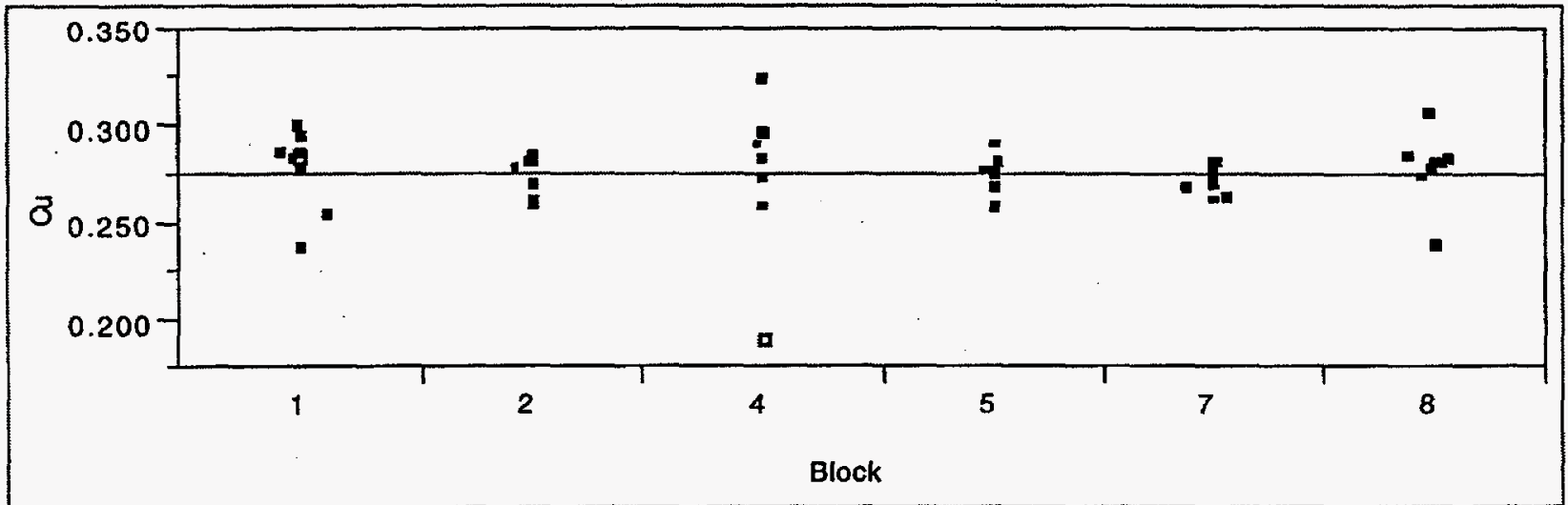

Fe By Block

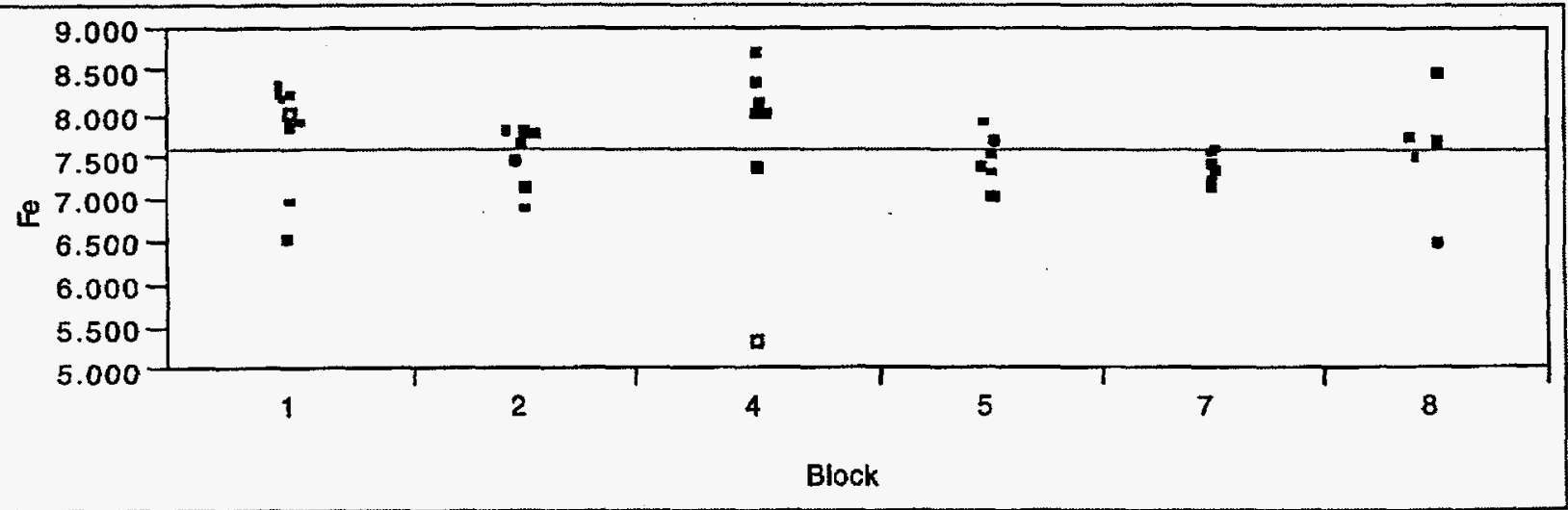


Figure 3(K-Mg). Insert Fusion Elemental Weight Percents

(Squares indicate outliers or unused data)

K By Block

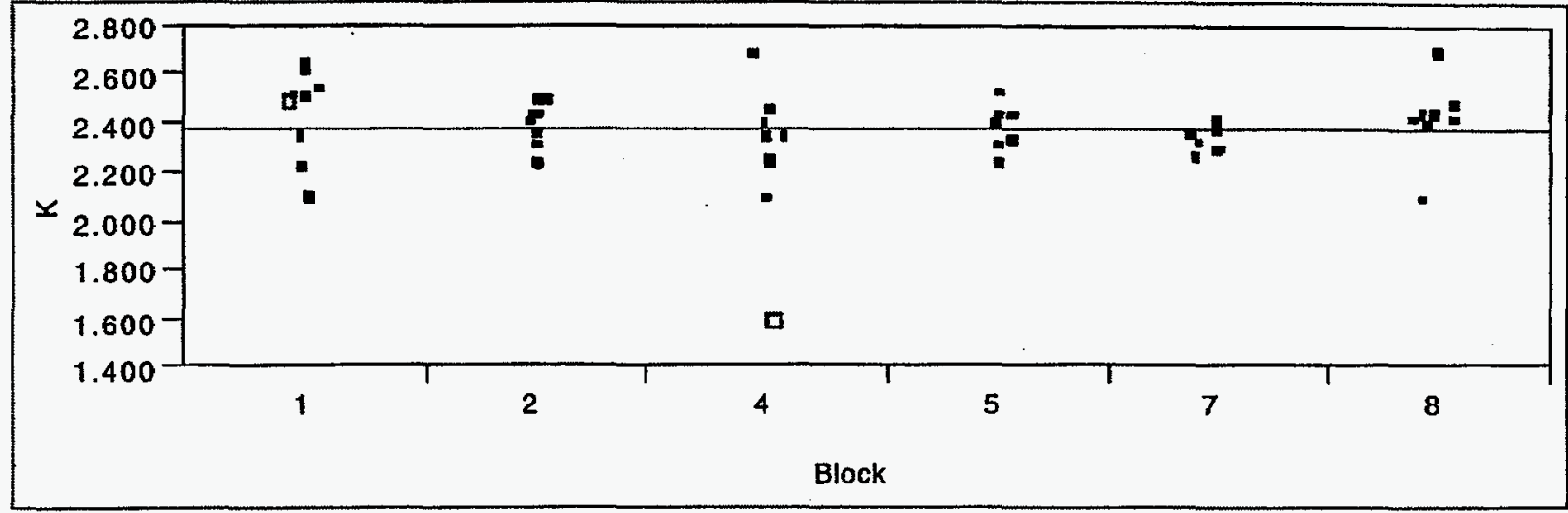

\section{Li By Block}

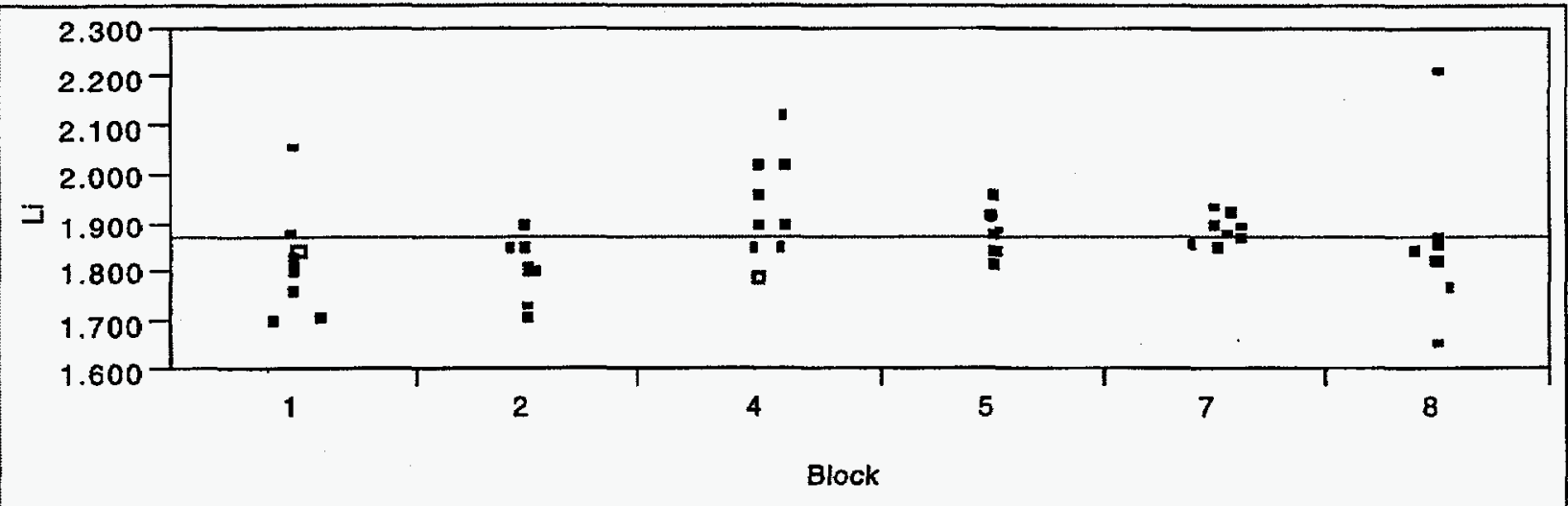

Mg By Block

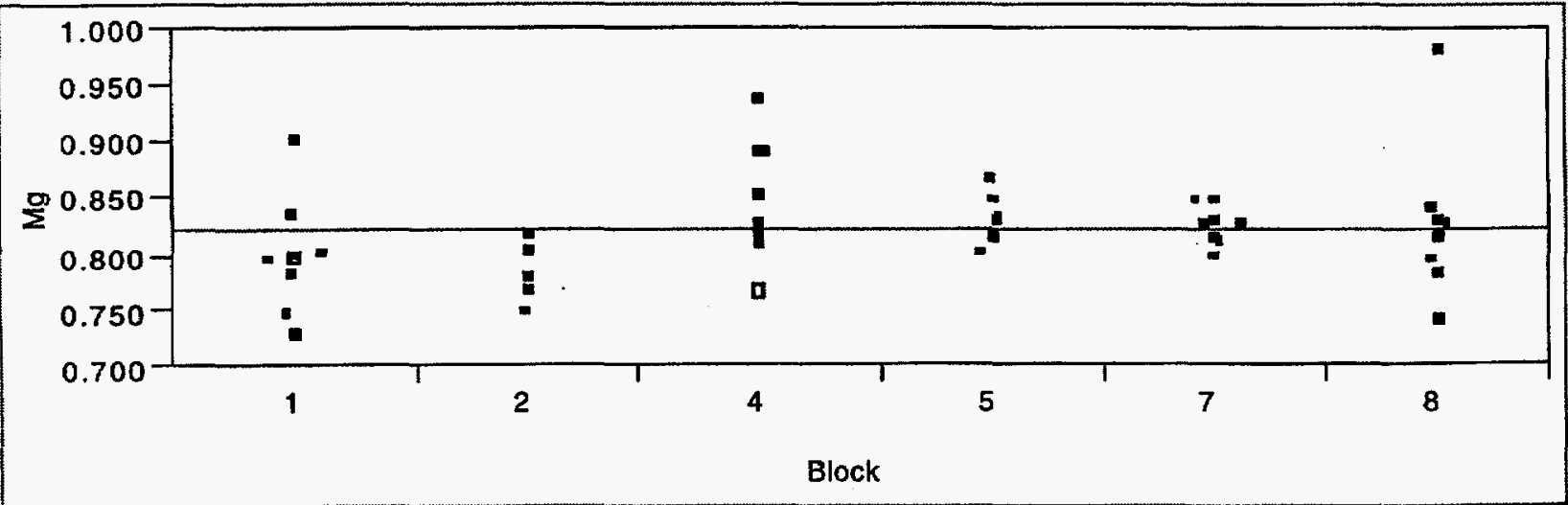


Figure 3(Mn-Ni). Insert Fusion Elemental Weight Percents

(Squares indicate outliers or unused data)

Mn By Block

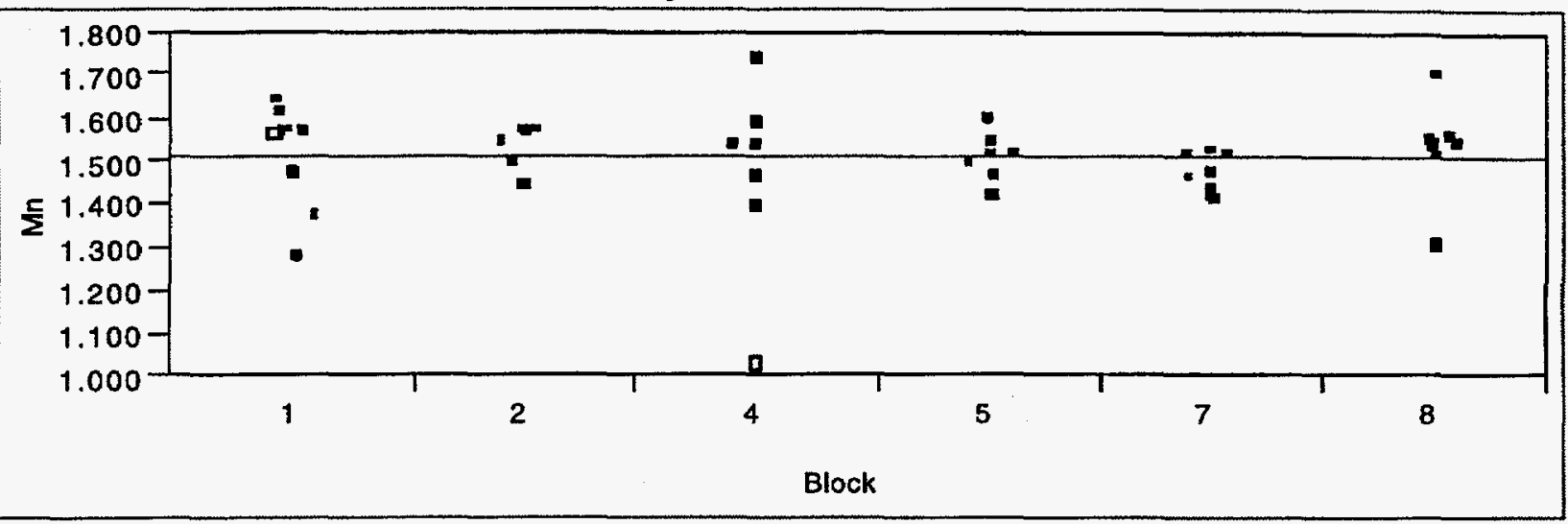

Na By Block (Set to 0 for Fusion)

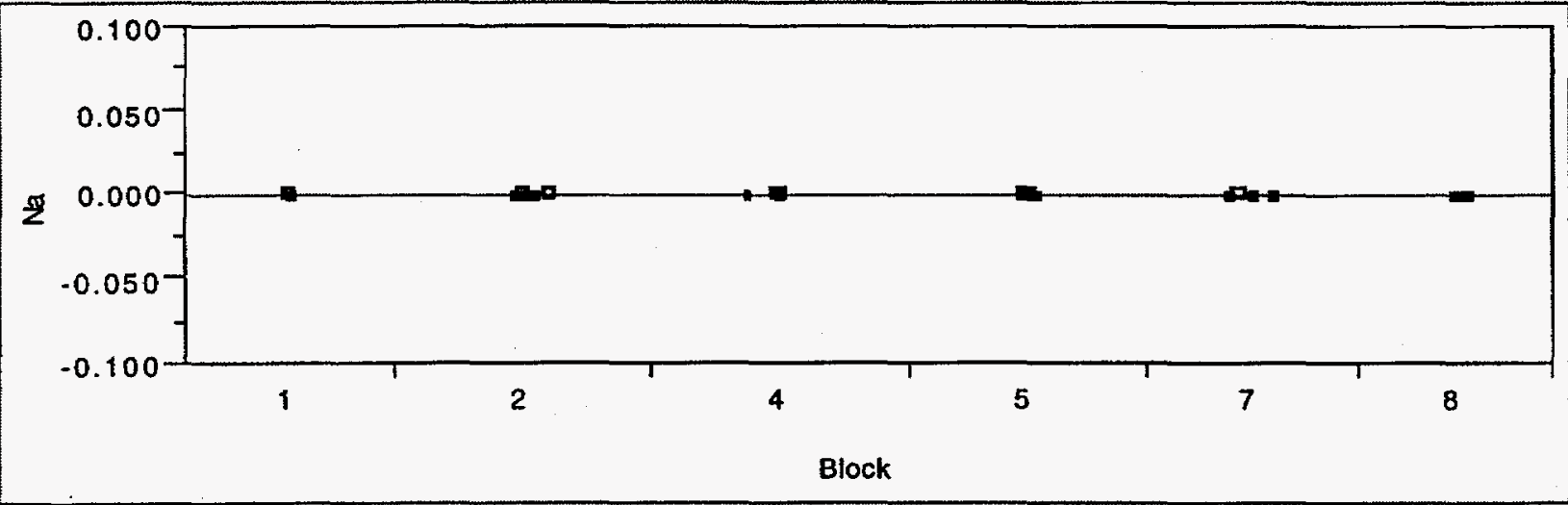

Ni By Block

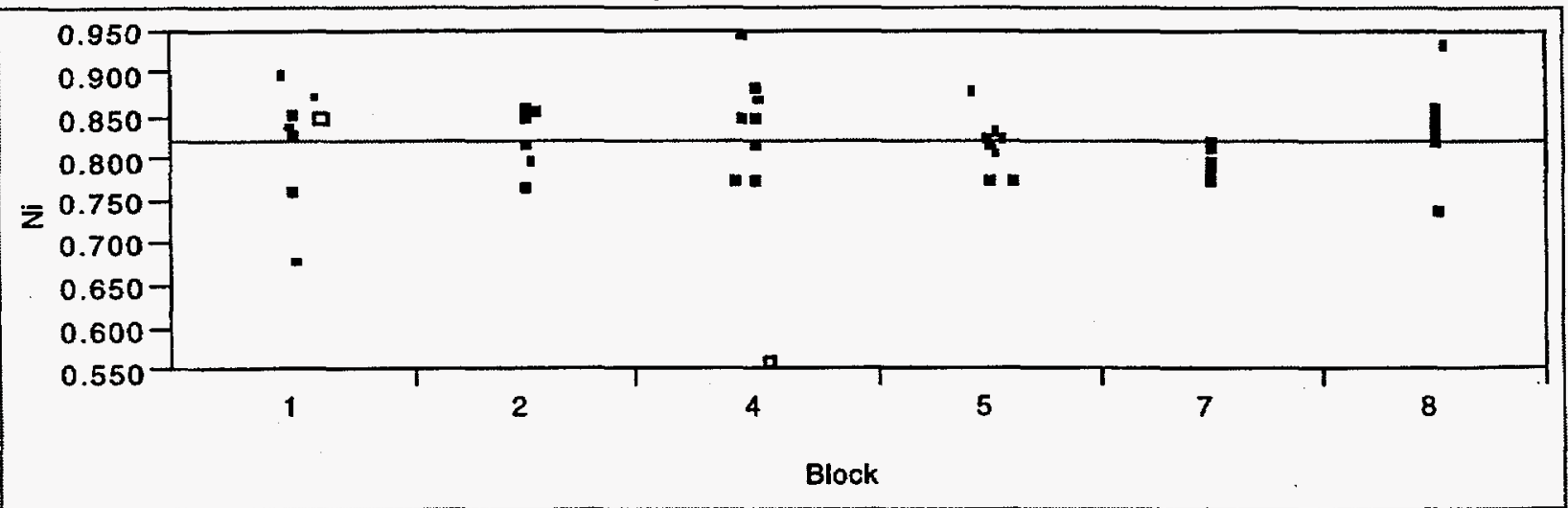


Figure 3(Si-Zr). Insert Fusion Elemental Weight Percents

(Squares indicate outliers or unused data)

\section{Si By Block}

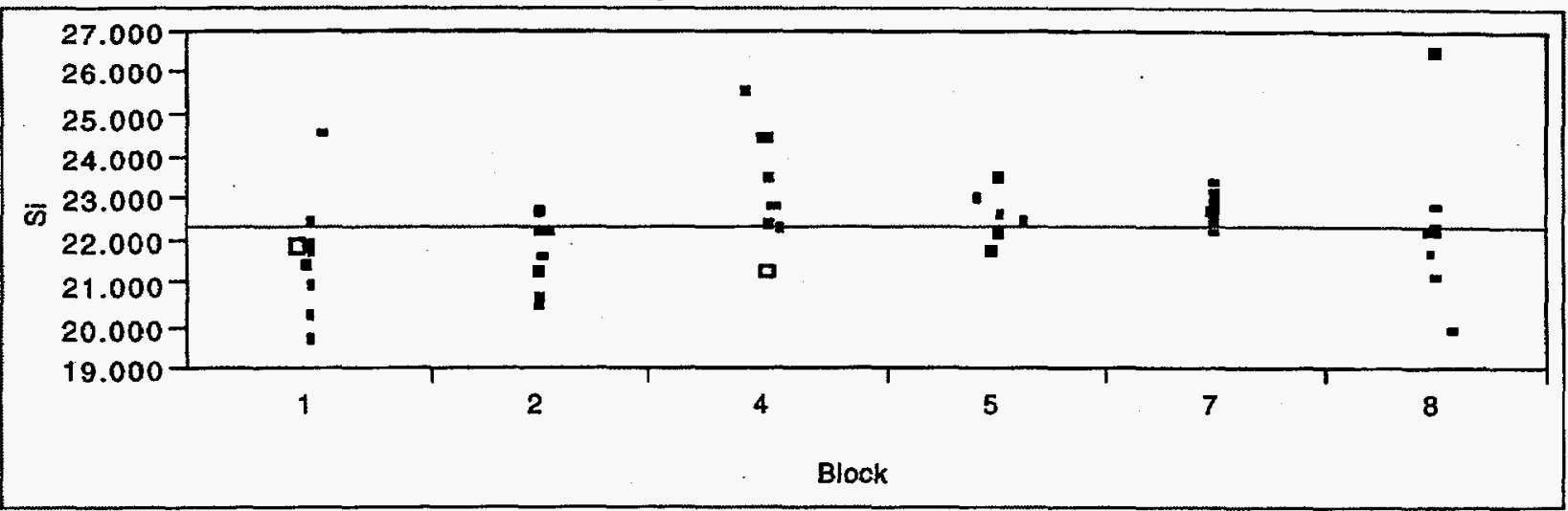

Ti By Block

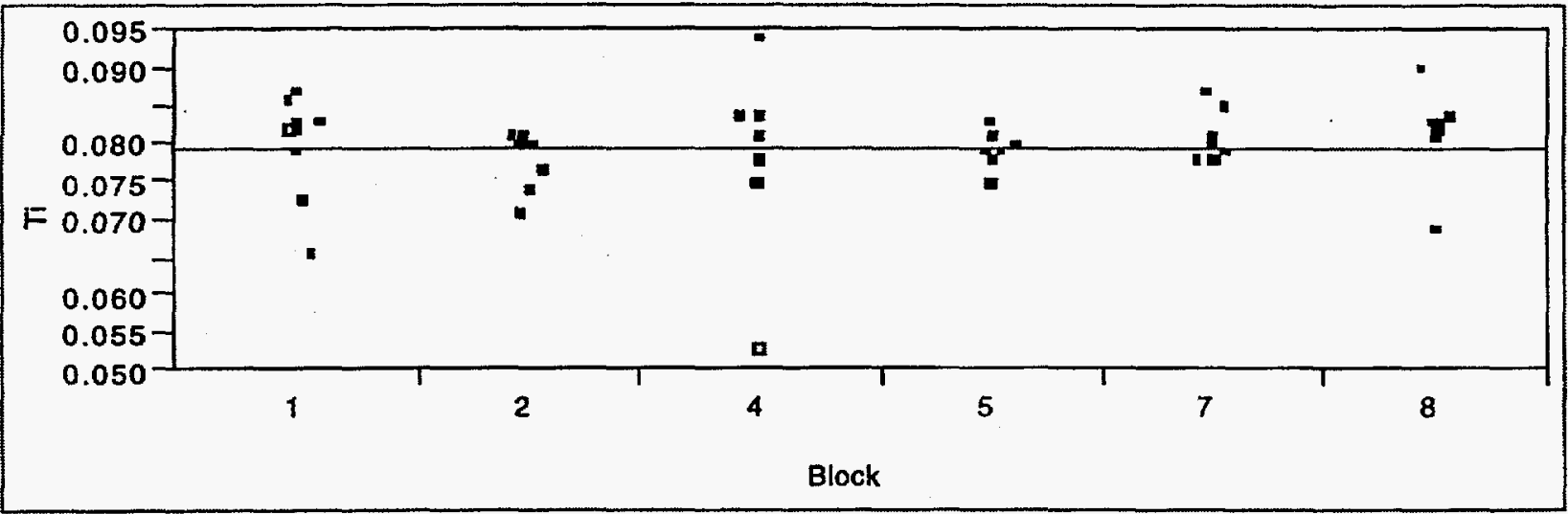

Zr By Block (Set to 0 for Fusion)

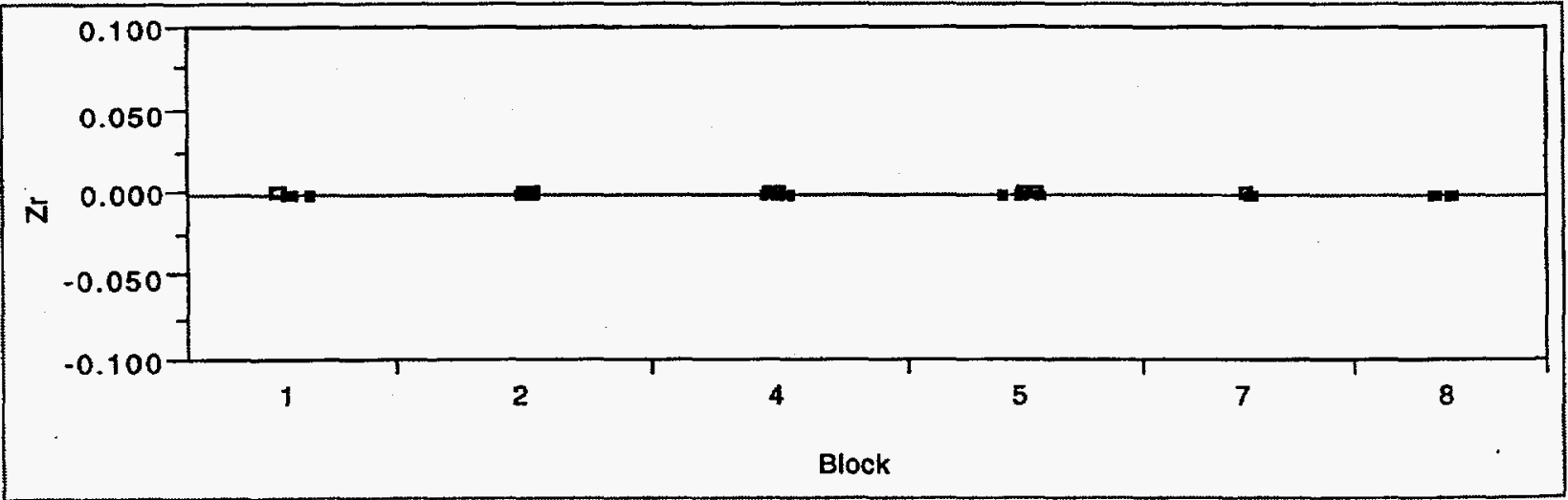

